\title{
First aid glucose administration routes for symptomatic hypoglycaemia (Review)
}

De Buck E, Borra V, Carlson JN, Zideman DA, Singletary EM, Djärv T

De Buck E, Borra V, Carlson JN, Zideman DA, Singletary EM, Djärv T.

First aid glucose administration routes for symptomatic hypoglycaemia.

Cochrane Database of Systematic Reviews 2019, Issue 4. Art. No.: CD013283.

DOI: 10.1002/14651858.CD013283.pub2.

www.cochranelibrary.com 
TABLE OF CONTENTS

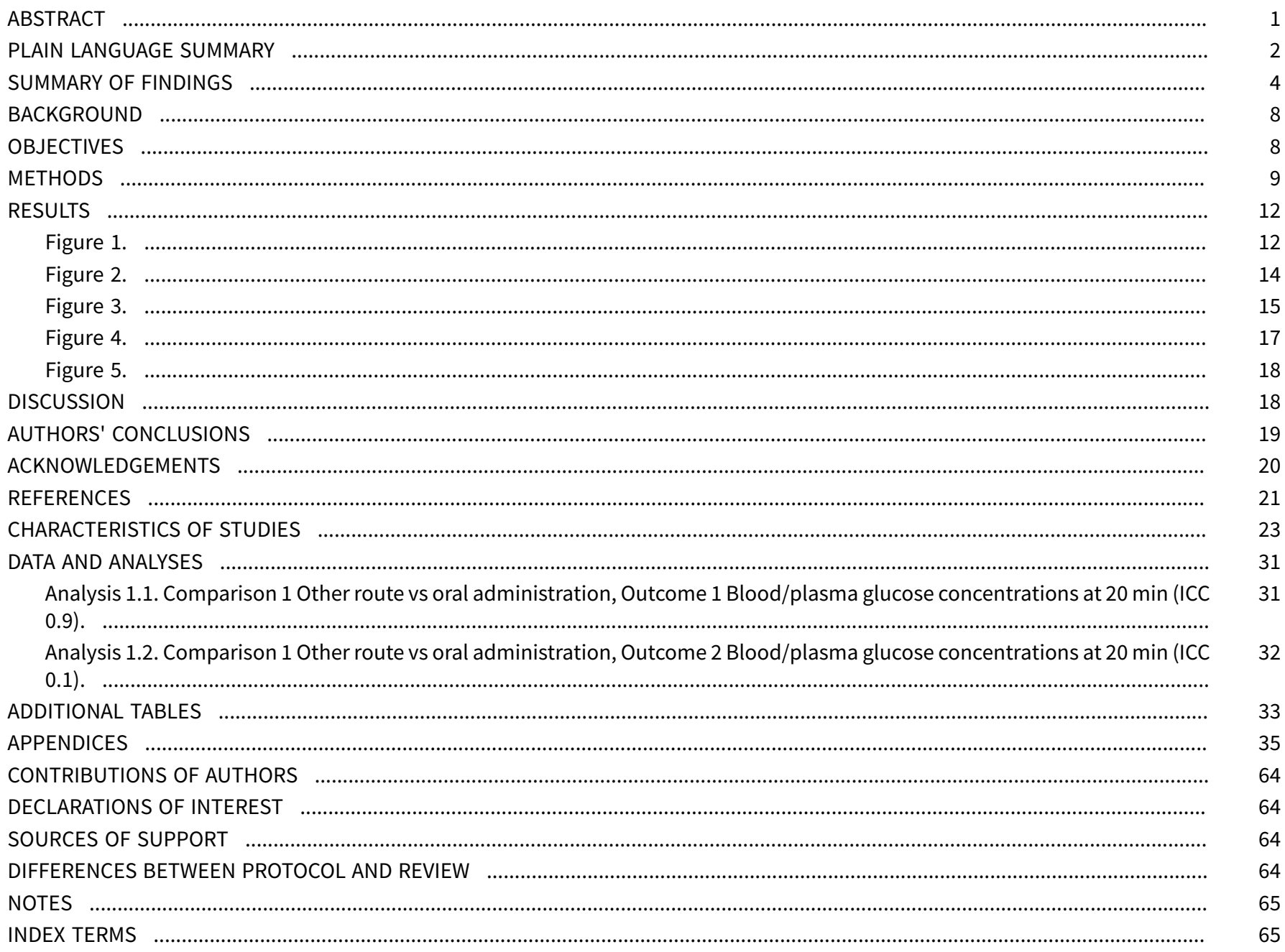


[Intervention Review]

\section{First aid glucose administration routes for symptomatic hypoglycaemia}

Emmy De Buck ${ }^{1}$, Vere Borra ${ }^{1}$, Jestin N Carlson², David A Zideman ${ }^{3}$, Eunice M Singletary ${ }^{4}$, Therese Djärv5

${ }^{1}$ Centre for Evidence-Based Practice (CEBaP), Belgian Red Cross, Mechelen, Belgium. ${ }^{2}$ Emergency Department, Allegheny Health Network, Erie, Pennsylvania, USA. ${ }^{3}$ Thames Valley Air Ambulance, Stokenchurch, UK. ${ }^{4}$ Department of Emergency Medicine, University of Virginia School of Medicine, Charlottesville, Virginia, USA. ${ }^{5}$ Function of Emergency Medicine, Karolinska University Hospital, Stockholm, Sweden

Contact: Emmy De Buck, Centre for Evidence-Based Practice (CEBaP), Belgian Red Cross, Motstraat 42, Mechelen, 2800, Belgium. emmy.debuck@rodekruis.be.

Editorial group: Cochrane Metabolic and Endocrine Disorders Group.

Publication status and date: New, published in Issue 4, 2019.

Citation: De Buck E, Borra V, Carlson JN, Zideman DA, Singletary EM, Djärv T. First aid glucose administration routes for symptomatic hypoglycaemia. Cochrane Database of Systematic Reviews 2019, Issue 4. Art. No.: CD013283. DOI: 10.1002/14651858.CD013283.pub2.

Copyright @ 2019 The Cochrane Collaboration. Published by John Wiley \& Sons, Ltd.

\section{A B S T R A C T}

\section{Background}

Hypoglycaemia is a common occurrence in people with diabetes but can also result from an imbalance in glucose homeostasis in the absence of diabetes. The best enteral route for glucose administration for suspected hypoglycaemia in a first aid situation is unknown.

\section{Objectives}

To assess the effects of first aid glucose administration by any route appropriate for use by first-aid providers (buccal, sublingual, oral, rectal) for symptomatic hypoglycaemia.

\section{Search methods}

We searched CENTRAL, MEDLINE, Embase, CINAHL as well as grey literature (records identified in the WHO ICTRP Search Portal, ClinicalTrials.gov and the EU Clinical Trials Register) up to July 2018. We searched reference lists of included studies retrieved by the above searches.

\section{Selection criteria}

We included studies involving adults and children with documented or suspected hypoglycaemia as well as healthy volunteers, in which glucose was administered by any enteral route appropriate for use by first-aid providers.

\section{Data collection and analysis}

Two review authors independently selected trials, assessed risk of bias, extracted data and evaluated trials for overall certainty of the evidence using the GRADE instrument. We used the Cochrane 'Risk of bias' tool to assess the risk of bias in the randomised controlled trials (RCTs), and the 'risk of bias In non-randomised studies of interventions' (ROBINS-I) tool, in addition to the Cochrane Handbook for Systematic Reviews of Interventions recommendations on cross-over studies, for the non-RCTs. We reported continuous outcomes as mean differences (MD) with 95\% confidence intervals (Cls) and dichotomous outcomes as risk ratios (RR) with 95\% Cls. All data on glucose concentrations were converted to $\mathrm{mg} / \mathrm{dL}$. We contacted authors of included studies to obtain missing data.

\section{Main results}

From 6394 references, we included four studies evaluating 77 participants, including two RCTs, studying children and adults with hypoglycaemia, respectively, and two non-RCTs with healthy volunteers. The studies included three different routes of glucose administration (sublingual, buccal and a combination of oral and buccal administration). All studies had a high risk of bias in one or more 'Risk of bias' domain. 
Glucose administration by the sublingual route, in the form of table sugar under the tongue, resulted in a higher blood glucose concentration after 20 minutes compared with the oral route in the very specific setting of children with hypoglycaemia and symptoms of concomitant malaria or respiratory tract infection (MD $17 \mathrm{mg} / \mathrm{dL}, 95 \% \mathrm{Cl} 4.4$ to $29.6 ; \mathrm{P}=0.008 ; 1$ study; 42 participants; very low-quality evidence). Resolution of hypoglycaemia at 80 minutes may favour sublingual administration (RR 2.10, 95\% $\mathrm{Cl} 1.24$ to $3.54 ; \mathrm{P}=0.006 ; 1$ study; 42 participants; very low-certainty evidence), but no substantial difference could be demonstrated at 20 minutes (RR $1.26,95 \% \mathrm{Cl} 0.91$ to $1.74 ; \mathrm{P}=0.16 ; 1$ study; 42 participants; very low-certainty evidence). A decrease in the time to resolution of hypoglycaemia was found in favour of sublingual administration (MD -51.5 min, $95 \% \mathrm{Cl}-58$ to $-45 ; \mathrm{P}<0.001 ; 1$ study; 42 participants; very low-certainty evidence). No adverse events were reported in either group. No data were available for resolution of symptoms and time to resolution of symptoms, and treatment delay.

Glucose administered by the buccal route in one study resulted in a lower plasma glucose concentration after 20 minutes compared with oral administration (MD - $14.4 \mathrm{mg} / \mathrm{dL}, 95 \% \mathrm{Cl}-17.5$ to -11.4 for an imputed within-participants correlation coefficient of $0.9 ; \mathrm{P}<0.001 ; 1$ trial; 16 participants; very low-quality evidence). In another study there were fewer participants with increased blood glucose at 20 minutes favouring oral glucose (RR $0.07,95 \% \mathrm{Cl} 0.00$ to $0.98 ; \mathrm{P}=0.05 ; 1$ study; 7 participants; very low-certainty evidence). No data were available for resolution of symptoms and time to resolution of symptoms, resolution of hypoglycaemia and time to resolution of hypoglycaemia, adverse events, and treatment delay.

For the combined oral and buccal mucosal route (in the form of a dextrose gel) the MD was $-15.3 \mathrm{mg} / \mathrm{dL}, 95 \% \mathrm{Cl}-33.6$ to $3 ; \mathrm{P}=0.09 ; 1 \mathrm{study}$; 18 participants; very low-quality evidence. No improvement was identified for either route in the resolution of symptoms at 20 minutes or less following glucose administration ( $\mathrm{RR} 0.36,95 \% \mathrm{Cl} 0.12$ to $1.14 ; \mathrm{P}=0.08 ; 1$ study; 18 participants; very low-certainty evidence). No data were available for time to resolution of symptoms, resolution of hypoglycaemia and time to resolution of hypoglycaemia, adverse events, and treatment delay.

\section{Authors' conclusions}

When providing first aid to individuals with hypoglycaemia, oral glucose administration results in a higher blood glucose concentrations after 20 minutes when compared with buccal administration of glucose. A difference in plasma glucose concentration could not be demonstrated, when administering a dextrose gel, defined as "a combined oral and buccal mucosal route" compared to oral administration of a glucose tablet or solution. In the specific population of children with concomitant malaria and respiratory illness, sublingual sugar results in a higher blood glucose concentration after 20 minutes when compared with oral administration.These results need to be interpreted cautiously because our confidence in the body of evidence is very low due to the low number of participants and studies as well as methodological deficiencies in the included studies.

\section{PLAIN LANGUAGE SUMMARY}

\section{First aid glucose administration routes for symptomatic hypoglycaemia}

\section{Review question}

We examined the effects of various routes of glucose administration as a first-aid treatment in people with suspected or symptomatic hypoglycaemia.

\section{Background}

Hypoglycaemia, or having low blood sugar levels, is a common occurrence in people with diabetes but may also occur in other persons due to an imbalance in blood sugar regulation. Symptoms of mild or moderate hypoglycaemia are for example, shakiness, dizziness, sweating or nervousness, First aid for this condition is usually self-administered but is often provided by family or friends, and glucose tablets compared with dietary forms of sugar such as juice, candies or dried fruit strips have shown to result in a better resolution of symptoms. Glucose can be given orally (swallowed), but also inside the cheek against the buccal mucosa ('buccal administration'), under the tongue ('sublingual administration') or via the rectal route. In the latter three ways of treatment, the glucose is not being swallowed as with the oral route.

\section{Study characteristics}

We identified four studies. One randomised study (clinical trials where people are randomly allocated to one of two or more treatment groups) compared sublingual glucose administration, in the form of table sugar, with an oral administration in 42 hypoglycaemic children between one and 15 years old. Two non-randomised studies compared buccal glucose administration with oral administration in 23 adult healthy fasting volunteers. One randomised study compared a dextrose gel with oral administration of glucose in 18 people with type 1 diabetes and hypoglycaemia.

\section{Key results}

Providing sugar under the tongue (sublingual) resulted in a greater rise in blood glucose after 20 minutes than giving the sugar orally, but this was in a specific setting including children with hypoglycaemia and symptoms of concomitant malaria or respiratory tract infection. On the other hand, giving glucose by the buccal mucosa route resulted in a lower plasma glucose concentration than with the oral route. For 
dextrose gel (where uptake of the glucose occurs through a combination of oral swallowing and via the buccal mucosa), no clear benefit was shown compared to oral glucose administration (glucose tablets or glucose solutions). Most studies did not report on time to resolution of symptoms, resolution of hypoglycaemia as defined by blood glucose levels above a certain threshold, time to resolution of hypoglycaemia, adverse events, and treatment delay.

\section{Certainty of the evidence}

The evidence is of very low certainty due to limitations in study design, few studies and small number of participants in the studies, and because half of the studies were performed with healthy volunteers rather than in people with characteristic hypoglycaemia. 
SUMMARY OF FINDINGS

Summary of findings for the main comparison. Sublingual glucose compared to oral (swallowed) glucose for treatment of hypoglycaemia

Sublingual glucose compared to oral (swallowed) glucose for treatment of hypoglycaemia

Patient or population: children with hypoglycaemia associated with moderate clinical symptoms of acute malaria or moderate respiratory tract infections Setting: first-aid setting, pre-hospital setting (Hamdallaye Health Center)

Intervention: sublingual glucose

Comparison: oral (swallowed) glucose

\begin{tabular}{|c|c|c|c|c|c|c|}
\hline Outcomes & $\begin{array}{l}\text { Risk with oral (swal- } \\
\text { lowed) glucose }\end{array}$ & $\begin{array}{l}\text { Risk with sublingual glu- } \\
\text { cose }\end{array}$ & $\begin{array}{l}\text { Relative effect } \\
(95 \% \mathrm{Cl})\end{array}$ & $\begin{array}{l}\text { № of partici- } \\
\text { pants } \\
\text { (studies) }\end{array}$ & $\begin{array}{l}\text { Certainty of } \\
\text { the evidence } \\
\text { (GRADE) }\end{array}$ & Comments \\
\hline $\begin{array}{l}\text { Resolution of symptoms, time to } \\
\text { resolution of symptoms }\end{array}$ & Not reported & & & & & \\
\hline $\begin{array}{l}\text { Blood/plasma glucose concentra- } \\
\text { tions at } 20 \text { minutes }\end{array}$ & $\begin{array}{l}\text { The mean blood/plas- } \\
\text { ma glucose concentra- } \\
\text { tions at } 20 \text { minutes was } \\
76 \mathrm{mg} / \mathrm{dL}\end{array}$ & $\begin{array}{l}\text { The MD was } 17 \mathbf{~ m g} / \mathbf{d L} \text { high- } \\
\text { er } \\
\text { ( } 4.4 \mathrm{mg} / \mathrm{dL} \text { higher to } 29.6 \\
\mathrm{mg} / \mathrm{dL} \text { higher) }\end{array}$ & - & $42(1)$ & $\begin{array}{l}\oplus \ominus \ominus \ominus \\
\text { very low }\end{array}$ & \\
\hline $\begin{array}{l}\text { Resolution of hypoglycaemia } \\
\text { Definition: } \\
\text { (a) within } 20 \text { minutes } \\
\text { (b) within } 80 \text { minutes }\end{array}$ & $\begin{array}{l}\text { (a) } 467 \text { per } 1000 \\
\text { (b) } 733 \text { per } 1000\end{array}$ & $\begin{array}{l}\text { (a) } 205 \text { per } 1000 \text { ( } 44 \text { to } 983) \\
\text { (b) } 14 \text { per } 1000 \text { (0 to } 252)\end{array}$ & $\begin{array}{l}\text { (a) } \mathbf{R} \mathbf{R} \mathbf{1 . 2 6} \\
\text { (0.91 to } 1.74 \text { ) } \\
\text { (b) RR } \mathbf{2 . 1 0} \\
\text { (1.24 to } 3.54 \text { ) }\end{array}$ & $(\mathrm{a}) /(\mathrm{b}) 42(1)$ & $\begin{array}{l}(\mathrm{a}) /(\mathrm{b}) \\
\oplus \odot \Theta \odot \\
\text { very low }\end{array}$ & \\
\hline $\begin{array}{l}\text { Time to resolution of hypogly- } \\
\text { caemia }\end{array}$ & $\begin{array}{l}\text { The mean time to reso- } \\
\text { lution of hypoglycaemia } \\
\text { was } 80 \text { minutes }\end{array}$ & $\begin{array}{l}\text { The MD was } \mathbf{5 1 . 5} \mathbf{~ m i n ~ l o w e r ~} \\
\text { (58 minutes lower to } 45 \mathrm{~min} \\
\text { lower) }\end{array}$ & - & $42(1)$ & $\begin{array}{l}\oplus \odot \odot \odot \\
\text { very low }\end{array}$ & \\
\hline $\begin{array}{l}\text { Adverse events } \\
\text { Follow-up: } 80 \text { minutes }\end{array}$ & See comment & & & $42(1)$ & $\begin{array}{l}\oplus \ominus \ominus \ominus \\
\text { very low }\end{array}$ & $\begin{array}{l}\text { No adverse } \\
\text { events were re- } \\
\text { ported in either } \\
\text { group. }\end{array}$ \\
\hline Treatment delay & Not reported & & & & & \\
\hline
\end{tabular}

Cl: confidence interval; MD: mean difference; RR: risk ratio

GRADE Working Group grades of evidence

High certainty: We are very confident that the true effect lies close to that of the estimate of the effect 
Moderate certainty: We are moderately confident in the effect estimate: The true effect is likely to be close to the estimate of the effect, but there is a possibility that it is substantially different

Low certainty: Our confidence in the effect estimate is limited: The true effect may be substantially different from the estimate of the effect

Very low certainty: We have very little confidence in the effect estimate: The true effect is likely to be substantially different from the estimate of effect

All outcomes downgraded by one level because of risk of bias and indirectness, and by two levels because of serious imprecision - see Appendix 14 .

\section{Summary of findings 2. Buccal glucose compared to oral (swallowed) glucose for treatment of hypoglycaemia}

Buccal glucose compared to oral (swallowed) glucose for treatment of hypoglycaemia

Patient or population: healthy volunteers (adults)

Setting: first-aid setting

Intervention: buccal glucose

Comparison: oral (swallowed) glucose

\begin{tabular}{|c|c|c|c|c|c|c|}
\hline Outcomes & $\begin{array}{l}\text { Risk with oral (swal- } \\
\text { lowed) glucose }\end{array}$ & $\begin{array}{l}\text { Risk with buccal } \\
\text { glucose }\end{array}$ & $\begin{array}{l}\text { Relative effect } \\
(95 \% \mathrm{Cl})\end{array}$ & $\begin{array}{l}\text { № of partici- } \\
\text { pants } \\
\text { (studies) }\end{array}$ & $\begin{array}{l}\text { Certainty of } \\
\text { the evidence } \\
\text { (GRADE) }\end{array}$ & Comments \\
\hline $\begin{array}{l}\text { Resolution of symptoms, time to resolution } \\
\text { of symptoms }\end{array}$ & Not reported & & & & & \\
\hline $\begin{array}{l}\text { Blood/plasma glucose concentrations at } 20 \\
\text { minutes }\end{array}$ & $\begin{array}{l}\text { The mean blood/plas- } \\
\text { ma glucose concen- } \\
\text { trations at } 20 \text { minutes } \\
\text { was } 112 \mathrm{mg} / \mathrm{dL}\end{array}$ & $\begin{array}{l}\text { The MD was } \mathbf{1 4 . 4} \\
\mathbf{m g} / \mathbf{d L} \text { lower }(17.5 \\
\text { lower to } 11.4 \text { low- } \\
\text { er) }\end{array}$ & - & $16(1)$ & $\begin{array}{l}\oplus \ominus \ominus \ominus \\
\text { very low }\end{array}$ & $\begin{array}{l}\text { Imputed with- } \\
\text { in-participants } \\
\text { correlation co- } \\
\text { efficient of } 0.9\end{array}$ \\
\hline Increased blood glucose at 20 minutes & 1000 per 1000 & $\begin{array}{l}70 \text { per } 1000 \text { ( } 0 \text { to } \\
980)\end{array}$ & $\begin{array}{l}\mathbf{R R} 0.07 \text { (0.00 to } \\
0.98)\end{array}$ & $7(1)$ & $\begin{array}{l}\oplus \ominus \ominus \ominus \\
\text { very low }\end{array}$ & \\
\hline
\end{tabular}

\begin{tabular}{ll}
\hline Resolution of hypoglycaemia & Not reported \\
\hline Time to resolution of hypoglycaemia & Not reported \\
\hline Adverse events & Not reported \\
\hline Ease of administration/treatment delay & Not reported
\end{tabular}

Cl: confidence interval; MD: mean difference; RR: risk ratio

\section{GRADE Working Group grades of evidence}

High certainty: We are very confident that the true effect lies close to that of the estimate of the effect. 
Moderate certainty: We are moderately confident in the effect estimate: The true effect is likely to be close to the estimate of the effect, but there is a possibility that it is substantially different.

Low certainty: Our confidence in the effect estimate is limited: The true effect may be substantially different from the estimate of the effect.

Very low certainty: We have very little confidence in the effect estimate: The true effect is likely to be substantially different from the estimate of effect.

All outcomes downgraded by one level because of risk of bias and indirectness, and by two levels because of serious imprecision - see Appendix 15 .

\section{Summary of findings 3. Oral + buccal glucose (dextrose gel) compared to oral (swallowed) glucose for treatment of hypoglycaemia}

\section{Oral + buccal glucose (glucose gel) compared to oral (swallowed) glucose for treatment of hypoglycaemia}

Patient or population: adult patients with insulin-dependent diabetes

Setting: first-aid setting, hospital

Intervention: oral + buccal glucose (glucose gel)

Comparison: oral (swallowed) glucose

\begin{tabular}{|c|c|c|c|c|c|c|}
\hline Outcomes & $\begin{array}{l}\text { Risk with oral (swal- } \\
\text { lowed) glucose }\end{array}$ & $\begin{array}{l}\text { Risk with oral + buc- } \\
\text { cal glucose (glucose } \\
\text { gel) }\end{array}$ & $\begin{array}{l}\text { Relative effect } \\
(95 \% \mathrm{Cl})\end{array}$ & $\begin{array}{l}\text { № of partici- } \\
\text { pants } \\
\text { (studies) }\end{array}$ & $\begin{array}{l}\text { Certainty of } \\
\text { the evidence } \\
\text { (GRADE) }\end{array}$ & Comments \\
\hline $\begin{array}{l}\text { Resolution of symptoms within } 20 \text { min- } \\
\text { utes }\end{array}$ & 917 per 1000 & $\begin{array}{l}330 \text { per } 1000 \text { (110 to } \\
1000)\end{array}$ & $\begin{array}{l}\text { RR } 0.36 \text { ( } 0.12 \text { to } \\
1.14)\end{array}$ & $18(1)$ & $\begin{array}{l}\oplus \ominus \ominus \ominus \\
\text { very low }\end{array}$ & \\
\hline Time to resolution of symptoms & Not reported & & & & & \\
\hline $\begin{array}{l}\text { Blood/plasma glucose concentrations } \\
\text { at } 20 \text { minutes }\end{array}$ & $\begin{array}{l}\text { The mean blood/plas- } \\
\text { ma glucose concen- } \\
\text { trations at } 20 \text { minutes } \\
\text { was } 77 \mathrm{mg} / \mathrm{dL}\end{array}$ & $\begin{array}{l}\text { The MD was } 15.3 \mathrm{mg} / \\
\text { dL lower ( } 33.6 \text { lower } \\
\text { to } 3 \text { higher) }\end{array}$ & - & $18(1)$ & $\begin{array}{l}\oplus \ominus \ominus \ominus \\
\text { very low } b\end{array}$ & \\
\hline Resolution of hypoglycaemia & Not reported & & & & & \\
\hline Time to resolution of hypoglycaemia & Not reported & & & & & \\
\hline Adverse events & Not reported & & & & & \\
\hline Ease of administration/treatment delay & Not reported & & & & & \\
\hline
\end{tabular}

CI: confidence interval; MD: mean difference; RR: risk ratio

\section{GRADE Working Group grades of evidence}

High certainty: We are very confident that the true effect lies close to that of the estimate of the effect 
Moderate certainty: We are moderately confident in the effect estimate: The true effect is likely to be close to the estimate of the effect, but there is a possibility that it is substantially different

Low certainty: Our confidence in the effect estimate is limited: The true effect may be substantially different from the estimate of the effect

Very low certainty: We have very little confidence in the effect estimate: The true effect is likely to be substantially different from the estimate of effect

aDowngraded by one level because of risk of bias and by two levels because of serious imprecision - see Appendix 16 .

bowngraded by three levels because of very serious imprecision (small sample size, 1 study only, $\mathrm{Cl}$ consistent with both benefit and harm) - see Appendix 16 . 


\section{B A C K G R O U N D}

\section{Description of the condition}

Hypoglycaemia is common in individuals with diabetes but can also occur in individuals without diabetes due to an imbalance in glucose homeostasis (e.g. poor dietary intake or acute disease) (Ostenson 2014; Sako 2017). Symptoms of hypoglycaemia range from mild (e.g. sweating and hunger) to severe (e.g. seizures and altered mental status). According to the International Diabetes Federation (IDF), there are over 425 million people living with diabetes worldwide, and hypoglycaemia carries a significant burden of disease (IDF 2017). Even mild hypoglycaemic events have a considerable impact on both individuals and society since they can require additional healthcare resources, and individuals with non-severe hypoglycaemia may experience loss of work time, estimated to cost approximately USD 2300 per diabetic patient per year (Geelhoed-Duijvestijn 2013; Ostenson 2014). Early treatment may consequently result in grossly underreported true rate of hypoglycaemia as prompt action helps to avoid the need for further medical care (Cain 2003; Ostenson 2014).

\section{Description of the intervention}

Treatment of mild hypoglycaemia is essential to prevent progression to a life-threatening condition. It consists of the intake of glucose or dietary sugars to quickly increase the blood sugar level. While multiple protocols are available to healthcare providers, first aid for this condition is often self-administered or provided by family or friends (Ostenson 2014; Rostykus 2016). While parenteral treatment with glucagon kits is available in some countries, this is typically reserved for use by trained family members in the presence of severe hypoglycaemia and unresponsiveness, or inability to swallow.

A systematic review has suggested oral glucose may be preferred over dietary sugars, such as orange juice, jelly beans, or Mentos ${ }^{\circledR}$ for treatment of less severe hypoglycaemia in people who are responsive, able to swallow, and able to follow commands (Carlson 2017). Current guidelines recommend oral glucose for the treatment of symptomatic hypoglycaemia in conscious people (Singletary 2015; Zideman 2015).

How best to deliver glucose, both in terms of efficacy (e.g. resolution of symptoms and rate of normalisation of blood glucose levels) and safety (e.g. complications including aspiration), is unknown (Singletary 2015; Zideman 2015). Possible administration routes to deliver glucose, and available in first-aid situations, include buccal, sublingual, oral, and rectal administration. Buccal administration is defined as the application of glucose to the inner cheek mucosa; sublingual administration as the administration of glucose under the tongue; and both routes do not require swallowing of the glucose.

\section{Adverse effects of the intervention}

In addition to aspects of bioavailability described below, various administration routes carry different safety concerns. For example, the oral route requires the individual to have the ability to swallow and may potentially be associated with aspiration if swallowing is impaired (e.g. due to an altered level of consciousness). As such, it is important to help individuals understand the risks and benefits associated with various treatment options.

\section{How the intervention might work}

While other routes, such as subcutaneous, intravenous or intraosseous administration, are available to professional caregivers these routes are not practical or feasible in many first-aid settings and are likely not needed in cases of mild hypoglycaemia. The buccal, sublingual, oral, and rectal routes could potentially be used by both hypoglycaemic individuals and first-aid providers managing hypoglycaemia; however their efficacy and safety are unknown. Each of these routes may have various levels and rates of bioavailability which may impact on clinical recovery rates.

In the case of buccal administration, medications or sugars are held inside the cheek and then diffuse through the oral mucosa to enter directly into the bloodstream. Compared to oral administration, the substance does not pass through the digestive system and has less chance of becoming degraded. Therefore, the drug can potentially act faster; however, the bioavailability of buccal-administered medications or sugars is unknown. With sublingual administration, a sugar or medicine diffuses into the blood through the mucous membrane under the tongue. As with buccal administration, it does not pass through the gastrointestinal tract and may be absorbed faster than the oral route. However, the total available area under the tongue for absorption may limit the extent of uptake. While many medications are specifically designed for buccal or sublingual administration, it is unknown which administration route is most effective for glucose.

\section{Why it is important to do this review}

To help guide first-aid care, the International Liaison Committee on Resuscitation (ILCOR) uses a continuous evidence evaluation process for resuscitation and relevant first-aid topics culminating in the production of a consensus on science with treatment recommendations (COSTR). Whilst previous work by ILCOR has helped to establish the role of oral glucose (i.e. tablets) over dietary sugars, the optimal enteral route for glucose administration is currently unknown (Carlson 2017; Singletary 2015; Zideman 2015). A Cochrane Review studied the use of oral dextrose gel massaged into the buccal mucosa for the treatment of hypoglycaemia in newborn infants, and showed positive effects towards outcomes as "separation from the mother" and "completing breast-feeding". However, we excluded this target group from this Cochrane Review, since the setting of treatment of newborns is less relevant to first aid (Weston 2016). We conducted this review in co-operation with the ILCOR First Aid Task Force. The aim of this systematic review is to answer the following research question: among adults and children with suspected hypoglycaemia, does administration of glucose by any route appropriate for use by first-aid providers compared to administration of glucose by another route appropriate for use by first-aid providers change resolution of symptoms, blood glucose concentration, resolution of hypoglycaemia, delay in treatment, or adverse events?

\section{OBJECTIVES}

To assess the effects of first aid glucose administration by any route appropriate for use by first-aid providers (buccal, sublingual, oral, rectal) for symptomatic hypoglycaemia. 


\section{METHODS}

\section{Criteria for considering studies for this review}

\section{Types of studies}

We included randomised controlled trials (RCTs) and non-RCTs. We excluded observational studies and unpublished studies (e.g. conference abstracts).

\section{Types of participants}

We included studies with adults and children with documented or suspected hypoglycaemia. Participants could be healthy volunteers or people with diabetes with hypoglycaemia.

\section{Types of interventions}

We planned to investigate the following comparisons of intervention versus control/comparator

\section{Intervention}

We included studies where glucose (in the form of glucose or dextrose spray, gel, liquids, syrup or tablets, liquid sugar (e.g. corn syrup), or table sugar (sucrose) in different forms (solid or liquid)), was administered by any route appropriate for use by first-aid providers (buccal, sublingual, oral, rectal). Buccal administration was defined as application to the cheek mucosa; sublingual administration as application under the tongue; both without intentional swallowing of glucose.

\section{Comparisons}

For the comparison, we included studies where the same sugar compound in the comparison group was administered by a different route of administration (buccal, sublingual, oral, rectal) than in the intervention group.

Concomitant interventions had to be the same in both the intervention and comparator groups to establish fair comparisons.

If a study included multiple arms, we planned to include any study arm that met the review inclusion criteria.

\section{Minimum duration of intervention}

Since glucose administration is a first-aid intervention with a quick response, this intervention is administered only once and no minimum duration of the intervention is defined.

\section{Minimum duration of follow-up}

Minimal duration of follow-up was 20 minutes.

We defined any follow-up period going beyond the original time frame for the primary outcome measure as specified in the power calculation of the study protocol as an extended follow-up period (also called 'open-label extension study') (Buch 2011; Megan 2012).

\section{Summary of specific exclusion criteria}

We excluded studies of the following category of participants or interventions.

- Neonates, as we considered that the presentation of hypoglycaemia in this population differs from adults and children, requiring skills beyond typical first aid.
- Intravenous administration of glucose.

- Administration of sugars that are not readily available to a firstaid provider (e.g. fructose or a specific mixture of different sugars).

- Administration of sugar-containing foods and beverages such as candies, juice, or confectionaries as these have been analysed in a recent systematic review (Carlson 2017).

\section{Types of outcome measures}

We did not exclude a study if it failed to report one or several of our primary or secondary outcome measures. If none of our primary or secondary outcomes was reported in the study, we did not include the study but planned to provide some basic information in the 'Characteristics of studies awaiting classification' table.

We investigated the following outcomes using the methods and time points specified below.

\section{Primary outcomes}

- Resolution of symptoms

- Time to resolution of symptoms

- Blood or plasma glucose concentration at 20 minutes

\section{Secondary outcomes}

- Resolution of hypoglycaemia

- Time to resolution of hypoglycaemia

- Adverse events

- Treatment delay

Method and timing of outcome measurement

- Resolution of symptoms: defined as the reversal of the initial symptoms.

- Time to resolution of symptoms: defined as the time from the administration of the glucose-containing solution until the symptoms resolved.

- Blood or plasma glucose concentration at 20 minutes: defined as the glucose level measured 20 minutes after the administration of the glucose substrate.

- Resolution of hypoglycaemia: defined as a rise in the blood or plasma glucose level $\geq 90 \mathrm{mg} / \mathrm{dL}$ or a rise in blood or plasma glucose within 20 minutes.

- Time to resolution of hypoglycaemia: defined as the time from the administration of the glucose substrate to the time for the blood or plasma glucose concentration to rise above the threshold for hypoglycaemia.

- Adverse events: defined as any event resulting from the treatment as defined by the study authors (e.g. aspiration).

- Treatment delay: defined as the delay in providing care as a result of the treatment arm.

\section{Search methods for identification of studies}

\section{Electronic searches}

We searched the following sources from the inception of each database to the date of search (11 July 2018) and placed no restrictions on the language of publication.

- Cochrane Central Register of Controlled Trials (CENTRAL) via the Cochrane Register of Studies Online (CRSO). 
- MEDLINE Ovid SP (Epub Ahead of Print, In-Process \& Other NonIndexed Citations, Ovid MEDLINE Daily and Ovid MEDLINE; from 1946 onwards).

- Embase Ovid SP.

- CINAHL EBSCO (Cumulative Index to Nursing and Allied Health Literature).

- ClinicalTrials.gov (www.clinicaltrials.gov).

- World Health Organization (WHO) International Clinical Trials Registry Platform (ICTRP) (www.who.int/trialsearch/).

- EU Clinical Trials Register (www.clinicaltrialsregister.eu/).

For detailed search strategies, see Appendix 1. We continuously applied an email alert service for MEDLINE via OvidSP to identify newly published studies using the search strategy detailed in Appendix 1

\section{Searching other resources}

We tried to identify other potentially eligible studies or ancillary publications by searching the reference lists of included studies, systematic reviews, meta-analyses, and health technology assessment reports. In addition, we tried to contact the authors of included studies to obtain additional information on the retrieved studies and establish whether we may have missed further studies.

We also searched the grey literature which we defined as searching clinical trials registers.

We decided not to use abstracts or conference proceedings for data extraction unless full data were available from study authors because this information source does not fulfil the CONSORT requirements which consist of "an evidence-based, minimum set of recommendations for reporting randomised trials" (CONSORT 2019; Scherer 2007). We planned to present information on abstracts or conference proceedings in the 'Characteristics of studies awaiting classification' table.

\section{Data collection and analysis}

\section{Selection of studies}

Two review authors (EDB and TD) independently screened the abstract or title, or both, of every record retrieved by the literature searches to determine which studies we should assess further. We obtained the full text of all potentially relevant records. We resolved disagreements through consensus or by recourse to a third review author (VB). If we could not resolve a disagreement, we planned to categorise the study as a Characteristics of studies awaiting classification and to contact the study authors for clarification. We presented an adapted PRISMA flow diagram to show the process of study selection (Liberati 2009). We listed all articles excluded after full-text assessment in the table Characteristics of excluded studies and provided the reasons for exclusion.

\section{Data extraction and management}

For studies that met the inclusion criteria of the review, two review authors (EDB and VB) independently extracted information on key participant and intervention characteristics. Two review authors (EDB and VB) independently extracted the following data using a standardised and a piloted data extraction form: general study information (author, year of publication, country of author), study design, study population (number of participants, mean age, patient characteristics if applicable), intervention (dose, details on intervention and administration route), outcome measures and risk of bias (for details see Characteristics of included studies; Table 1; Appendix 2; Appendix 3; Appendix 4; Appendix 5; Appendix 6; Appendix 7; Appendix 8; Appendix 9; Appendix 10; Appendix 11; Appendix 12; Appendix 13).

We resolved disagreements by discussion or, if required, by consulting a third review author (TD, JNC, EMS, or DAZ). We planned to provide information including trial identifier for potentially relevant ongoing trials in the Characteristics of ongoing studies table. We tried to find the protocol for each included study and reported in Appendix 9 primary, secondary, and other outcomes in comparison with data in publications.

We sought relevant missing information on the study from the primary study author(s), if required.

\section{Dealing with duplicate and companion publications}

In the event of duplicate publications, companion documents, or multiple reports of a primary study, we planned to maximise the information yield by collating all available data, and we used the most complete data set aggregated across all known publications. We wanted to list duplicate publications, companion documents, multiple reports of a primary study, and trial documents of included trials (such as trial registry information) as secondary references under the study ID of the included study. Furthermore, we planned to list duplicate publications, companion documents, multiple reports of a study, and trial documents of excluded studies (such as trial registry information) as secondary references under the study ID of the excluded study.

\section{Data from clinical trials registers}

If data from included studies were available as study results in clinical trials registers, such as ClinicalTrials.gov or similar sources, we planned to make full use of this information and extract the data. If there was also a full-text publication of the study, we collated and critically appraised all available data. If an included study was marked as a completed study in a clinical trials register but no additional information (study results, publication, or both) was available, we planned to add this study to the table Characteristics of studies awaiting classification.

\section{Assessment of risk of bias in included studies}

Two review authors (EDB and VB) independently assessed the risk of bias for each included study. We resolved disagreements by consensus or by consulting a third review author (TD). In the case of disagreement, we consulted the remainder of the review author team and made a judgment based on consensus. If adequate information was unavailable from the publications, trial protocols, or other sources, we contacted the study authors for more details and to request missing data on 'Risk of bias' items.

For the RCTs, we used the Cochrane 'Risk of bias' assessment tool (Higgins 2017), assigning assessments of low, high, or unclear risk of bias (for details, see Appendix 2; Appendix 3). We evaluated individual bias items as described in the Cochrane Handbook for Systematic Reviews of Interventions, according to the criteria and associated categorisations contained therein (Higgins 2017).

For the non-RCTs, we assessed the different items of the 'risk of bias In non-randomised studies of interventions' (ROBINS-I) tool (Sterne 2016) (see Appendix 4). In the case of cross-over studies, 
we additionally assessed the items described in the Cochrane Handbook for Systematic Reviews of Interventions for cross-over studies (Higgins 2011).

\section{Summary assessment of risk of bias}

We presented a 'Risk of bias' graph and a 'Risk of bias' summary figure. A study was overall considered as at high risk of bias if we found that one of the domains within the Cochrane 'Risk of bias' or ROBINS-I tool has at high risk of bias.

\section{Measures of treatment effect}

We reported dichotomous data as a risk ratio (RR) with 95\% confidence intervals (Cls). For continuous outcomes measured on the same scale (e.g. glucose concentrations in $\mathrm{mg} / \mathrm{dL}$ ), we estimated the intervention effect using the mean difference (MD) with $95 \% \mathrm{Cls}$. We converted all data on glucose concentrations to $\mathrm{mg} / \mathrm{dL}$. We planned to express time-to-event data as a hazard ratio (HR) with $95 \% \mathrm{Cls}$.

\section{Unit of analysis issues}

We took into account the level at which randomisation occurred, such as cross-over studies, cluster-randomised studies, and multiple observations for the same outcome. In the case of multiarm studies, we planned to combine groups to create a single pairwise comparison. We anticipated identifying studies with paired data ('within-subjects designs'), which we analysed as reported by Elbourne 2002.

\section{Dealing with missing data}

If possible, we obtained missing data from the authors of included studies (see Appendix 13). Where necessary, we extracted data from graphs from the included studies. Where necessary and if possible, we imputed missing values. We planned to investigate the impact of imputation on meta-analyses by performing sensitivity analyses.

\section{Assessment of heterogeneity}

In the event of substantial clinical or methodological heterogeneity, we did not report study results as the pooled effect estimate in a meta-analysis. We planned to identify heterogeneity (inconsistency) by visually inspecting the forest plots and by using a standard Chi2 test with a significance level of $\alpha=0.1$ (Deeks 2017). In view of the low power of this test, we also considered the 12 statistic, which quantifies inconsistency across studies, to assess the impact of heterogeneity on the meta-analysis (Higgins 2002; Higgins 2003). We would also have considered heterogeneity to be substantial if the $1^{2}$ value was greater than $60 \%$.

When we found heterogeneity, we attempted to determine possible reasons for this by examining individual study and subgroup characteristics.

\section{Assessment of reporting biases}

Had we included 10 or more studies that investigated a particular outcome, we planned to use funnel plots to assess smallstudy effects. Several explanations may account for funnel plot asymmetry, including true heterogeneity of effect with respect to study size, poor methodological design (and hence bias of small studies), and publication bias (Sterne 2017). Therefore, we planned to interpret the results carefully (Sterne 2011).

\section{Data synthesis}

We planned to undertake (or display) a meta-analysis only if we judged participants, interventions, comparisons, and outcomes to be sufficiently similar to ensure an answer that was clinically meaningful.

Unless good evidence showed homogeneous effects across studies of different methodological quality, we primarily wanted to summarise low risk of bias data using a random-effects model (Wood 2008). Our analyses were stratified based on administration route (buccal, sublingual, oral, rectal). Since we anticipated variation between studies, we used the random-effects model. We used the Mantel-Haenszel method for dichotomous outcomes and the inverse variance method for continuous outcomes. A P value less than 0.05 was considered significant. We established metaanalyses involving paired data from within-participants designs using R software, version 3.2.5 (R software 2019).

\section{Subgroup analysis and investigation of heterogeneity}

We expected the following characteristics to introduce clinical heterogeneity, and we planned to undertake the following subgroup analyses including investigation of interactions (Altman 2003).

- Paediatric versus adult individuals.

- Individuals with insulin-dependent (type 1 diabetes) versus noninsulin dependent diabetes (type 2 diabetes).

- Unconscious versus conscious individuals.

\section{Sensitivity analysis}

We planned to perform sensitivity analyses to explore the influence of the following factors (when applicable) on effect sizes by restricting analysis to the following.

- Effect of risk of bias, as specified in the Assessment of risk of bias in included studies section.

- Effect of an assumed correlation coefficient of 0.1 (low degree of correlation) and 0.9 (high degree of correlation), in case the correlation between the results from the two treatment periods was not known for paired data study designs.

\section{Certainty of the evidence}

We presented the overall certainty of the evidence for each outcome specified below, according to the GRADE approach, which takes into account issues related not only to internal validity (risk of bias, inconsistency, imprecision, publication bias), but also to external validity, such as directness of results (Guyatt 2008; Schünemann 2017). Two review authors (EDB and VB) independently rated the certainty of the evidence for each outcome. We resolved differences in assessment by discussion or by consulting a third review author (TD).

We used the GRADEpro Guideline Development Tool (GDT) software (GRADEproGDT 2015) and presented evidence as an appendix (Appendix 14; Appendix 15; Appendix 16) adapted to Meader 2014. We presented results for outcomes as described in the Types of outcome measures section. If meta-analysis was not possible, we presented the results in a narrative format in the 'Summary of findings' table. We justified all decisions to downgrade the certainty of the evidence using footnotes, and we made comments to aid the reader's understanding of the Cochrane Review when necessary. 


\section{'Summary of findings' table}

We presented a summary of the evidence in Summary of findings for the main comparison; Summary of findings 2; Summary of findings 3. This provided key information about the best estimate of the magnitude of effect, in relative terms and as absolute differences for each relevant comparison of alternative management strategies, numbers of participants and studies addressing each important outcome, and a rating of overall confidence in effect estimates for each outcome.

In the 'Summary of findings' table we reported on the 'intervention' glucose (in the form of glucose or dextrose spray, gel, liquids, syrup or tablets, liquid sugar (e.g. corn syrup), or table sugar (sucrose) in different forms (solid or liquid)), administered by any route appropriate for use by first-aid providers (buccal, sublingual, oral, rectal)) versus the 'comparator' using the same sugar but administered by a different route of administration.

We created the 'Summary of findings' tables using the methods described in the Cochrane Handbook for Systematic Reviews of Interventions (Schünemann 2017), along with Review Manager 5 (RevMan 5.3) table editor (RevMan 2014). We reported the following outcomes.

- Resolution of symptoms

Figure 1. Study flow diagram.

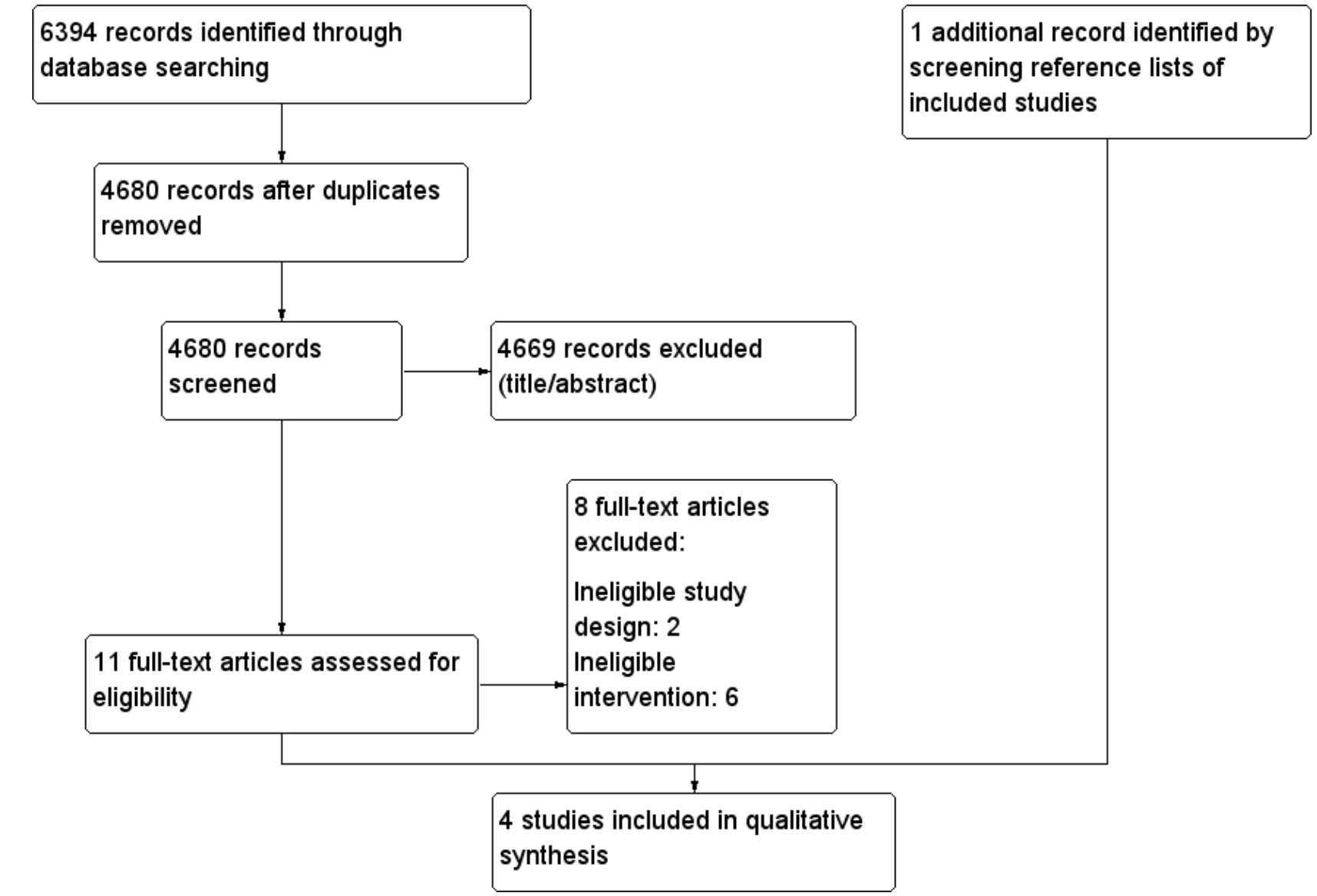

- Time to resolution of symptoms

- Blood or plasma glucose concentration at 20 minutes

- Resolution of hypoglycaemia

- Time to resolution of hypoglycaemia

- Adverse events

- Treatment delay

\section{RE S U L T S}

\section{Description of studies}

For a detailed description of studies, see Table 1, the 'Characteristics of included studies' and 'Characteristics of excluded studies' sections. We tried to obtain missing information through contact with study authors (see Appendix 13).

\section{Results of the search}

We identified 6394 references through database searching and added one study based on the reference list of one of the selected studies, resulting in four studies being included (Barennes 2005; Chlup 2009; Gunning 1978; Slama 1990). We excluded eight studies based on full-text evaluation because the interventions described did not fulfil our selection criteria.

Figure 1 illustrates the PRISMA study selection diagram including reasons for article exclusion. 


\section{Included studies}

See Characteristics of included studies for more details on the study characteristics.

\section{Source of data}

All data presented in the review were obtained from published literature.

\section{Comparisons}

One study compared sublingual glucose with oral glucose (Barennes 2005), two studies compared buccal glucose administration with oral administration (Chlup 2009; Gunning 1978), and one study compared oral administration of $15 \mathrm{~g}$ of glucose supplied as $40 \mathrm{~g}$ of a $40 \%$ dextrose gel, with the oral administration of glucose (Slama 1990).

\section{Overview of study populations}

Individual sample sizes of the studies were small, ranging from seven to 69 . In the study with sublingual glucose administration, 69 participants were included, of which 25 received sublingual glucose and 15 received oral glucose (Barennes 2005). The data of participants who received intravenous glucose were not extracted. Both studies where buccal glucose was tested were small studies, with respectively 16 and 7 participants, receiving both intervention and control (cross-over design) (Chlup 2009; Gunning 1978). The study that tested the dextrose gel included 41 participants, of which six participants received the dextrose gel and 12 participants received oral glucose (glucose tablets) (Slama 1990). All participants assigned to either intervention or control groups finished the studies.

\section{Study design}

We identified two randomised controlled trials (RCTs) (Barennes 2005; Slama 1990) and two non-RCTs with a cross-over design (Chlup 2009; Gunning 1978). Since glucose administration is a firstaid intervention with a quick response, the studies were of short duration, and follow-up ranged from 20 minutes to 80 minutes.

\section{Settings}

We identified one study from Burkina Faso (Barennes 2005), one from the Czech Republic (Chlup 2009), one from the USA (Gunning 1978) and one from France (Slama 1990). One study was performed in a pre-hospital setting (Hamdallaye Health Center) (Barennes 2005), two in an experimental out-of-hospital setting (Chlup 2009; Gunning 1978) and one in a hospital setting (Slama 1990).

\section{Participants}

The studies that looked at sublingual administration included children (gender not reported) between one and 15 years old with moderate symptoms of malaria or respiratory tract infections and low blood glucose concentrations but no severe clinical symptoms of hypoglycaemia (Barennes 2005). The two studies that investigated buccal glucose included adult healthy fasting volunteers, 14 men and two women with a mean age of 21.8 years (Chlup 2009), and seven volunteers (no information on gender or age) (Gunning 1978). The study that administered dextrose gel included fasting participants (mean age 28 years) with type 1 diabetes and insulin-induced hypoglycaemia (Slama 1990).

\section{Diagnosis}

Only two studies included participants with hypoglycaemia. Hypoglycaemia was defined or induced in different ways, according to the study authors: the first study included children with moderate clinical symptoms of concomitant acute malaria or moderate respiratory tract infections, and a blood glucose concentration between $50 \mathrm{mg} / \mathrm{dL}$ and $80 \mathrm{mg} / \mathrm{dL}$ following overnight fasting, however no severe clinical symptoms of hypoglycaemia were present (Barennes 2005); the second study included participants with type 1 diabetes where hypoglycaemia was induced with intravenous insulin until symptoms of hypoglycaemia occurred or blood glucose was below $49 \mathrm{mg} /$ $\mathrm{dL}$ (Slama 1990). The two other studies investigated healthy volunteers without hypoglycaemia (participants only fasted overnight) (Chlup 2009; Gunning 1978).

\section{Interventions}

One study compared sublingual glucose administration (2.5 g of wet sugar under the tongue) with oral administration ( $2.5 \mathrm{~g}$ of sugar on the tongue) (Barennes 2005). Two studies compared buccal glucose administration with oral administration: the first study administered 10 glucose spray doses (five doses to each cheek mucosa, total of $0.84 \mathrm{~g}$ glucose) compared to a $6 \mathrm{~g}$ dextrose tablet to be chewed and swallowed (Chlup 2009); the second study provided $15 \mathrm{~g}$ of instant glucose, placed between the teeth and the cheek of each participant, compared to $15 \mathrm{~g}$ of instant glucose to be swallowed (Gunning 1978). The participants who received buccal glucose were encouraged not to swallow. One study compared the oral administration of $15 \mathrm{~g}$ of glucose supplied as $40 \mathrm{~g}$ of a $40 \%$ dextrose gel, with the oral administration of glucose (either a 15 g glucose tablet to be chewed and swallowed without water, or a $15 \mathrm{~g}$ glucose solution in $150 \mathrm{ml}$ of water, swallowed; the two oral administration groups were combined as one "oral group" in the data analyses) (Slama 1990). In this study, the authors noted that the dextrose gel adhered to the mucosa and was not completely swallowed, and therefore this administration form was labelled as "combined oral and buccal mucosal administration" in this review. We did not identify any studies testing the rectal administration of glucose.

\section{Outcomes}

Only one study explicitly stated primary and secondary endpoints, and primary endpoints were 'treatment failure rate' (failure to reach a blood glucose concentration of $\geq 90 \mathrm{mg} / \mathrm{dL}$ during the study period), or as 'early treatment failure rate' (no blood glucose increase at 20 minutes), which contained the data for the review's outcome of 'resolution of hypoglycaemia' (Barennes 2005). All studies measured blood or plasma glucose concentration, or the number of participants with increased blood glucose at 20 minutes, as an endpoint.

\section{Excluded studies}

The main reason for excluding studies at the level of full text evaluation was the lack of a comparison group for administration routes (see Characteristics of excluded studies).

\section{Risk of bias in included studies}

We assessed both RCTs to be at high risk of bias, as they had a high risk of bias in several domains for a particular outcome (Barennes 
2005; Slama 1990). A detailed description of allocation, blinding, incomplete outcome data and selective reporting is listed below.

For details on the risk of bias of the included studies see Characteristics of included studies.
For an overview of review authors' judgements about each 'Risk of bias' item for individual studies and across all studies see Figure 2 and Figure 3.

Figure 2. 'Risk of bias' graph: review authors' judgements about each risk of bias item presented as percentages across all included studies (blank cells for randomised controlled trials (Barennes 2005; Slama 1990) indicate that the particular outcome was not measured in the study and blank cells for non-randomised controlled trials (Chlup 2009 and Gunning 1978) indicate that overall low risk of bias was established according to the ROBINS-I (risk of bias in non-randomised studies of interventions, see Appendix 4)).

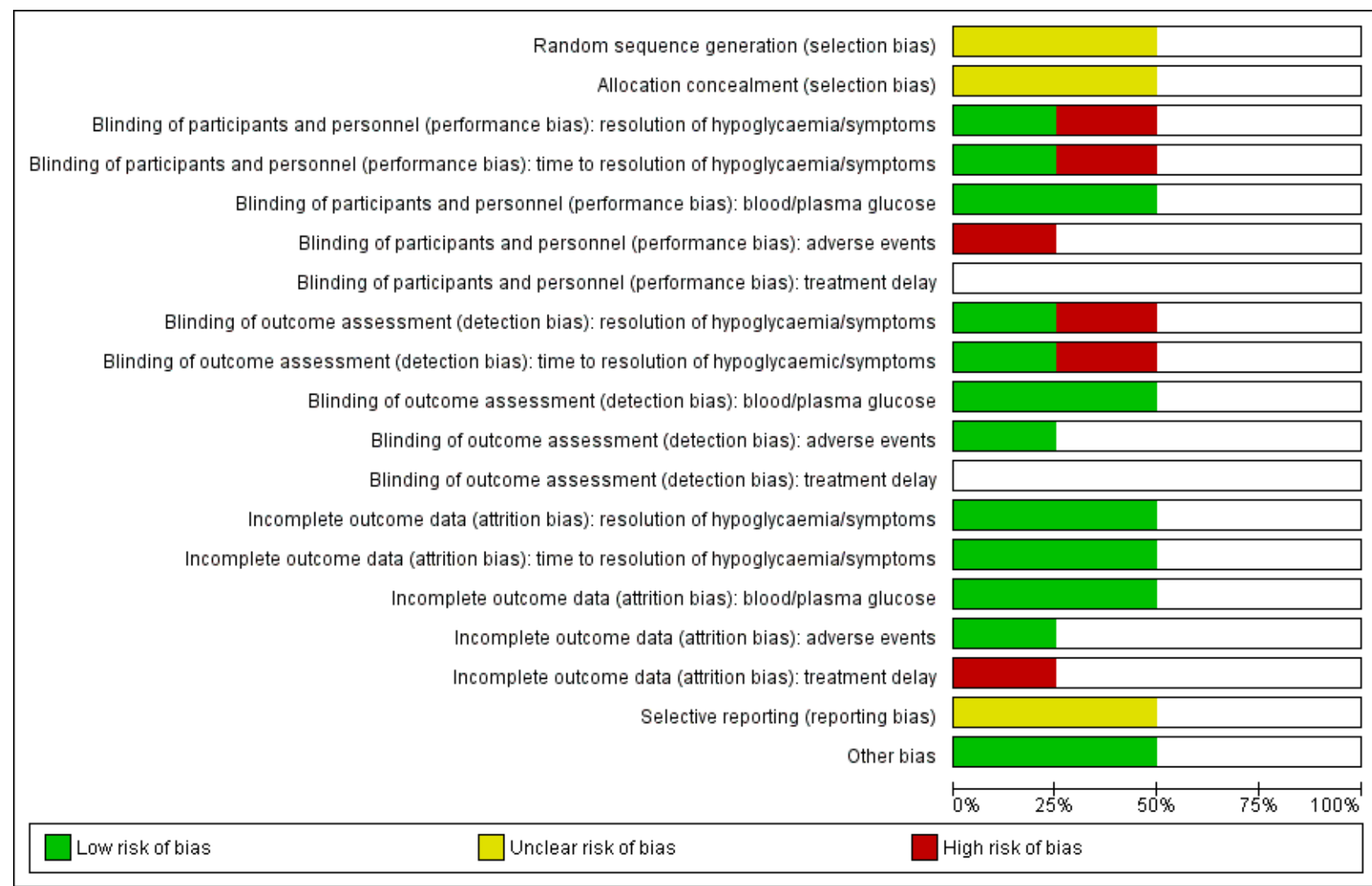


Figure 3. 'Risk of bias' summary: review authors' judgements about each risk of bias item for each included study: blank cells for randomised controlled trials (Barennes 2005; Slama 1990) indicate that the particular outcome was not measured in the study); blank cells for non-randomised controlled trials (Chlup 2009 and Gunning 1978) indicate that overall low risk of bias was established according to the ROBINS-I (risk of bias in non-randomised studies of interventions, see Appendix 4).

\begin{tabular}{|c|c|c|c|c|c|c|c|c|c|c|c|c|c|c|c|c|c|c|c|}
\hline & 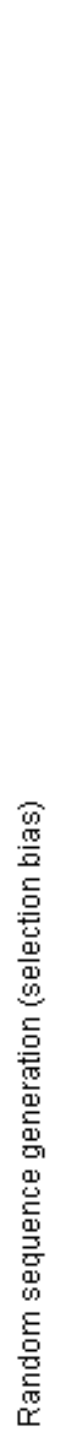 & 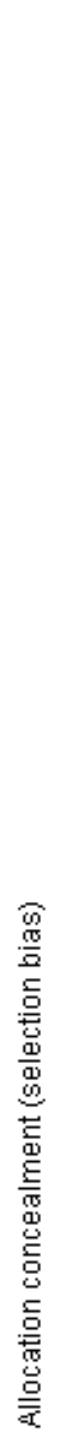 & 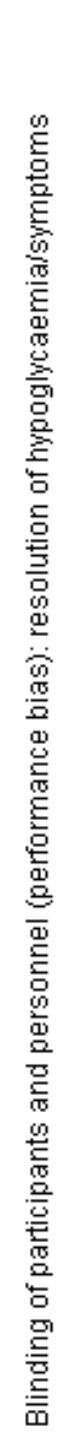 & 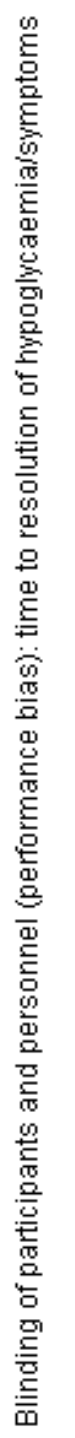 & 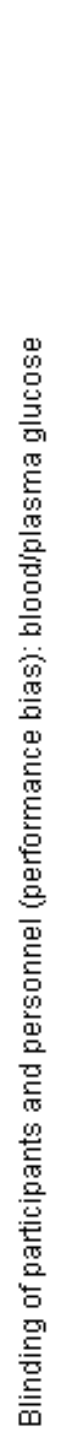 & 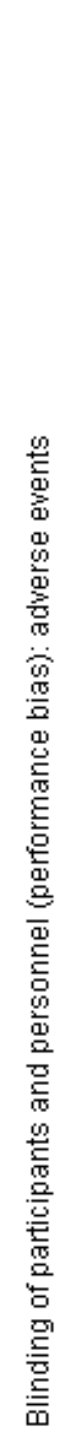 & 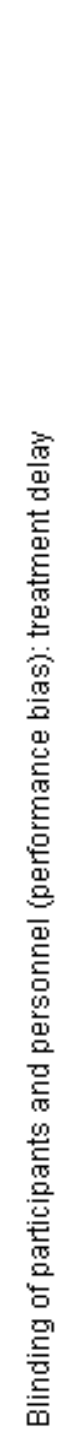 & 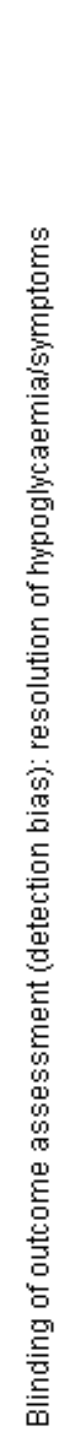 & 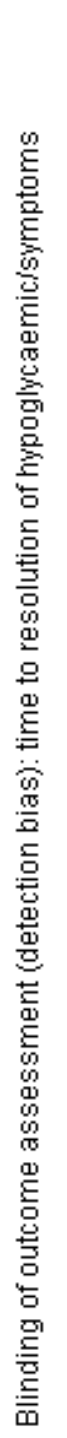 & 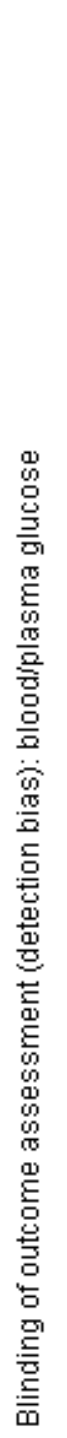 & 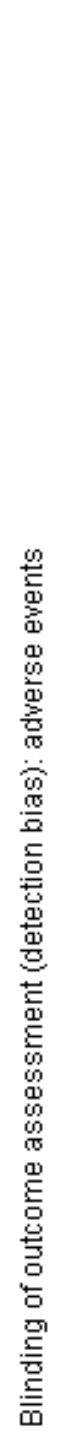 & 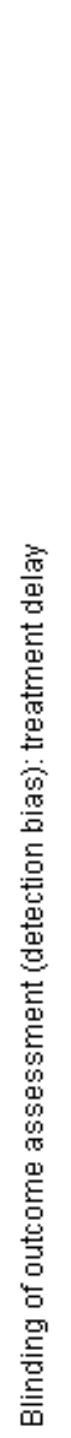 & 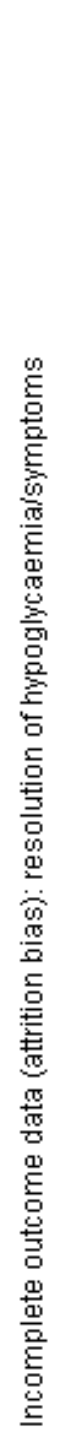 & 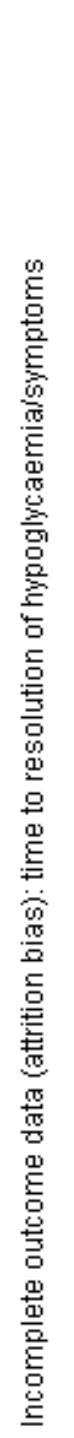 & 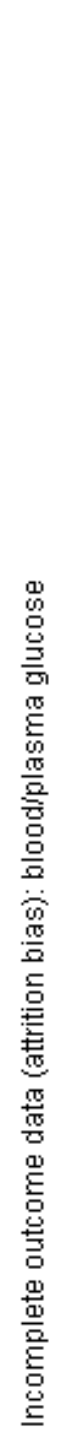 & 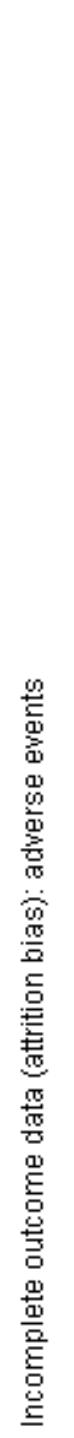 & 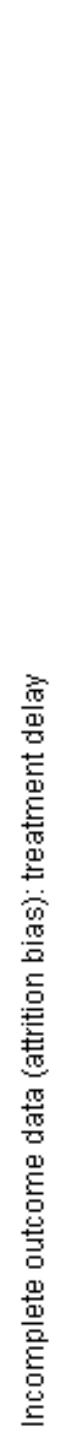 & 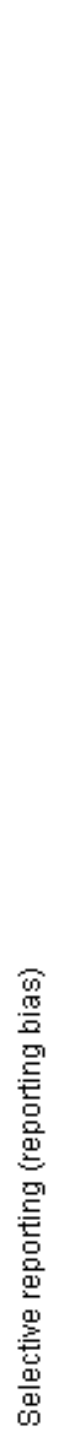 & 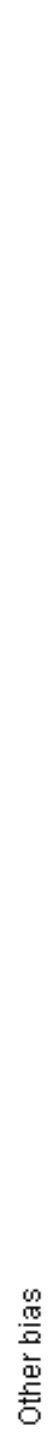 \\
\hline Barennes 2005 & $?$ & $?$ & + & + & + & - & & + & $\odot$ & $\odot$ & + & & $\odot$ & $\odot$ & $\odot$ & $\odot$ & - & $?$ & + \\
\hline Chlup 2009 & & & & & & & & & & & & & & & & & & & \\
\hline Gunning 1978 & & & & & & & & & & & & & & & & & & & \\
\hline Slama 1990 & $?$ & $?$ & - & 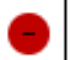 & $*$ & & & $\odot$ & 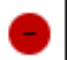 & $\odot$ & & & $\odot$ & $\odot$ & $\odot$ & & & $?$ & + \\
\hline
\end{tabular}

We assessed both non-RCTs as high risk of bias studies, and details are described under 'Other potential sources of bias' (Chlup 2009; Gunning 1978).

\section{Blinding}

For at least one outcome measure both RCTs had a high risk of performance and detection bias (Barennes 2005; Slama 1990).

\section{Allocation}

Randomisation and allocation concealment was unclear in both RCTs (Barennes 2005; Slama 1990). 


\section{Incomplete outcome data}

In one study, we noted incomplete accounting of outcome events (Barennes 2005).

\section{Selective reporting}

A rise in blood or plasma glucose concentration is generally seen as the main measure of treatment success. The two RCTs both measured this outcome, and no reporting bias was determined. However, no protocols were published for any study which makes the overall judgement for reporting bias unclear.

\section{Other potential sources of bias}

Two of the included studies were non-randomised cross-over studies. For these studies we considered the different items of the ROBINS-I tool (see Appendix 4). According to the ROBINS-I tool no high risk of bias was identified, but this was mainly due to the cross-over design. In addition, we assessed the items described in the Cochrane Handbook for Systematic Reviews of Interventions for cross-over studies (Higgins 2011), although in these cross-over studies it is clear that all participants received the treatments in the same order. The cross-over design was considered a suitable design since they studied a condition where long-term follow-up is not required. A possible concern is the carry-over effect from one treatment period to the next. In the study by Chlup 2009 a fasting time of eight to nine hours was taken into account between the different treatments. For the study of Gunning 1978 this is unclear, but it was mentioned that the control treatment was given in a preliminary study, indicating that this was done at a different time point. The fact that the participants received the treatments in the same order is an important source of bias, since there may be a trend in outcomes over time in addition to the change in treatments. Therefore, we assessed both studies as high risk of bias.

\section{Effects of interventions}

See: Summary of findings for the main comparison Sublingual glucose compared to oral (swallowed) glucose for treatment of hypoglycaemia; Summary of findings 2 Buccal glucose compared to oral (swallowed) glucose for treatment of hypoglycaemia; Summary of findings 3 Oral + buccal glucose (dextrose gel) compared to oral (swallowed) glucose for treatment of hypoglycaemia

\section{Baseline characteristics}

For details of baseline characteristics, see Appendix 7 and Appendix 8.

\section{Sublingual glucose administration compared with oral glucose} administration

Only one study evaluated sublingual administration of sugar (Barennes 2005). This was undertaken in children between one and 15 years old with hypoglycaemia associated with moderate clinical symptoms of concomitant acute malaria or moderate respiratory tract infections (see Summary of findings for the main comparison).

\section{Primary outcomes}

\section{Resolution of symptoms}

No data were available for this outcome.

\section{Time to resolution of symptoms}

No data were available for this outcome.

\section{Blood or plasma glucose concentration at 20 minutes}

There was an increase in the blood or plasma glucose concentrations at 20 minutes in the sublingual administration group compared with the oral administration group (mean difference (MD) $17 \mathrm{mg} / \mathrm{dL}, 95 \%$ confidence interval (Cl) 4.4 to 29.6; $\mathrm{P}=0.008$; 1 study; 42 participants; Analysis 1.1.1; very low-certainty evidence)

\section{Secondary outcomes}

\section{Resolution of hypoglycaemia}

There was a higher resolution of hypoglycaemia during the study period at 80 minutes (i.e. reaching a blood glucose concentration of $\geq 90 \mathrm{mg} / \mathrm{dL}$ during the study period) in favour of sublingual administration, compared with oral administration (risk ratio (RR) $2.10,95 \% \mathrm{Cl} 1.24$ to $3.54 ; \mathrm{P}=0.006 ; 1$ study; 42 participants; very low-certainty evidence). However, a difference in resolution of symptoms at 20 minutes (i.e. blood glucose increase at 20 minutes ) could not be demonstrated (RR $1.26,95 \% \mathrm{Cl} 0.91$ to $1.74 ; \mathrm{P}=0.16 ; 1$ study; 42 participants; very low-certainty evidence).

\section{Time to resolution of hypoglycaemia}

A decrease in the time to resolution of hypoglycaemia was found in favour of sublingual administration, compared with oral administration (MD $-51.5 \mathrm{~min}, 95 \% \mathrm{Cl}-58$ to -45 ; $\mathrm{P}<0.001 ; 1$ study; 42 participants; very low-certainty evidence).

\section{Adverse events}

No adverse events were reported in either group.

\section{Treatment delay}

No data were available for this outcome.

\section{Buccal glucose administration compared with oral glucose administration}

Two studies compared buccal administration of glucose with oral administration (Chlup 2009; Gunning 1978). See Summary of findings 2 .

\section{Primary outcomes}

Resolution of symptoms

No data were available for this outcome.

Time to resolution of symptoms

No data were available for this outcome.

\section{Blood or plasma glucose concentration at 20 minutes}

In the first study (Chlup 2009) plasma glucose concentration at 20 minutes was lower in the group receiving buccal glucose compared with oral administration (MD $-14.4 \mathrm{mg} / \mathrm{dL}, 95 \% \mathrm{Cl}$ -23.6 to $-5.2 ; \mathrm{P}=0.002 ; 1$ study; 16 participants; Analysis 1.2.2; very low-certainty evidence), with an imputed within-participants correlation coefficient of 0.1 . With an imputed within-participants correlation coefficient of $0.9 \mathrm{MD}$ was $-14.4 \mathrm{mg} / \mathrm{dL}, 95 \% \mathrm{Cl}-17.5$ to -11.4; $\mathrm{P}<0.001$; 1 study; 16 participants; Analysis 1.1.2; very lowcertainty evidence. 
In the second study (Gunning 1978), there were fewer participants with increased blood glucose at 20 minutes, again favouring oral glucose (RR $0.07,95 \% \mathrm{Cl} 0.00$ to $0.98 ; \mathrm{P}=0.05 ; 1$ study; 7 participants; very low-certainty evidence).

\section{Secondary outcome}

\section{Resolution of hypoglycaemia}

No data were available for this outcome.

\section{Time to resolution of hypoglycaemia}

No data were available for this outcome.

\section{Adverse events}

No data were available for this outcome.

\section{Treatment delay}

No data were available for this outcome.

Combined oral and buccal mucosal (dextrose gel) glucose administration compared with oral glucose administration

One study (Slama 1990) administered a dextrose gel (labelled as a combined oral and buccal mucosal administration route) compared with different oral administration form (see Summary of findings 3 ).

\section{Primary outcome}

\section{Resolution of symptoms}

No improvement was identified for either route in the resolution of symptoms at 20 minutes or less following glucose administration
(RR $0.36,95 \% \mathrm{Cl} 0.12$ to $1.14 ; \mathrm{P}=0.08 ; 1$ study; 18 participants; very low-certainty evidence).

Time to resolution of symptoms

No data were available for this outcome.

Blood or plasma glucose concentration at $\mathbf{2 0}$ minutes

Plasma glucose concentration at 20 minutes for either route showed a MD of $-15.3 \mathrm{mg} / \mathrm{dL}, 95 \% \mathrm{Cl}-33.6$ to $3 ; \mathrm{P}=0.09 ; 1$ study; 18 participants; Analysis 1.1.3; very low-certainty evidence.

\section{Resolution of hypoglycaemia}

No data were available for this outcome.

Time to resolution of hypoglycaemia

No data were available for this outcome.

Adverse events

No data were available for this outcome.

Treatment delay

No data were available for this outcome.

\section{Subgroup analyses}

Since blood or plasma glucose concentration at 20 minutes was the only outcome that was measured in three of the four included studies, the results are represented in a forest plot, with subgroups based on the routes of administration (Figure 4; Figure 5).

Figure 4. Forest plot of comparison: Oral glucose vs other route, outcome: $1.1 \mathrm{Blood} / \mathrm{plasma}$ glucose concentrations at 20 minutes.

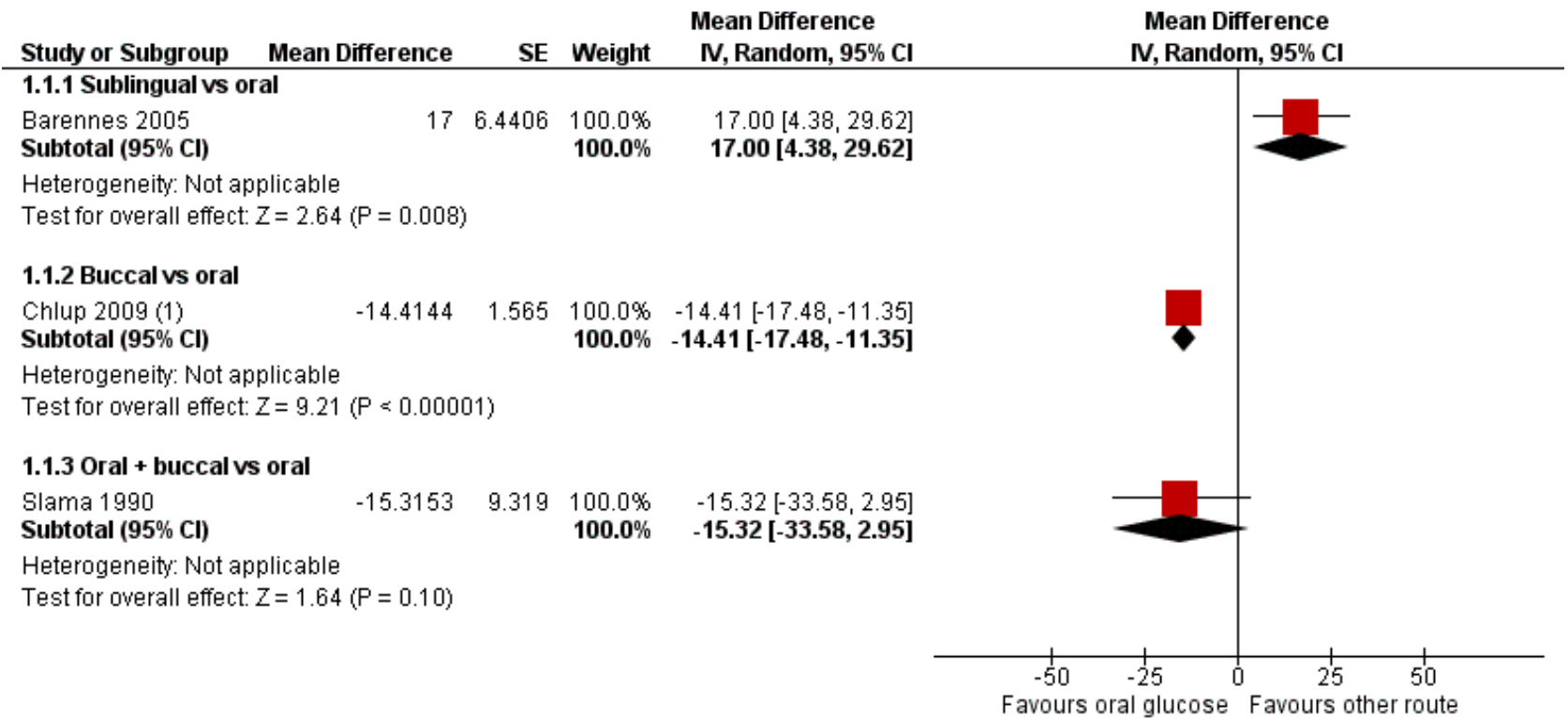

Footnotes

(1) Imputed within participants correlation coefficient of 0.9 
Figure 5. Forest plot of comparison: Oral glucose vs other route, outcome: $1.2 \mathrm{Blood} / \mathrm{plasma}$ glucose concentrations at 20 minutes.

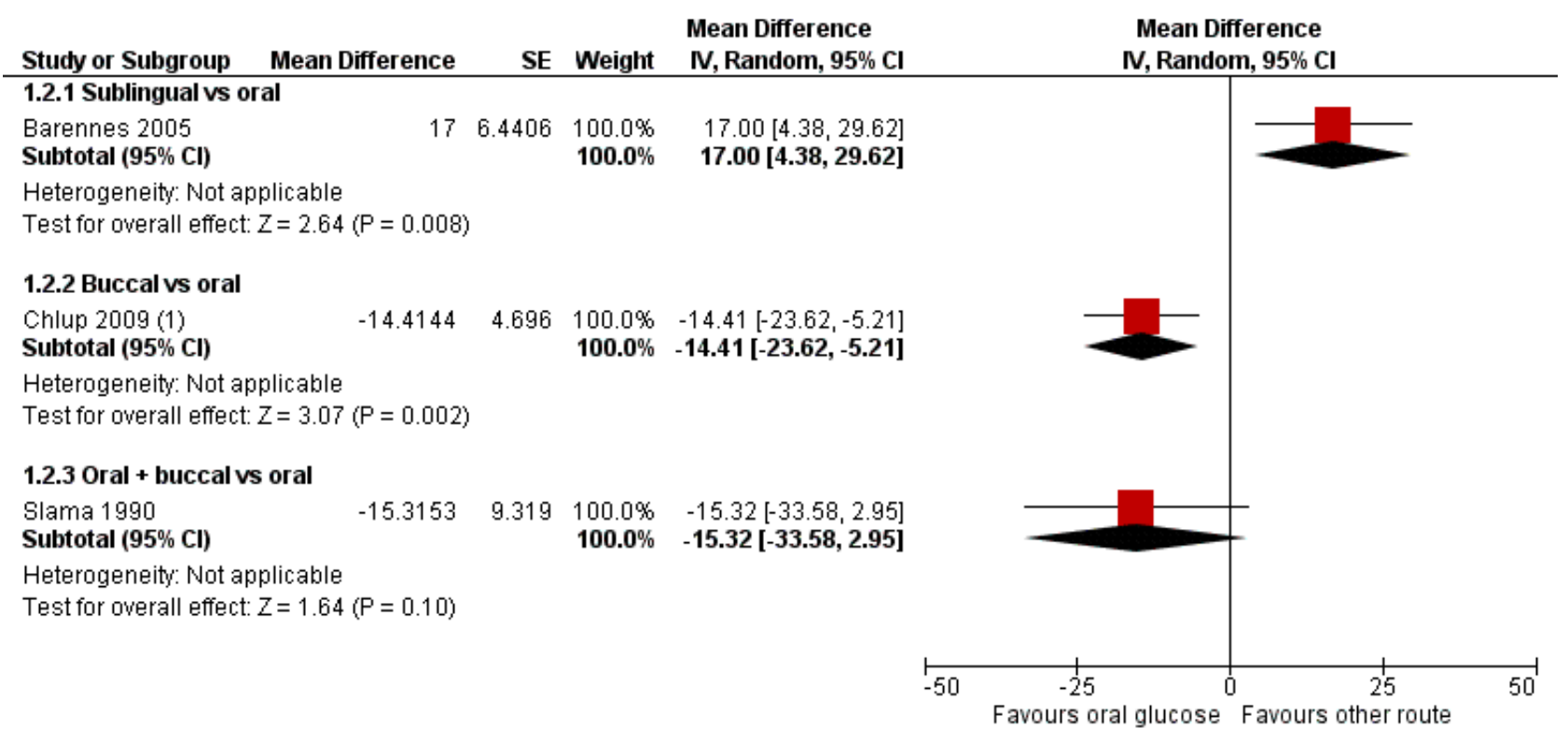

Footnotes

(1) Imputed within participants correlation coefficient of 0.1

\section{Sensitivity analyses}

We could not perform sensitivity analysis due to lack of data.

\section{Assessment of reporting bias}

We did not draw funnel plots due to limited number of studies ( $\mathrm{N}$ $=4)$.

\section{Ongoing trials}

We found no ongoing RCTs.

\section{DISCUSSION}

This systematic review searched for the optimal route for the first-aid administration of glucose in individuals with symptomatic hypoglycaemia. The hypothesis behind comparing different routes of administration is that they are associated with unequal bioavailability.

\section{Summary of main results}

We identified two non-randomised controlled trials (RCTs) (Chlup 2009; Gunning 1978); results suggest that oral administration would be preferable over buccal administration of glucose for the critical outcome 'blood or plasma glucose concentration at 20 minutes'. Sublingual sugar administration, compared with oral administration, increased the blood glucose concentration at 20 minutes in a very specific setting. For the dextrose gel, defined as "a combined oral and buccal mucosal route", a substantial difference in plasma glucose concentration could not be demonstrated.

\section{Overall completeness and applicability of evidence}

We sought to identify studies that compared different routes of administration (buccal, sublingual, oral and rectal) of glucose to an individual with suspected hypoglycaemia, but we only identified a limited number of small studies.

Only two studies included participants with hypoglycaemia (Barennes 2005; Slama 1990). The two other studies investigated healthy volunteers without hypoglycaemia (participants only fasted overnight), and thus these serve as indirect evidence (Chlup 2009; Gunning 1978). In one of these studies the mean blood glucose concentration after overnight fasting was $80 \mathrm{mg} /$ dL (Gunning 1978); in the other study the participants had initial concentrations of $90 \mathrm{mg} / \mathrm{dL}$ (mean value for control group at time zero, extracted from graph) (Chlup 2009). Because hypoglycaemia was either induced, or absent, the applicability of the evidence to clinical situations is limited.

We identified studies that researched the buccal, sublingual and oral routes, including one study that tested the sublingual route, two studies investigating the buccal route and one study that tested a dextrose gel, interpreted as a combined oral and buccal mucosal administration. All studies compared the researched route of administration versus the oral route.

The number of outcomes measured in each study was limited. All studies measured blood or plasma glucose concentrations. No study measured or reported 'time to resolution of symptoms' or 'treatment delay', and other outcomes were reported only in one of the studies.

Overall, the identified evidence is scarce, and the certainty of the evidence is very low. This impedes making conclusions for any of the administration routes. 


\section{Quality of the evidence}

For sublingual administration the certainty of evidence was based on one RCT, and thus the initial certainty of evidence was defined as high (Barennes 2005). For the three outcomes measured the certainty of evidence was lowered for risk of bias, indirectness (since the study included children with symptoms of concomitant malaria or respiratory illness) and serious imprecision (limited sample size) moving the certainty of evidence from high to very low.

For buccal administration we included two non-randomised studies, and therefore the initial certainty of evidence was defined as low, according to the GRADE approach (Chlup 2009; Gunning 1978). For the two outcomes measured, we lowered the certainty of evidence for risk of bias, indirectness (since the studies included healthy volunteers without hypoglycaemia) and serious imprecision (limited sample size or low number of events) moving the certainty from low to very low.

For the combined oral and buccal mucosal group, one RCT was included for which the certainty of evidence was initially high (Slama 1990). For the two outcomes measured, the certainty of evidence was downgraded because of (very) serious imprecision (limited sample size or low number of events, and a large variability of results), and for the outcome 'resolution of symptoms' we further downgraded because of risk of bias. This resulted in very lowcertainty evidence for 'blood or plasma glucose concentration at 20 minutes' (95\% confidence interval $(\mathrm{Cl})$ consistent with both benefit and harm), and very low-certainty evidence for 'resolution of symptoms'.

We identified an insufficient number of studies to generate funnel plots to judge publication bias for any of these comparisons.

\section{Potential biases in the review process}

Our review has several limitations. Only studies using glucose, including the isomer dextrose, and table sugar were included. Other sugars (e.g. fructose) were not examined. For many of the excluded studies, the exact content of the preparation was not reported, or the preparations are not currently manufactured. We did not include other routes of glucose administration (e.g. intravenous) as it was felt that individuals, family members or other first-aid providers would not typically administer them. In the study by Slama and colleagues, the administration route was unclear. The study authors suggested there may be some gel that remained adherent to the mucosa in the mouth and not all the gel was swallowed (Slama 1990). Therefore, for the purposes of this review, this was interpreted as a combination of the oral and buccal mucosal routes. It is noteworthy that the manufacturers' user guide on the administration of the dextrose gel (e.g. Glucogel, BBI HealthCare, Bridgend, UK) advises to either place the gel in the cheek and massage (not swallow) or to swallow. After contacting the study author, it was clarified that the participants in this study swallowed the gel. The study by Barennes and colleagues was limited in that both groups were given lower doses of glucose than recommended; only $75 \%$ of the oral study group received the correct dose, which might have affected the treatment failure rate (Barennes 2005). A further limitation was that 'blood or plasma glucose concentration at 20 minutes' was the only outcome measured in three of the four included studies and several of the pre-specified outcomes were not reported in the identified studies (Barennes 2005; Chlup 2009; Slama 1990). Finally, because of heterogeneity in terms of administration routes, populations (adults versus children, individuals with hypoglycaemia versus healthy volunteers) and study types (RCTs versus non-RCTs with cross-over designs), it was not possible to perform a meta-analysis.

\section{Agreements and disagreements with other studies or reviews}

The World Health Organization (WHO) has published a guideline on hospital care for children, describing the management of common illnesses in hospitals with limited resources (WHO 2013). This guideline includes recommendations about the use of glucose in hypoglycaemia. To support the guideline with evidence, a limited evidence review (only searching MEDLINE) was conducted to look at the efficacy of sublingual, oral and intravenous glucose (Ganeshalingam 2009). Only one study was included in the review, which was also included in our systematic review (Barennes 2005). The review concluded that oral or intravenous glucose should be used, depending on the severity of the presentation, and that the sublingual route might be of benefit as an immediate first-aid treatment of moderate hypoglycaemia associated with moderate symptoms of concomitant malaria or respiratory tract infections, when intravenous access is impossible or delayed. This is in line with our conclusions, where sublingual glucose administration may be used before oral administration in this specific population.

A Cochrane systematic review studied the use of oral dextrose gel for the treatment of hypoglycaemia in newborn infants, a target group that was excluded in our review (Weston 2016). Oral dextrose gel was compared with placebo, no treatment or other treatments. Only two studies were included comparing dextrose gel, massaged into the buccal mucosa, with either a placebo gel or no treatment. The oral dextrose gel reduced the incidence of separation from the mother for treatment and increased the likelihood of being able to complete breast-feeding. We were not able to compare these findings with our findings, because of the different target group (neonates compared to adults), and since no comparison with another administration route was made.

We also identified a pilot randomised clinical study that looked at sublingual sugar in comparison with intravenous glucose, in children with severe malaria (Graz 2008). No differences were found in treatment response and treatment failures. Sublingual sugar was suggested as an effective and promising method of raising blood sugar in severely ill children. This is in line with our findings, suggesting that sublingual sugar administration may be effective in raising blood sugar.

\section{AUTHORS' CONCLUSIONS}

\section{Implications for practice}

These results have important implications for individuals with symptoms of mild to moderate hypoglycaemia, their family members and first-aid providers. Based on the current evidence (1) the oral route for the administration of glucose appears to be the preferred route when compared with the buccal route, (2) dextrose gels administered through the combined oral and buccal mucosal route may perform equally to oral glucose in raising blood glucose, and (3) sublingual administration might be preferable over oral administration for the very specific setting of children with hypoglycaemia and moderate clinical symptoms of concomitant malaria or respiratory tract infections and potential difficulty in 
swallowing. However, due to the very low-quality of the evidence we are uncertain about these effects. Also, the oral route requires the individual to have the ability to swallow. Individuals with more severe hypoglycaemia typically present with altered mental status, and difficulty in swallowing could theoretically lead to aspiration with the oral route. The parenteral administration of glucose or glucagon by advanced care providers may be required in this setting.

\section{Implications for research}

Oral glucose administration may result in higher blood glucose levels 20 minutes after treatment compared with buccal administration. Some specific populations may benefit from alternative routes of glucose administration (e.g. sublingual sugar for children with concomitant malaria and respiratory illness), however, this cannot be generalised to people with diabetes and hypoglycaemia. More research is needed to help identify the best route of glucose administration in various first-aid settings.

\section{ACKNOWLEDGEMENTS}

We thank the following people for their valuable support in improving this protocol: the International Liaison Committee on Resuscitation (ILCOR) First Aid Task Force members, Carolyn Ziegler (St. Michael's Hospital Information Specialist), Peter Morley, Jerry Nolan, and Eddy Lang. 
R E F E R E N C E S

\section{References to studies included in this review}

Barennes 2005 \{published data only\}

Barennes H, Valea I, Nagot N, Van de Perre P, Pussard E. Sublingual sugar administration as an alternative to intravenous dextrose administration to correct hypoglycemia among children in the tropics. Pediatrics 2005;116(5):e648-53.

\section{Chlup 2009 \{published data only\}}

Chlup R, Zapletalova J, Peterson K, Poljakova I, Lenhartova E, Tancred A, et al. Impact of buccal glucose spray, liquid sugars and dextrose tablets on the evolution of plasma glucose concentration in healthy persons. Biomedical Papers of the Medical Faculty of the University Palacky, Olomouc, Czechoslovakia 2009;153(3):205-9.

\section{Gunning 1978 \{published data only\}}

Gunning RR, Garber AJ. Bioactivity of instant glucose. Failure of absorption through oral mucosa. JAMA 1978;240(15):1611-2.

\section{Slama 1990 \{published data only\}}

Slama G, Traynard P-Y, Desplanque N, Pudar H, Dhunputh I, Letanoux M, et al. The search for an optimized treatment of hypoglycemia. Carbohydrates in tablets, solution, or gel for the correction of insulin reactions. Archives of Internal Medicine 1990;150:589-93.

\section{References to studies excluded from this review}

\section{Balentine 1998 \{published data only\}}

Balentine JR, Gaeta TJ, Kessler D, Bagiella E, Lee T. Effect of 50 milliliters of $50 \%$ dextrose in water administration on the blood sugar of euglycemic volunteers. Academic Emergency Medicine 1998;5(7):691-4.

\section{Booley 2015 \{published data only\}}

Booley MR, Welzel T. A cross-sectional analysis of the shortterm outcomes of patients receiving prehospital treatment for symptomatic hypoglycaemia in Cape Town. African Journal of Emergency Medicine 2015;5(4):159-64.

\section{Crapo 1982 \{published data only\}}

Crapo PA, Scarlett JA, Kolterman OG, Sanders LR, Hofeldt FD, Olefsky JM. The effects of oral fructose, sucrose, and glucose in subjects with reactive hypoglycemia. Diabetes Care 1982;5(5):512-7.

\section{Ganeshalingam 2009 \{published data only\}}

Ganeshalingam R, O'Connor M. Evidence behind the WHO guidelines: hospital care for children: what is the efficacy of sublingual, oral and intravenous glucose in the treatment of hypoglycaemia?. Journal of Tropical Pediatrics 2009;55(5):287-9.

\section{Gentilcore 2009 \{published data only\}}

Gentilcore D, Nair NS, Vanis L, Rayner CK, Meyer JH, Hausken T, et al. Comparative effects of oral and intraduodenal glucose on blood pressure, heart rate, and splanchnic blood flow in healthy older subjects. American Journal of Physiology. Regulatory, Integrative and Comparative Physiology 2009;297(3):R716-22.
Graz 2008 \{published data only\}

Graz B, Dicko M, Willcox ML, Lambert B, Falquet J, Forster M, et al. Sublingual sugar for hypoglycaemia in children with severe malaria: a pilot clinical study. Malaria Journal 2007;8:242.

Husband 2009 \{published data only\}

Husband AC, Crawford S, McCoy LA, Pacaud D. The effectiveness of glucose, sucrose, and fructose in treating hypoglycemia in children with type 1 diabetes. Pediatric Diabetes 2010;11(3):154-8.

\section{Rippon 2016 \{published data only\}}

Rippon T, Delisle JA, Monnier D, Muller MR. Buccal dextrose gel decreases NICU admissions for hypoglycemia and increases breastfeeding exclusivity rates. Journal of Obstetric, Gynecologic \& Neonatal Nursing 2016;45:S3.

\section{Additional references}

\section{Altman 2003}

Altman DG, Bland JM. Interaction revisited: the difference between two estimates. BMJ 2003;326(7382):219. [PUBMED: 12543843]

\section{Buch 2011}

Buch MH, Aletaha D, Emery P, Smolen JS. Reporting of longterm extension studies: lack of consistency calls for consensus. Annals of the Rheumatic Diseases 2011;70(6):886-90.

\section{Cain 2003}

Cain E, Ackroyd-Stolarz S, Alexiadis P, Murray D. Prehospital hypoglycaemia: the safety of not transporting treated patients. Prehospital Emergency Care 2003;7(4):458-65.

\section{Carlson 2017}

Carlson JN, Schunder-Tatzber S, Neilson CJ, Hood N. Dietary sugars versus glucose tablets for first-aid treatment of symptomatic hypoglycaemia in awake patients with diabetes: a systematic review and meta-analysis. Emergency Medicine Journal 2017;34(2):100-6. [DOI: 10.1136/emermed-2015-205637]

\section{CONSORT 2019}

Consolidated Standards of Reporting Trials (CONSORT). The CONSORT statement. www.consort-statement.org (accessed 20 February 2019).

\section{Corbett 2014}

Corbett MS, Higgins JP, Woolacott NF. Assessing baseline imbalance in randomised trials: implications for the Cochrane risk of bias tool. Research Synthesis Methods 2014;5(1):79-85.

\section{Deeks 2017}

Deeks JJ, Higgins JP, Altman DG (editors), on behalf of the Cochrane Statistical Methods Group. Chapter 9: Analysing data and undertaking meta-analyses. In: Higgins JP, Churchill R, Chandler J, Cumpston MS (editors). Cochrane Handbook for Systematic Reviews of Interventions version 
5.2.0 (updated June 2017), Cochrane, 2017. Available from training.cochrane.org/handbook.

\section{Elbourne 2002}

Elbourne DR, Alman DG, Higgins JP, Curtin F, Worthington HV, Vail A. Meta-analysis involving cross-over trials: methodological issues. International Journal of Epidemiology 2002;31(1):140-9.

\section{Geelhoed-Duijvestijn 2013}

Geelhoed-Duijvestijn PH, Pedersen-Bjergaard U, Weitgasser R, Lahtela J, Jensen MM, Östenson CG. Effects of patientreported non-severe hypoglycaemia on healthcare resource use, work-time loss, and wellbeing in insulin-treated patients with diabetes in seven European countries. Journal of Medical Economics 2013;16(12):1453-61. [DOI: 10.3111/13696998.2013.852098]

\section{GRADEproGDT 2015 [Computer program]}

McMaster University (developed by Evidence Prime). GRADEpro GDT. Version accessed 20 February 2019. Hamilton (ON): McMaster University (developed by Evidence Prime), 2015.

\section{Guyatt 2008}

Guyatt GH, Oxman AD, Vist GE, Kunz R, Falck-Ytter Y, AlonsoCoello $P$, et al. GRADE: an emerging consensus on rating quality of evidence and strength of recommendations. $B M J$ 2008;336(7650):924-6. [DOI: 10.1136/bmj.39489.470347]

\section{Higgins 2002}

Higgins JP, Thompson SG. Quantifying heterogeneity in a metaanalysis. Statistics in Medicine 2002;21(11):1539-58.

\section{Higgins 2003}

Higgins JP, Thompson SG, Deeks JJ, Altman DG. Measuring inconsistency in meta-analysis. BMJ 2003;327(7414):557-60.

\section{Higgins 2011}

Higgins JP, Deeks JJ, Altman DG, editor(s), on behalf of the Cochrane Statistical Methods Group. Chapter 16: Special topics in statistics. In: Higgins JP, Green S, editor(s). Cochrane Handbook for Systematic Reviews of Interventions Version 5.1.0 (updated March 2011). The Cochrane Collaboration, 2011. Available from handbook.cochrane.org.

\section{Higgins 2017}

Higgins JP, Altman DG, Sterne JA (editors). Chapter 8: Assessing risk of bias in included studies. In: Higgins JP, Churchill R, Chandler J, Cumpston MS (editors), Cochrane Handbook for Systematic Reviews of Interventions Version 5.2.0 (updated June 2017), Cochrane, 2017. Available from training.cochrane.org/handbook.

\section{Hróbjartsson 2013}

Hróbjartsson A, Thomsen AS, Emanuelsson F, Tendal B, Hilden J, Boutron I, et al. Observer bias in randomized clinical trials with measurement scale outcomes: a systematic review of trials with both blinded and nonblinded assessors. Canadian Medical Association Journal 2013;185(4):E201-11.

\section{IDF 2017}

International Diabetes Federation. IDF Diabetes Atlas. Eighth edition 2017. www.idf.org/component/attachments/ attachments.html?id=1405\&task=download (accessed 20 February 2019).

\section{Kirkham 2010}

Kirkham JJ, Dwan KM, Altman DG, Gamble C, Dodd S, Smyth R, et al. The impact of outcome reporting bias in randomised controlled trials on a cohort of systematic reviews. BMJ 2010;340:c365. [DOI: 10.1136/bmj.c365]

\section{Liberati 2009}

Liberati A, Altman DG, Tetzlaff J, Mulrow C, Gøtzsche PC, loannidis JP, et al. The PRISMA statement for reporting systematic and meta-analyses of studies that evaluate interventions: explanation and elaboration. PLOS Medicine 2009;6(7):e1000100. [DOI: 10.1371/journal.pmed.1000100]

\section{Meader 2014}

Meader N, King K, Llewellyn A, Norman G, Brown J, Rodgers M, et al. A checklist designed to aid consistency and reproducibility of GRADE assessments: development and pilot validation. Systematic Reviews 2014;3:82.

\section{Megan 2012}

Megan B, Pickering RM, Weatherall M. Design, objectives, execution and reporting of published open-label extension studies. Journal of Evaluation in Clinical Practice 2012;18(2):209-15.

\section{Ostenson 2014}

Ostenson CG, Geelhoed-Duijvestijn P, Lahtela J, Weitgasser R, Markert Jensen M, Pedersen-Bjergaard U. Self-reported nonsevere hypoglycaemic events in Europe. Diabetic Medicine 2014;31(1):92-101. [DOI: 10.1111/dme.12261]

\section{R software 2019}

The R project for statistical computing. www.r-project.org (accessed 4 March 2019).

\section{RevMan 2014 [Computer program]}

Nordic Cochrane Centre, The Cochrane Collaboration. Review Manager 5 (RevMan 5). Version 5.3. Copenhagen: Nordic Cochrane Centre, The Cochrane Collaboration, 2014.

\section{Rostykus 2016}

Rostykus P, Kennel J, Adair K, Fillinger M, Palmberg R, Quinn A, et al. Variability in the treatment of prehospital hypoglycaemia: a structured review of EMS protocols in the United States. Prehospital Emergency Care 2016;20(4):524-30. [DOI: 10.3109/10903127.2015.1128031]

\section{Sako 2017}

Sako A, Yasunaga H, Matsui H, Fushimi K, Hamasaki H, Katsuyama $\mathrm{H}$, et al. Hospitalization with hypoglycaemia in patients without diabetes mellitus: a retrospective study using a national inpatient database in Japan. Medicine (Baltimore) 2017;96(25):e7271. [DOI: 10.1097/MD.0000000000007271] 


\section{Scherer 2007}

Scherer RW, Langenberg P, von Elm E. Full publication of results initially presented in abstracts. Cochrane Database of Systematic Reviews 2007, Issue 2. [DOI: 10.1002/14651858.MR000005.pub3]

\section{Schünemann 2017}

Schünemann HJ, Oxman AD, Higgins JP, Vist GE, Glasziou P, Akl E, et al. on behalf of the Cochrane GRADEing Methods Group and the Cochrane Statistical Methods Group. Chapter 11: Completing 'Summary of findings' tables and grading the confidence in or quality of the evidence. In: Higgins JP, Churchill R, Chandler J, Cumpston MS (editors), Cochrane Handbook for Systematic Reviews of Interventions version 5.2.0 (updated June 2017). Cochrane, 2017. Available from training.cochrane.org/handbook.

\section{Singletary 2015}

Singletary EM, Zideman DA, De Buck ED, Chang WT, Jensen JL, Swain JM, et al. Part 9: First aid: 2015 International consensus on cardiopulmonary resuscitation and emergency cardiovascular care science with treatment recommendations. Circulation 2015;132(16 Suppl 1):S269-311.

\section{Sterne 2011}

Sterne JA, Sutton AJ, Ioannidis JP, Terrin N, Jones DR, Lau J, et al. Recommendations for examining and interpreting funnel plot asymmetry in meta-analyses of randomised controlled trials. BMJ 2011;343:d4002.

\section{Sterne 2016}

Sterne JA, Hernán MA, Reeves BC, Savović J, Berman ND, Viswanathan M, et al. ROBINS-I: a tool for assessing risk of bias in non-randomised studies of interventions. BMJ 2016;355:i4919.

\section{Sterne 2017}

Sterne JA, Egger M, Moher D, Boutron I (editors). Chapter 10: Addressing reporting biases. In: Higgins JP, Churchill R,

\section{CHARACTERISTICS OF STUDIES}

Characteristics of included studies [ordered by study ID]
Chandler J, Cumpston MS (editors), Cochrane Handbook for Systematic Reviews of Interventions version 5.2.0 (updated June 2017), Cochrane, 2017. Available from training.cochrane.org/handbook.

\section{Weston 2016}

Weston PJ, Harris DLH, Battin M, Brown J, Hegarty JE, Harding JE. Oral dextrose gel for the treatment of hypoglycaemia in newborn infants. Cochrane Database of Systematic Reviews 2016, Issue 5. [DOI: 10.1002/14651858.CD011027.pub2]

\section{WHO 2013}

World Health Organization. Pocket book of hospital care for children. Guideline for the management of common childhood illnesses. Geneva: World Health Organization, 2013.

\section{Wood 2008}

Wood L, Egger M, Gluud LL, Schulz KF, Jüni P, Altman DG, et al. Empirical evidence of bias in treatment effect estimates in controlled trials with different interventions and outcomes: meta-epidemiological study. BMJ 2008;336(7644):601-5.

\section{Zideman 2015}

Zideman DA, Singletary EM, De Buck ED, Chang WT, Jensen JL, Swain JM, et al. Part 9: First aid: 2015 International consensus on first aid science with treatment recommendations. Resuscitation 2015;95:e225-61. [DOI: 10.1016/j.resuscitation.2015.07.047]

\section{References to other published versions of this review De Buck 2019}

De Buck E, Borra V, Carlson JN, Zideman DA, Singletary EM, Djärv T. First aid glucose administration routes for symptomatic hypoglycaemia. Cochrane Database of Systematic Reviews 2019, Issue 3. [DOI: 10.1002/14651858.CD013283]

\section{Barennes 2005}

Methods Study design: randomised controlled trial

Participants

Inclusion criteria: no specific inclusion criteria mentioned

Exclusion criteria: no specific exclusion criteria mentioned

Diagnostic criteria: moderate clinical symptoms of acute malaria or moderate respiratory tract infections, and blood glucose concentrations between $0.5 \mathrm{~g} / \mathrm{L}$ and $0.8 \mathrm{~g} / \mathrm{L}$

Setting: pre-hospital setting (Hamdallaye Health Center)

Age group: 69 children between 1 to 15 years of age

Gender distribution: not specified

Country where study was performed: Burkina Faso 
Sublingual treatment: 25 children, mean age $7.8 \pm 3.8$ years, mean sugar dose $130.2 \mathrm{mg} / \mathrm{kg} \pm 44.6 \mathrm{mg} /$ $\mathrm{kg}$

Oral treatment: 15 children, mean age $6.6 \pm 4.2$ years, mean sugar dose $130.2 \mathrm{mg} / \mathrm{kg} \pm 44.6 \mathrm{mg} / \mathrm{kg}$

Comparator: oral treatment: $2.5 \mathrm{~g}$ of sugar on the tongue

Duration of intervention: mean time for complete disappearance of sugar from under the tongue was estimated at 20 minutes

Duration of follow-up: 80 minutes

Run-in period: the study started after an overnight fasting period

Number of study centres: -

Reported outcomes in full text of publication
- Blood or plasma glucose concentration at 20 minutes $(\mathrm{mg} / \mathrm{dL})$ (blood glucose concentration)
- Resolution of hypoglycaemia within 80 minutes (based on the outcome 'treatment failure rate', as
reported by the study authors)
- Resolution of hypoglycaemia within 20 minutes (based on the outcome 'early treatment failure rate',
as reported by the study authors)
- Time to resolution of hypoglycaemia (minutes)
Adverse events

\begin{tabular}{ll}
\hline Study registration $\quad N A$ \\
\hline
\end{tabular}

Publication details Language of publication: English

Funding: commercial funding (Impact Malaria, Sanofi-Synthelabo (Gentilly, France))

Publication status: peer-reviewed journal

Stated aim for study

Quote from publication: "we conducted the first clinical trial aimed at evaluating whether early correction of hypoglycemia could be achieved with sublingual administration of dextrose among moderately hypoglycemic children, with or without malaria, in Burkina Faso."

Notes

The 'early treatment failure rate' was the proportion of children with no blood glucose gain at 20 minutes. The 'treatment failure rate' was failure to reach a blood glucose concentration of $\geq 90 \mathrm{mg} / \mathrm{dL}$ during the study period ( 80 minutes). These data were used to determine the 'resolution of hypoglycaemia'.

\section{Risk of bias}

\begin{tabular}{lll}
\hline Bias & Authors' judgement & Support for judgement \\
\hline $\begin{array}{l}\text { Random sequence genera- } \\
\text { tion (selection bias) }\end{array}$ & Unclear risk & Comment: insufficient information about the sequence generation process \\
\hline
\end{tabular}

Allocation concealment Unclear risk Comment: insufficient information about the allocation concealment
(selection bias)

\begin{tabular}{ll}
\hline $\begin{array}{l}\text { Blinding of participants } \\
\text { and personnel (perfor- }\end{array}$ & Low risk \\
$\begin{array}{l}\text { mance bias) } \\
\text { resolution of hypogly- }\end{array}$ & $\begin{array}{l}\text { Quote from publication: "A randomized, open, clinical trial. A first physician } \\
\text { (the same one throughout the study) performed the patients' enrollment and }\end{array}$ \\
themia/symptoms &
\end{tabular}


Comment: participants were not blinded but we judge that the outcome is unlikely to have been influenced by lack of blinding (investigator-assessed outcome measurement)

Blinding of participants Low risk and personnel (performance bias) time to resolution of hypoglycaemia/symptoms
Quote from publication: "A randomized, open, clinical trial. A first physician (the same one throughout the study) performed the patients' enrollment and the treatment administration."

Comment: participants were not blinded but we judge that the outcome is unlikely to have been influenced by lack of blinding (investigator-assessed outcome measurement)

\section{Blinding of participants Low risk and personnel (perfor- mance bias) \\ Quote from publication: "A randomized, open, clinical trial. A first physician (the same one throughout the study) performed the patients' enrollment and the treatment administration."} blood/plasma glucose
Comment: participants were not blinded but we judge that the outcome is unlikely to have been influenced by lack of blinding (investigator-assessed outcome measurement)

\begin{tabular}{|c|c|c|}
\hline $\begin{array}{l}\text { Blinding of participants } \\
\text { and personnel (perfor- } \\
\text { mance bias) }\end{array}$ & High risk & $\begin{array}{l}\text { Quote from publication: "A randomized, open, clinical trial. A first physician } \\
\text { (the same one throughout the study) performed the patients' enrollment and } \\
\text { the treatment administration." }\end{array}$ \\
\hline
\end{tabular}

adverse events

Comment: no blinding, and the outcome is likely to have been influenced by lack of blinding (investigator-assessed/self-reported outcome measurement)

Blinding of outcome as- $\quad$ Low risk
sessment (detection bias)
resolution of hypogly-
caemia/symptoms

Quote from publication: "A second physician collected and analyzed the data, in a blinded manner."

Comment: blinding of outcome assessment is ensured, and it is unlikely that the blinding could have been broken (investigator-assessed outcome measurement)

\begin{tabular}{|c|c|c|}
\hline $\begin{array}{l}\text { Blinding of outcome as- } \\
\text { sessment (detection bias) }\end{array}$ & Low risk & $\begin{array}{l}\text { Quote from publication: "A second physician collected and analyzed the da- } \\
\text { ta, in a blinded manner." }\end{array}$ \\
\hline
\end{tabular}
sessment (detection bias) time to resolution of hypoglycaemic/symptoms

Comment: blinding of outcome assessment is ensured, ant it is unlikely that the blinding could have been broken (investigator-assessed outcome measurement)

Blinding of outcome as- $\quad$ Low risk
sessment (detection bias)
blood/plasma glucose

Quote from publication: "A second physician collected and analyzed the data, in a blinded manner."

Comment: blinding of outcome assessment is ensured, ant it is unlikely that the blinding could have been broken (investigator-assessed outcome measurement)

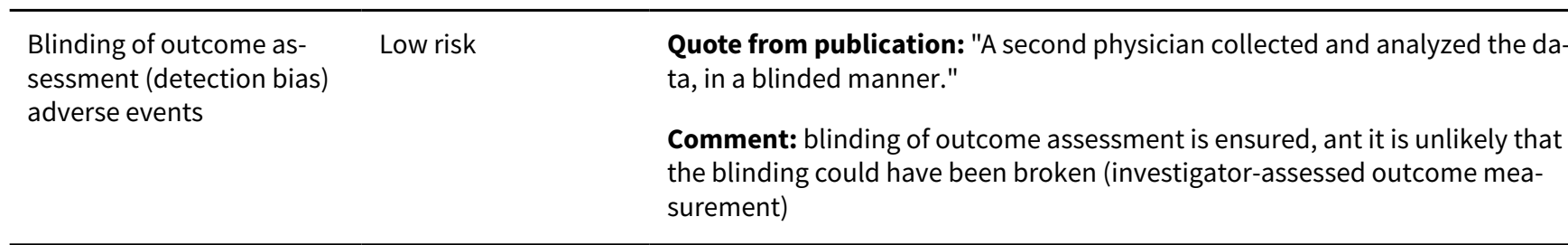

\begin{tabular}{|c|c|c|}
\hline $\begin{array}{l}\text { Incomplete outcome data } \\
\text { (attrition bias) } \\
\text { resolution of hypogly- }\end{array}$ & Low risk & $\begin{array}{l}\text { Quote from publication: "There were no treatment failures in the sublingual } \\
\text { group compared with } 8(53 \%) \text { in the oral group. There were also more early } \\
\text { treatment failures in the oral group than in the sublingual group." }\end{array}$ \\
\hline
\end{tabular}

caemia/symptoms

Comment: reported and reasons explained 


\section{Barennes 2005 (Continued)} (attrition bias) time to resolution of hypoglycaemia/symptoms
Comment: data for sublingual group are reported in a table, data for oral group were extracted from graph (only reported)
Incomplete outcome data Low risk (attrition bias)

blood/plasma glucose
Quote from publication: "In the oral group, glucose concentrations increased slowly for all children but 4 received $0.10 \mathrm{~g} / \mathrm{kg}$ sugar. The increase in glucose concentrations was rapid for all sublingual group children."

Comment: glucose concentrations are shown in a graph (only reported)

the follow-up period were observed among hypoglycemic children, and all treatments were well tolerated."

Comment: only reported

Incomplete outcome data Low risk

(attrition bias)

adverse events

Comment: no data for treatment delay for oral glucose group

Incomplete outcome data High risk

(attrition bias)

treatment delay

Selective reporting (re- Unclear risk Comment: insufficient information about selective reporting
porting bias)

Other bias Low risk Comment: the study seems to be free from other sources of bias

Chlup 2009

\begin{tabular}{ll}
\hline Methods & Study design: non-randomised controlled trial (cross-over study) \\
\hline Participants & Inclusion criteria: no specific inclusion criteria mentioned \\
Exclusion criteria: no specific exclusion criteria mentioned \\
Diagnostic criteria: being healthy \\
Setting: experimental setting in healthy volunteers \\
Age group: 16 healthy adults (mean $( \pm \mathrm{SE})$, age $21.8 \pm 0.78$ years \\
Gender distribution: 2 females and 14 males \\
Country where study was performed: Czech Republic
\end{tabular}

Interventions

Intervention: buccal treatment: 10 glucose spray doses (five doses on the mucosa of each cheek, without swallowing)

Comparators: oral treatments:

- one sachet of liquid sugars (5.2 g glucose, $5.2 \mathrm{~g}$ sucrose, $5.2 \mathrm{~g}$ fructose)

- dextrose tablet to be chewed (only these data fulfilled selection criteria and were extracted)

Duration of intervention: 3 sequential sets of 4 sessions. In each set there was one control session and 3 sessions testing different products of dextrose and other sugars

Duration of follow-up: 30 minutes

Run-in period: the study started after an average fasting time of 8 to 9 hours (range 6 to 13 hours) 
Chlup 2009 (Continued)

$$
\text { Number of study centres: - }
$$

Outcomes Reported outcome(s) in full text of publication: blood or plasma glucose concentration at 20 minutes (mg/dL) (plasma glucose concentration)

\begin{tabular}{ll}
\hline Study registration & NA \\
\hline Publication details & $\begin{array}{l}\text { Language of publication: English } \\
\text { Funding: non-commercial funding (supported by the grants IGA NR 7825-3, IGA 10823, Ministry of } \\
\text { Health, and MSM 6198959216, Ministry of Education, Czech Republic) } \\
\text { Publication status: peer-reviewed journal }\end{array}$ \\
\hline Stated aim for study & $\begin{array}{l}\text { Quote from publication: "The purpose of this prospective controlled trial was to assess the efficacy of } \\
\text { three commercially available glucose products (1) buccal glucose spray, (2) liquid sugars, and (3) dex- } \\
\text { trose tablet on the evolution of plasma glucose concentration." }\end{array}$ \\
\hline Notes & Risk of bias assessed with ROBINS-I tool for non-randomised studies (see Appendix 4) \\
\hline
\end{tabular}

Gunning 1978

\begin{tabular}{ll}
\hline Methods & Study design: non-randomised controlled trial (cross-over study) \\
\hline Participants & Inclusion criteria: volunteers with intact oral mucosa \\
Exclusion criteria: - \\
Diagnostic criteria: no clinical or chemical evidence of disease or a history of diabetes mellitus \\
Setting: experimental setting in healthy volunteers \\
Age group: 7 adults \\
Gender distribution: not specified \\
Country where study was performed: USA \\
\hline
\end{tabular}
each participant; participants were encouraged not to swallow

Comparator: oral treatment: $15 \mathrm{~g}$ doses of instant glucose, to be swallowed by the participants

Duration of intervention: not specified

Duration of follow-up: 30 minutes after sugar administration

Run-in period: 12 -hour overnight fast

Number of study centres: -

\begin{tabular}{ll}
\hline Outcomes & Reported outcome(s) in full text of publication: blood or plasma glucose concentration at 20 min- \\
utes (reported as dichotomous outcome 'number of participants with increased blood glucose at 20 \\
minutes')
\end{tabular}

Study registration NA

Publication details Language of publication: English


Funding: non-commercial funding (this study was funded by grant RR00350 from the Division of Research Resources, the National Instistutes of Health, and by grants from the Kelsey-Leary Foundation and the Texas Diabetes Research Foundation)

Publication status: peer-reviewed journal

Stated aim for study Quote from publication: "We have evaluated the efficacy of instant glucose by studying the absorption of instant glucose in normal volunteers."

Notes

Risk of bias assessed with ROBINS-I tool for non-randomised studies (see Appendix 4)

Slama 1990

\begin{tabular}{|c|c|}
\hline Methods & Study design: randomised controlled trial \\
\hline \multirow[t]{7}{*}{ Participants } & $\begin{array}{l}\text { Inclusion criteria: participants in general good health, with insulin-dependent diabetes. Free from } \\
\text { clinical signs and symptoms of peripheral or autonomic neuropathy }\end{array}$ \\
\hline & Exclusion criteria: any known coronary heart disease, hypertension, or advanced retinopathy \\
\hline & $\begin{array}{l}\text { Diagnostic criteria: intravenous insulin was given until symptoms of hypoglycaemia occurred or blood } \\
\text { glucose values reached } 2.7 \mathrm{mmol} / \mathrm{L} \text { (or } 49 \mathrm{mg} / \mathrm{dL} \text { ) }\end{array}$ \\
\hline & Setting: hospital setting \\
\hline & Age group: 41 adults (mean age: $28 \pm 2$ years (mean \pm SEM)) \\
\hline & Gender distribution: 14 females and 28 males \\
\hline & Country where study was performed: France \\
\hline
\end{tabular}

Combined oral + buccal treatment:

- $15 \mathrm{~g}$ of glucose supplied in the form of $40 \mathrm{~g}$ of a $40 \%$ dextrose gel

\section{Comparators}

Oral treatments:

- $15 \mathrm{~g}$ of glucose in tablet form to be chewed and swallowed without water (only these data fulfilled selection criteria and were extracted)

- $15 \mathrm{~g}$ sucrose tablets to be chewed and swallowed without water

- A solution of $15 \mathrm{~g}$ of glucose in $150 \mathrm{~mL}$ of water (only these data fulfilled selection criteria and were extracted)

- A solution of $15 \mathrm{~g}$ of sucrose in $150 \mathrm{~mL}$ of water

- $15 \mathrm{~g}$ of a cornstarch hydrolysate

- $125 \mathrm{~mL}$ canned orange juice

Duration of intervention: carbohydrate to be swallowed in less than 1 minute

Duration of follow-up: 20 minutes after glucose administration

Run-in period: last intermediate insulin was given at $6 \mathrm{PM}$ the evening before the test. The study started after a 12-hour overnight fast

\section{Number of study centres: -}


Resolution of symptoms at 10, 15, 20 and $>20$ minutes (data from time points 10,15 and 20 minutes were cumulated to obtain the number 'within 20 minutes')

Blood or plasma glucose concentration at 20 minutes $(\mathrm{mg} / \mathrm{dL})$ (plasma glucose concentration)

\begin{tabular}{ll}
\hline Study registration & NA \\
\hline Publication details & Language of publication: English \\
& $\begin{array}{l}\text { Funding: non-commercial funding (this work was supported by grant } 863387 \mathrm{E} \text { from Inserm, Paris, and } \\
\text { by University Pierre et Marie Curie, Paris, France) }\end{array}$
\end{tabular}

Publication status: peer-reviewed journal

Stated aim for study Quote from publication: "We have evaluated the efficacy of different forms of sugars, each giving $15 \mathrm{~g}$ of carbohydrate, in correcting the hypoglycemic reactions of insulin-treated diabetic patients."

\section{Notes}

\section{Risk of bias}

\begin{tabular}{lll}
\hline Bias & Authors' judgement & Support for judgement \\
\hline $\begin{array}{l}\text { Random sequence genera- } \\
\text { tion (selection bias) }\end{array}$ & Unclear risk & $\begin{array}{l}\text { Quote from publication: "Seven carbohydrate preparations were randomly } \\
\text { tested in seven groups of patients." }\end{array}$ \\
& & Comment: insufficient information about the allocation concealment
\end{tabular}

Allocation concealment Unclear risk Comment: insufficient information about the allocation concealment
(selection bias)

\begin{tabular}{|c|c|c|}
\hline $\begin{array}{l}\text { Blinding of participants } \\
\text { and personnel (perfor- } \\
\text { mance bias) }\end{array}$ & High risk & $\begin{array}{l}\text { Quote from publication: "Clinical recovery time was estimated according to } \\
\text { the patient's own opinion (on complete symptomatic relief) from hypogly- } \\
\text { caemia." }\end{array}$ \\
\hline
\end{tabular}
resolution of hypoglycaemia/symptoms

Comment: no information on blinding of participants and personnel. Probably not blinded due to nature of interventions. The outcome is likely to have been influenced by lack of blinding (self-reported outcome measurement)

\begin{tabular}{|c|c|c|}
\hline $\begin{array}{l}\text { Blinding of participants } \\
\text { and personnel (perfor- } \\
\text { mance bias) }\end{array}$ & High risk & $\begin{array}{l}\text { Quote from publication: "Clinical recovery time was estimated according to } \\
\text { the patient's own opinion (on complete symptomatic relief) from hypogly- } \\
\text { caemia." }\end{array}$ \\
\hline
\end{tabular}

time to resolution of hypoglycaemia/symptoms

Comment: no information on blinding of participants and personnel. Probably not blinded due to nature of interventions. The outcome is likely to have been influenced by lack of blinding (self-reported outcome measurement)

\begin{tabular}{lll}
\hline $\begin{array}{l}\text { Blinding of participants } \\
\text { and personnel (perfor- } \\
\text { mance bias) } \\
\text { blood/plasma glucose }\end{array}$ & Low risk & $\begin{array}{l}\text { Comment: } \text { no information on blinding of participants and personnel, but we } \\
\text { judge that the outcome is unlikely to have been influenced by lack of blinding. } \\
\text { (investigator-assessed outcome measurement) }\end{array}$ \\
\hline $\begin{array}{l}\text { Blinding of outcome as- } \\
\text { sessment (detection bias) } \\
\text { resolution of hypogly- } \\
\text { caemia/symptoms }\end{array}$ & High risk & $\begin{array}{l}\text { Comment: } \text { no information on blinding of participants (who are for this out- } \\
\text { come also the outcome assessors). Probably not blinded due to nature of in- } \\
\text { terventions. Outcome measurement was likely to have been influenced by lack } \\
\text { or blinding (self-reported outcome measurement) }\end{array}$
\end{tabular}

Blinding of outcome as- High risk
sessment (detection bias)

Comment: no information on blinding of participants (who are for this outcome also the outcome assessors). Probably not blinded due to nature of in- 
Slama 1990 (Continued) time to resolution of hypoglycaemic/symptoms terventions. Outcome measurement was likely to have been influenced by lack or blinding (self-reported outcome measurement)

$\begin{array}{lll}\begin{array}{l}\text { Blinding of outcome as- } \\ \text { sessment (detection bias) }\end{array} & \text { Low risk } & \begin{array}{l}\text { Comment: no information on blinding of outcome assessors, but we judge } \\ \text { that the outcome measurement is unlikely to have been influenced by lack of }\end{array} \\ \text { blinding. (investigator-assessed outcome measurement) }\end{array}$

Incomplete outcome data Low risk

(attrition bias)

Quote from publication: "The relatively poor results observed with the glu-

resolution of hypogly-

caemia/symptoms cose gel could be because the gel partially remains in the mouth and, probably, the upper digestive tract and is not completely absorbed. The viscosity of the gel may also have diminished gastric emptying."

Comment: data presented in table (reported and reasons explained)

Incomplete outcome data Low risk (attrition bias)

time to resolution of hy-

poglycaemia/symptoms
Quote from publication: "The relatively poor results observed with the glucose gel could be because the gel partially remains in the mouth and, probably, the upper digestive tract and is not completely absorbed. The viscosity of the gel may also have diminished gastric emptying."

Comment: data presented in table (reported and reasons explained)
Incomplete outcome data Low risk (attrition bias)

blood/plasma glucose
Quote from publication: "The relatively poor results observed with the glucose gel could be because the gel partially remains in the mouth and, probably, the upper digestive tract and is not completely absorbed. The viscosity of the gel may also have diminished gastric emptying."

Comment: data presented in graph (reported and reasons explained)

Selective reporting (re- Unclear risk Comment: insufficient information about selective reporting
porting bias)

porting bias)

Other bias Low risk Comment: the study appears to be free from other bias

-: denotes not reported

Note: where the judgement is 'Unclear' and the description is blank, the study did not report that particular outcome.

dL: decilitre; g: gram; kg: kilogram; L: litre; mg: milligram; mL: millilitre; NA: not applicable; SE: standard error; SEM: standard error of the means; ROBINS-I: risk of bias In non-randomised studies of interventions

\section{Characteristics of excluded studies [ordered by study ID]}

\begin{tabular}{ll}
\hline Study & Reason for exclusion \\
\hline Balentine 1998 & Ineligible intervention: only intravenous administration \\
\hline Booley 2015 & $\begin{array}{l}\text { Ineligible intervention: no question posed about type of pre-hospital treatment and link to health } \\
\text { outcome }\end{array}$ \\
\hline Crapo 1982 & Ineligible intervention: only compares different oral treatments \\
\hline Ganeshalingam 2009 & $\begin{array}{l}\text { Inelgible study design: a systematic review used to support a guideline, but limited to children and } \\
\text { very limited search strategy; one study included which is covered by our included studies }\end{array}$ \\
\hline Gentilcore 2009 & Ineligible intervention: only compares intraduodenal infusion with oral administration \\
\hline Graz 2008 & Ineligible intervention: only compares sublingual with intravenous administration \\
\hline Husband 2009 & Ineligible intervention: only compares different oral treatments \\
\hline \hline
\end{tabular}




\begin{tabular}{ll}
\hline Study & Reason for exclusion \\
\hline Rippon 2016 & $\begin{array}{l}\text { Ineligible study design: conference abstract, not a study but consensus statement, neonatal partic- } \\
\text { ipants }\end{array}$ \\
\hline
\end{tabular}

DATA AND ANALYSES

\section{Comparison 1. Other route vs oral administration}

\begin{tabular}{|c|c|c|c|c|}
\hline Outcome or subgroup title & No. of studies & $\begin{array}{l}\text { No. of partici- } \\
\text { pants }\end{array}$ & Statistical method & Effect size \\
\hline $\begin{array}{l}1 \text { Blood/plasma glucose con- } \\
\text { centrations at } 20 \text { min (ICC 0.9) }\end{array}$ & 3 & & $\begin{array}{l}\text { Mean Difference (Random, 95\% } \\
\mathrm{Cl} \text { ) }\end{array}$ & Subtotals only \\
\hline 1.1 Sublingual vs oral & 1 & & $\begin{array}{l}\text { Mean Difference (Random, 95\% } \\
\mathrm{Cl} \text { ) }\end{array}$ & $17.0[4.38,29.62]$ \\
\hline 1.2 Buccal vs oral & 1 & & $\begin{array}{l}\text { Mean Difference (Random, 95\% } \\
\mathrm{Cl} \text { ) }\end{array}$ & $-14.41[-17.48,-11.35]$ \\
\hline 1.3 Oral + buccal vs oral & 1 & & $\begin{array}{l}\text { Mean Difference (Random, 95\% } \\
\mathrm{Cl} \text { ) }\end{array}$ & $-15.32[-33.58,2.95]$ \\
\hline $\begin{array}{l}2 \text { Blood/plasma glucose con- } \\
\text { centrations at } 20 \mathrm{~min}(\text { ICC } 0.1 \text { ) }\end{array}$ & 3 & & $\begin{array}{l}\text { Mean Difference (Random, 95\% } \\
\mathrm{Cl} \text { ) }\end{array}$ & Subtotals only \\
\hline 2.1 Sublingual vs oral & 1 & & $\begin{array}{l}\text { Mean Difference (Random, 95\% } \\
\mathrm{Cl} \text { ) }\end{array}$ & $17.0[4.38,29.62]$ \\
\hline 2.2 Buccal vs oral & 1 & & $\begin{array}{l}\text { Mean Difference (Random, 95\% } \\
\mathrm{Cl} \text { ) }\end{array}$ & $-14.41[-23.62,-5.21]$ \\
\hline 2.3 Oral + buccal vs oral & 1 & & $\begin{array}{l}\text { Mean Difference (Random, 95\% } \\
\mathrm{Cl} \text { ) }\end{array}$ & $-15.32[-33.58,2.95]$ \\
\hline
\end{tabular}

Analysis 1.1. Comparison 1 Other route vs oral administration, Outcome $1 \mathrm{Blood} /$ plasma glucose concentrations at $20 \mathrm{~min}$ (ICC 0.9).

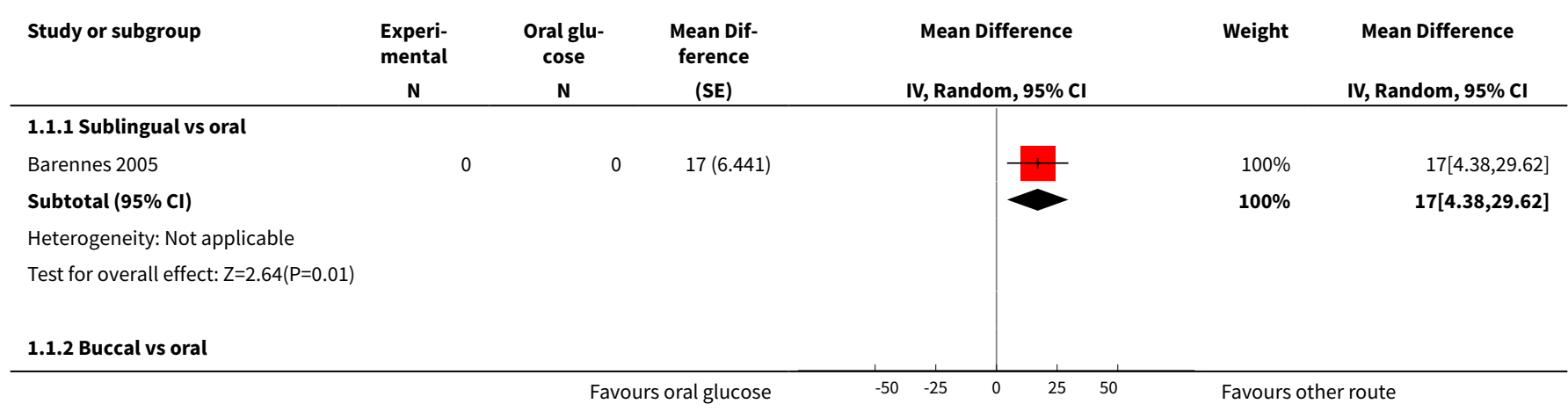




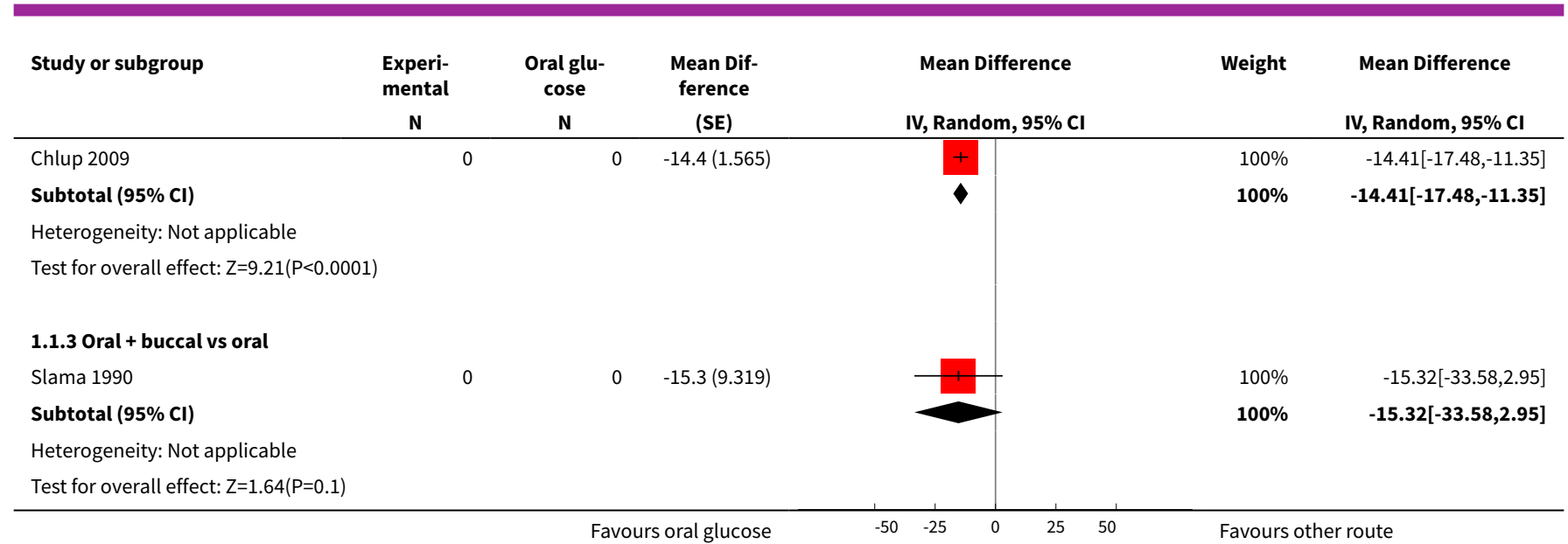

Analysis 1.2. Comparison 1 Other route vs oral administration, Outcome 2 Blood/plasma glucose concentrations at $20 \mathrm{~min}$ (ICC 0.1).

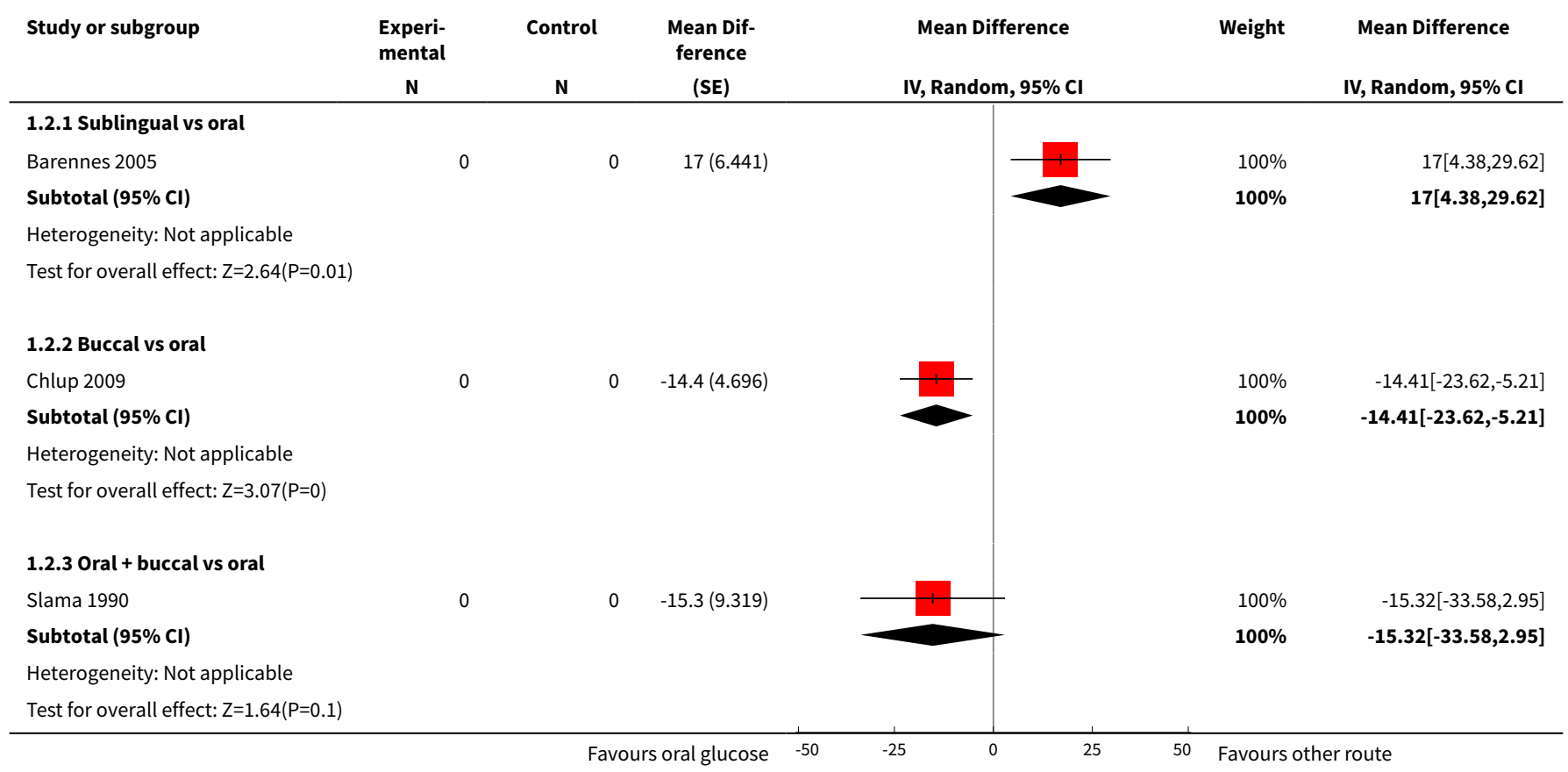




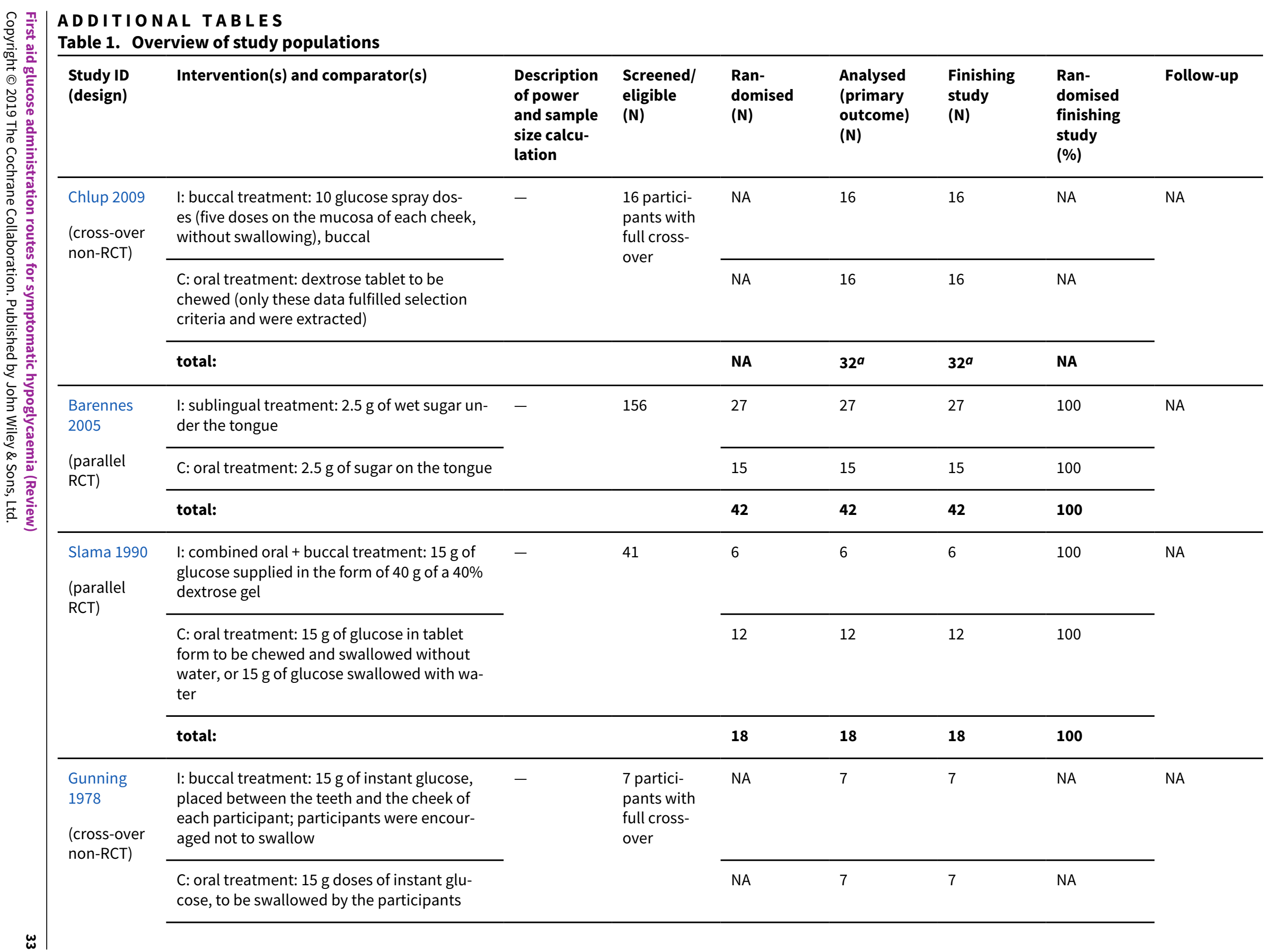




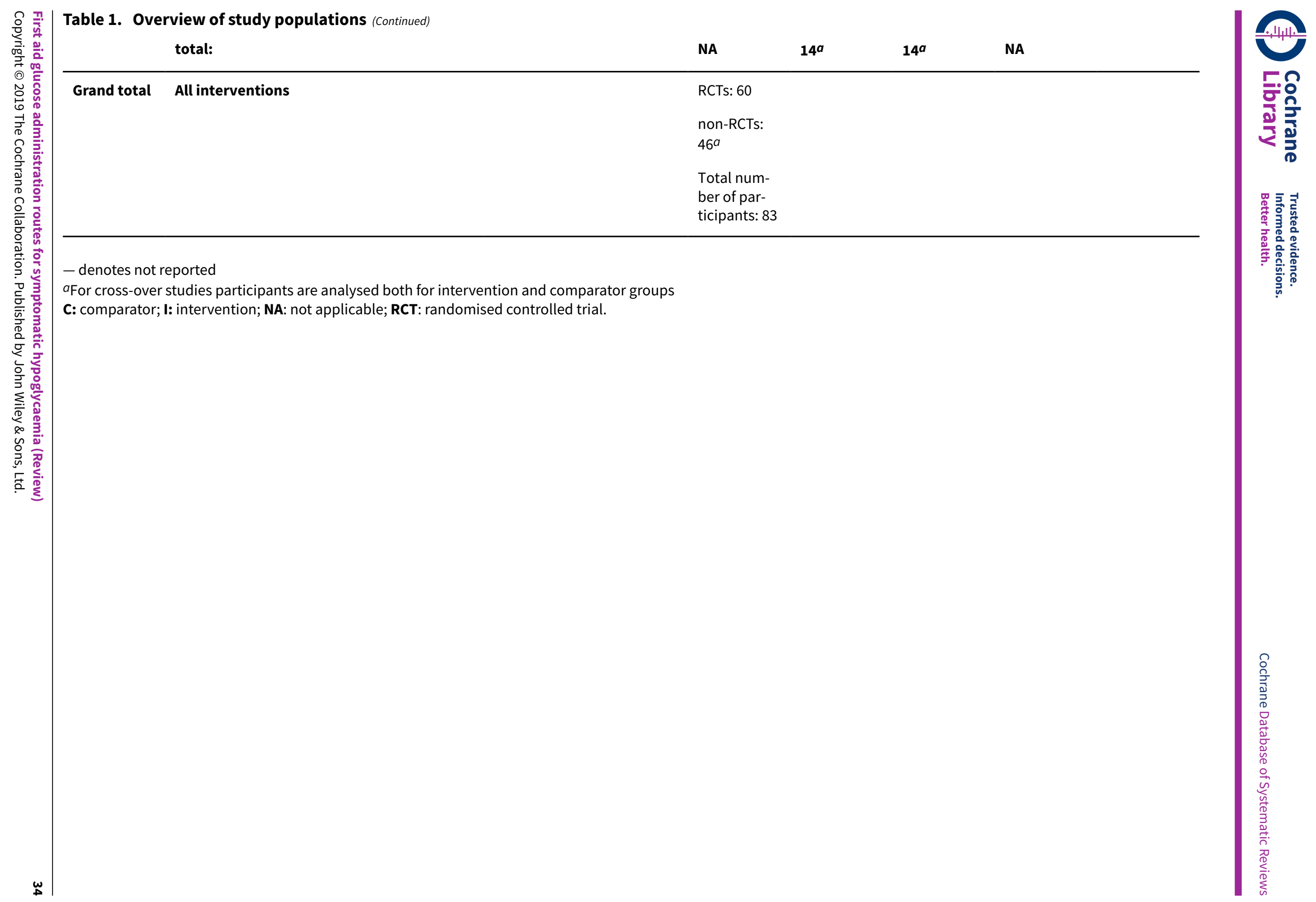




\section{AP PEN DICES}

\section{Appendix 1. Search strategies}

\section{MEDLINE (Ovid SP)}

1 Hypoglycemia/

2 (Hypoglycemi or hypoglycaemi*).tw,kf.

3 Healthy Volunteers/

4 (healthy participant or healthy participants or healthy subject or healthy subjects or healthy volunteer or healthy volunteers or human volunteer or human volunteers or normal volunteer or normal volunteers).tw, kf.

5 healthy people.tw,kf.

6 healthy persons.tw,kf.

71 or 2 or 3 or 4 or 5 or 6

8 Glucose/

9 (glucose or sugar).tw,kf.

108 or 9

11 drug administration routes/ or administration, inhalation/ or exp administration, oral/ or Administration, Rectal/

12 administ* ${ }^{\star} . \mathrm{tw}, \mathrm{kf}$.

1311 or 12

14 (buccal $^{\star}$ or sublingual ${ }^{*}$ or oral ${ }^{\star}$ or by mouth or rectal ${ }^{\star}$ or tablet ${ }^{\star}$ or liquid ${ }^{\star}$ or gel or gels or sachet ${ }^{\star}$ or spray or sprays or tongue or cheek or swallow* ${ }^{\star}$ or administration route ${ }^{\star}$ ).tw,kf.

15 Solutions/

16 Tablets/

17 Cheek/

18 Gels/

1914 or 15 or 16 or 17 or 18

207 and 10 and 13 and 19

21 limit 20 to (case reports or comment or congresses or editorial or letter)

2220 not 21

2322 not (animals/ not humans/)

24 remove duplicates from 23

\section{Cochrane Central Register of Controlled Trials (Cochrane Register of Studies Online)}

1 Hypoglycemia/

2 (Hypoglycemi* or hypoglycaemi*).tw,kf.

3 Healthy Volunteers/ 
(Continued)

4 (healthy participant or healthy participants or healthy subject or healthy subjects or healthy volunteer or healthy volunteers or human volunteer or human volunteers or normal volunteer or normal volunteers).tw, kf.

5 healthy people.tw,kf.

6 healthy persons.tw,kf.

71 or 2 or 3 or 4 or 5 or 6

8 Glucose/

9 (glucose or sugar).tw,kf.

108 or 9

11 drug administration routes/ or administration, inhalation/ or exp administration, oral/ or Administration, Rectal/

12 administ*.tw,kf.

1311 or 12

14 (buccal $^{\star}$ or sublingual ${ }^{\star}$ or oral ${ }^{\star}$ or by mouth or rectal ${ }^{\star}$ or tablet ${ }^{\star}$ or liquid ${ }^{\star}$ or gel or gels or sachet ${ }^{\star}$ or spray or sprays or tongue or cheek or swallow* or administration route*).tw,kf.

15 Solutions/

16 Tablets/

17 Cheek/

18 Gels/

1914 or 15 or 16 or 17 or 18

207 and 10 and 13 and 19

21 remove duplicates from 20

\section{Embase (Ovid SP)}

1 hypoglycemia/ or insulin hypoglycemia/ or nocturnal hypoglycemia/

2 experimental hypoglycemia/

3 normal human/

4 (healthy participant or healthy participants or healthy subject or healthy subjects or healthy volunteer or healthy volunteers or human volunteer or human volunteers or normal volunteer or normal volunteers or healthy people or healthy persons).tw.

51 or 2 or 3 or 4

6 glucose/

7 (glucose or sugar).tw.

\section{6 or 7}

9 drug administration route/

10 oral drug administration/

11 enteral drug administration/

12 sublingual drug administration/

13 exp buccal drug administration/ 
(Continued)

14 rectal drug administration/

15 administ ${ }^{\star}$. tw .

169 or 10 or 11 or 12 or 13 or 14 or 15

17 (buccal $^{\star}$ or sublingual ${ }^{\star}$ or oral ${ }^{\star}$ or by mouth or rectal ${ }^{\star}$ or tablet ${ }^{\star}$ or liquid ${ }^{\star}$ or gel or gels or sachet ${ }^{\star}$ or spray or sprays or tongue or cheek or swallow* or administration route $\left.{ }^{\star}\right)$.tw.

\section{8 cheek/}

19 aerosol/ or drug solution/ or gel/ or lozenge/ or oral drops/ or oral spray/ or paste/ or exp tablet/

\section{7 or 18 or 19}

215 and 8 and 16 and 20

22 limit 21 to (books or "book review" or chapter or conference abstract or conference paper or "conference review" or editorial or letter or note)

2321 not 22

2423 not ((exp animal/ or nonhuman/) not exp human/)

25 remove duplicates from 24

26 limit 25 to embase

CINAHL Plus with full text (EBSCOhost Research Databases)

S1 (MH "Hypoglycemia")

S2 TI ( (Hypoglycemi^ or hypoglycaemi $\left.{ }^{\star}\right)$ ) OR AB ( (Hypoglycemi or hypoglycaemi`) )

S3 TI ( (healthy participant or healthy participants or healthy subject or healthy subjects or healthy volunteer or healthy volunteers or human volunteer or human volunteers or normal volunteer or normal volunteers or healthy people or healthy persons) ) OR $A B$ ( (healthy participant or healthy participants or healthy subject or healthy subjects or healthy volunteer or healthy volunteers or human volunteer or human volunteers or normal volunteer or normal volunteers or healthy people or healthy persons) )

\section{S4 S1 OR S2 OR S3}

S5 (MH "Glucose")

S6 TI (glucose or sugar) OR AB ( glucose or sugar)

S7 S5 OR S6

S8 (MH "Drug Administration Routes") OR (MH "Administration, Oral+") OR (MH "Administration, Rectal") OR (MH "Administration, Inhalation")

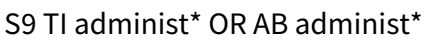

\section{S10 S8 OR S9}

S11 TI ( (buccal ${ }^{\star}$ or sublingual* or oral ${ }^{\star}$ or by mouth or rectal ${ }^{\star}$ or tablet ${ }^{\star}$ or liquid ${ }^{*}$ or gel or gels or sachet* or spray or sprays or tongue or cheek or swallow* or administration route $\left.{ }^{\star}\right)$ ) AND AB ( (buccal ${ }^{\star}$ or sublingual* or oral ${ }^{\star}$ or by mouth or rectal ${ }^{\star}$ or tablet ${ }^{\star}$ or liquid* or gel or gels or sachet* or spray or sprays or tongue or cheek or swallow* or administration route*) )

S12 (MH "Solutions") OR (MH "Tablets") OR (MH "Aerosols") OR (MH "Gels")

S13 (MH "Cheek")

S14 (MH "Tongue")

S15 S11 OR S12 OR S13 OR S14

First aid glucose administration routes for symptomatic hypoglycaemia (Review) 
(Continued)

S16 S4 AND S7 AND S10 AND S15

\section{ClinicalTrials.gov (standard search)}

Condition or disease: Hypoglycemia

Other terms: Hypoglycaemia

Study type: Interventional Studies

Intervention/treatment: Glucose

World Health Organization (WHO) International Clinical Trials Registry Platform (ICTRP) Search Portal (standard search)

hypoglycemia OR hypoglycaemia

\section{EU Clinical Trials Register}

(hypoglycemia OR hypoglycaemia) AND glucose

\section{Appendix 2. Assessment of risk of bias}

\section{Risk of bias domains}

\section{Random sequence generation (selection bias due to inadequate generation of a randomised sequence)}

For each included study, we will describe the method used to generate the allocation sequence in sufficient detail to allow an assessment of whether it should produce comparable groups.

- Low risk of bias: the study authors achieved sequence generation using computer-generated random numbers or a random numbers table. Drawing of lots, tossing a coin, shuffling cards or envelopes, and throwing dice are adequate if an independent person performed this who was not otherwise involved in the study. We will consider the use of the minimisation technique as equivalent to being random.

- Unclear risk of bias: insufficient information about the sequence generation process.

- High risk of bias: the sequence generation method was non-random or quasi-random (e.g. sequence generated by odd or even date of birth; sequence generated by some rule based on date (or day) of admission; sequence generated by some rule based on hospital or clinic record number; allocation by judgment of the clinician; allocation by preference of the participant; allocation based on the results of a laboratory test or a series of tests; or allocation by availability of the intervention).

\section{Allocation concealment (selection bias due to inadequate concealment of allocation prior to assignment)}

We will describe for each included study the method used to conceal allocation to interventions prior to assignment and we will assess whether intervention allocation could have been foreseen in advance of or during recruitment, or changed after assignment.

- Low risk of bias: central allocation (including telephone, interactive voice-recorder, web-based and pharmacy-controlled randomisation); sequentially numbered drug containers of identical appearance; sequentially numbered, opaque, sealed envelopes.

- Unclear risk of bias: insufficient information about the allocation concealment.

- High risk of bias: used an open random allocation schedule (e.g. a list of random numbers); assignment envelopes used without appropriate safeguards; alternation or rotation; date of birth; case record number; any other explicitly unconcealed procedure.

We will also evaluate study baseline data to incorporate assessment of baseline imbalance into the 'Risk of bias' judgment for selection bias (Corbett 2014). Chance imbalances may also affect judgments on the risk of attrition bias. In the case of unadjusted analyses, we will distinguish between studies that we rate as being at low risk of bias on the basis of both randomisation methods and baseline similarity, and studies that we judge as being at low risk of bias on the basis of baseline similarity alone (Corbett 2014). We will reclassify judgements of unclear, low or high risk of selection bias as specified in Appendix 3. 
(Continued)

Blinding of participants and study personnel (performance bias due to knowledge of the allocated interventions by participants and personnel during the study)

We will evaluate the risk of detection bias separately for each outcome (Hróbjartsson 2013). We will note whether endpoints were self-reported, investigator-assessed or adjudicated outcome measures (see below).

- Low risk of bias: blinding of participants and key study personnel was ensured, and it was unlikely that the blinding could have been broken; no blinding or incomplete blinding, but we judge that the outcome is unlikely to have been influenced by lack of blinding.

- Unclear risk of bias: insufficient information about the blinding of participants and study personnel; the study does not address this outcome.

- High risk of bias: no blinding or incomplete blinding, and the outcome is likely to have been influenced by lack of blinding; blinding of study participants and key personnel attempted, but likely that the blinding could have been broken, and the outcome is likely to be influenced by lack of blinding.

\section{Blinding of outcome assessment (detection bias due to knowledge of the allocated interventions by outcome assessment}

We will evaluate the risk of detection bias separately for each outcome (Hróbjartsson 2013). We will note whether endpoints were self-reported, investigator-assessed or adjudicated outcome measures (see below).

- Low risk of bias: blinding of outcome assessment is ensured, and it is unlikely that the blinding could have been broken; no blinding of outcome assessment, but we judge that the outcome measurement is unlikely to have been influenced by lack of blinding.

- Unclear risk of bias: insufficient information about the blinding of outcome assessors; the study did not address this outcome.

- High risk of bias: no blinding of outcome assessment, and the outcome measurement was likely to have been influenced by lack of blinding; blinding of outcome assessment, but likely that the blinding could have been broken, and the outcome measurement was likely to be influenced by lack of blinding.

\section{Incomplete outcome data (attrition bias due to amount, nature or handling of incomplete outcome data)}

For each included study and/or each outcome, we will describe the completeness of data, including attrition and exclusions from the analyses. We will state whether the study reported attrition and exclusions, and report the number of participants included in the analysis at each stage (compared with the number of randomised participants per intervention/comparator groups). We will also note if the study reported the reasons for attrition or exclusion and whether missing data were balanced across groups or were related to outcomes. We will consider the implications of missing outcome data per outcome such as high dropout rates (e.g. above 15\%) or disparate attrition rates (e.g. difference of $10 \%$ or more between study arms).

- Low risk of bias: no missing outcome data; reasons for missing outcome data unlikely to be related to true outcome (for survival data, censoring unlikely to introduce bias); missing outcome data balanced in numbers across intervention groups, with similar reasons for missing data across groups; for dichotomous outcome data, the proportion of missing outcomes compared with observed event risk was not enough to have a clinically relevant impact on the intervention effect estimate; for continuous outcome data, plausible effect size (mean difference or standardised mean difference) among missing outcomes was not enough to have a clinically relevant impact on observed effect size; appropriate methods, such as multiple imputation, were used to handle missing data.

- Unclear risk of bias: insufficient information to assess whether missing data in combination with the method used to handle missing data were likely to induce bias; the study did not address this outcome.

- High risk of bias: reason for missing outcome data was likely to be related to true outcome, with either imbalance in numbers or reasons for missing data across intervention groups; for dichotomous outcome data, the proportion of missing outcomes compared with observed event risk enough to induce clinically relevant bias in the intervention effect estimate; for continuous outcome data, plausible effect size (mean difference or standardised mean difference) among missing outcomes enough to induce clinically-relevant bias in observed effect size; 'as-treated' or similar analysis done with substantial departure of the intervention received from that assigned at randomisation; potentially inappropriate application of simple imputation.

\section{Selective reporting (reporting bias due to selective outcome reporting)}

We will assess outcome reporting bias and apply the 'High risk of outcome reporting bias according to the Outcome Reporting Bias In Trials (ORBIT)' classification (Kirkham 2010). This analysis will form the basis for the judgement of selective reporting.

- Low risk of bias: the study protocol was available and all the studies' prespecified (primary and secondary) outcomes that were of interest to this review were reported in the prespecified way; the study protocol was unavailable, but it was clear that the published reports included all expected outcomes (ORBIT classification).

- Unclear risk of bias: insufficient information about selective reporting.

- High risk of bias: not all the studies' prespecified primary outcomes were reported; one or more primary outcomes were reported using measurements, analysis methods or subsets of the data (e.g. subscales) that were not prespecified; one or more reported primary outcomes were not prespecified (unless clear justification for their reporting was provided, such as an unexpected adverse

First aid glucose administration routes for symptomatic hypoglycaemia (Review) 
(Continued)

effect); one or more outcomes of interest in the Cochrane Review were reported incompletely so that we cannot enter them in a meta-analysis; the study report failed to include results for a key outcome that we would expect to have been reported for such a study (ORBIT classification).

\section{Other bias}

- Low risk of bias: the study appears to be free from other sources of bias.

- Unclear risk of bias: there was insufficient information to assess whether an important risk of bias existed; insufficient rationale or evidence that an identified problem introduced bias.

- High risk of bias: the study had a potential source of bias related to the specific study design used; the study was claimed to be fraudulent; or the study had some other serious problem.

\section{Appendix 3. Selection bias decisions}

\section{Selection bias decisions for studies that reported unadjusted analyses: comparison of results obtained using method details alone versus results obtained using method details and study baseline informationa}

\begin{tabular}{|c|c|c|c|}
\hline $\begin{array}{l}\text { Reported randomi- } \\
\text { sation and alloca- } \\
\text { tion concealment } \\
\text { methods }\end{array}$ & $\begin{array}{l}\text { 'Risk of bias' } \\
\text { judgement using } \\
\text { methods reporting }\end{array}$ & Information gained from study characteristics data & $\begin{array}{l}\text { 'Risk of bias' using } \\
\text { baseline informa- } \\
\text { tion and methods } \\
\text { reporting }\end{array}$ \\
\hline
\end{tabular}

\begin{tabular}{llll}
\hline Unclear methods $\quad$ Unclear risk & $\begin{array}{l}\text { Baseline imbalances present for important prognostic vari- } \\
\text { able(s) }\end{array}$ & High risk
\end{tabular}

Groups appear similar at baseline for all important prognostic Low risk
variables

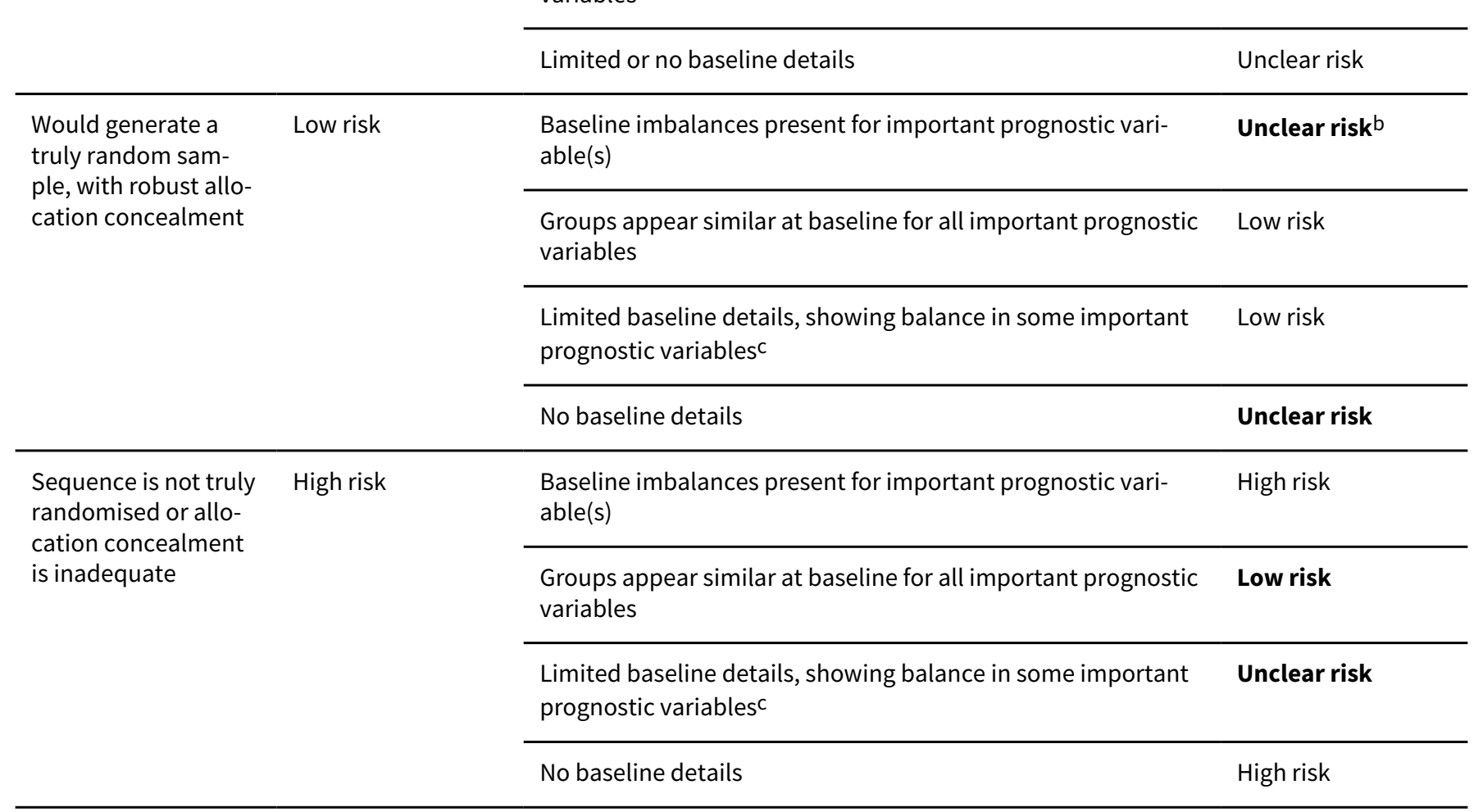

\footnotetext{
aTaken from Corbett 2014; judgements highlighted in bold indicate situations in which the addition of baseline assessments would change the judgement about risk of selection bias compared with using methods reporting alone.
} 
(Continued)

bImbalance was identified that appears likely to be due to chance.

cDetails for the remaining important prognostic variables are not reported.

\section{Appendix 4. Risk of bias assessment of non-RCTs}

\begin{tabular}{|c|c|c|c|c|}
\hline Study author & $\begin{array}{l}\text { Study/bias do- } \\
\text { main }\end{array}$ & Question & Answer & Explanation \\
\hline \multirow[t]{3}{*}{ Chlup 2009} & $\begin{array}{l}\text { Bias due to con- } \\
\text { founding }\end{array}$ & $\begin{array}{l}1.1 \text { Is there potential for confounding of the } \\
\text { effect of intervention in this study? }\end{array}$ & No & $\begin{array}{l}\text { No prognostic factors } \\
\text { are known; also, the } \\
\text { study is a cross-over } \\
\text { study and thus the } \\
\text { characteristics of the } \\
\text { intervention group are } \\
\text { identical to those of } \\
\text { the control group }\end{array}$ \\
\hline & & Risk of bias judgment & Low & \\
\hline & $\begin{array}{l}\text { Bias in selection } \\
\text { of participants } \\
\text { into the study }\end{array}$ & $\begin{array}{l}\text { 2.1 Was selection of participants into the } \\
\text { study (or into the analysis) based on partici- } \\
\text { pant characteristics observed after the start } \\
\text { of intervention? }\end{array}$ & Probably no & $\begin{array}{l}\text { Sixteen healthy vol- } \\
\text { unteers provided in- } \\
\text { formed written con- } \\
\text { sent and entered } \\
\text { the study; not clear } \\
\text { if these participants } \\
\text { were selected based } \\
\text { on certain characteris- } \\
\text { tics. } \\
\text { However, because of } \\
\text { the cross-over design, } \\
\text { there were no differ- } \\
\text { ences in characteris- } \\
\text { tics between the inter- } \\
\text { vention and control } \\
\text { group }\end{array}$ \\
\hline
\end{tabular}

2.4 Do start of follow-up and start of interven- Yes tion coincide for most participants?

\begin{tabular}{lll}
\cline { 2 - 3 } & 'Risk of bias' judgment & Low \\
\hline $\begin{array}{ll}\text { Bias in classifi- } \\
\text { cation of inter- } \\
\text { ventions }\end{array}$ & 3.1 Were intervention groups clearly defined? & Yes \\
\cline { 2 - 3 } & $\begin{array}{l}\text { 3.2 Was the information used to define inter- } \\
\text { vention groups recorded at the start of the in- } \\
\text { tervention? }\end{array}$ & Yes \\
\hline
\end{tabular}

3.3 Could classification of intervention status No have been affected by knowledge of the outcome or risk of the outcome?

'Risk of bias' judgment Low 


\begin{tabular}{|c|c|c|}
\hline \multirow{2}{*}{$\begin{array}{l}\text { Bias due to de- } \\
\text { viations from } \\
\text { intended inter- } \\
\text { ventions }\end{array}$} & $\begin{array}{l}4.1 \text { Were there deviations from the intended } \\
\text { intervention beyond what would be expected } \\
\text { in usual practice? }\end{array}$ & No \\
\hline & 'Risk of bias' judgment & Low \\
\hline \multirow[t]{5}{*}{$\begin{array}{l}\text { Bias due to } \\
\text { missing data }\end{array}$} & $\begin{array}{l}5.1 \text { Were outcome data available for all, or } \\
\text { nearly all, participants? }\end{array}$ & Yes \\
\hline & $\begin{array}{l}\text { 5.2 Were participants excluded due to missing } \\
\text { data on intervention status? }\end{array}$ & No \\
\hline & $\begin{array}{l}5.3 \text { Were participants excluded due to missing } \\
\text { data on other variables needed }\end{array}$ & No \\
\hline & for the analysis? & \\
\hline & 'Risk of bias' judgment & Low \\
\hline $\begin{array}{l}\text { Bias in mea- } \\
\text { surement of } \\
\text { outcomes }\end{array}$ & $\begin{array}{l}6.1 \text { Could the outcome measure have been in- } \\
\text { fluenced by knowledge of the intervention re- } \\
\text { ceived? }\end{array}$ & No \\
\hline
\end{tabular}

6.2 Were outcome assessors aware of the in- Probably yes tervention received by study participants?

6.3 Were the methods of outcome assessment Yes comparable across intervention groups?

6.4 Were any systematic errors in measure-

No ment of the outcome related to intervention received?

'Risk of bias' judgment Low

\begin{tabular}{|c|c|c|c|}
\hline $\begin{array}{l}\text { Bias in selection } \\
\text { of the reported } \\
\text { result }\end{array}$ & $\begin{array}{l}\text { Is the reported effect estimate likely to be se- } \\
\text { lected, on the basis of the results, } \\
\text { from... } \\
7.1 \text {... multiple outcome measurements with- } \\
\text { in the outcome domain? }\end{array}$ & Probably no & $\begin{array}{l}\text { The outcome was } \\
\text { measured at different } \\
\text { time points, and out- } \\
\text { comes until } 30 \text { min- } \\
\text { utes following the in- } \\
\text { tervention were mea- } \\
\text { sured; however this is } \\
\text { the time frame where } \\
\text { the effect most likely } \\
\text { is observed }\end{array}$ \\
\hline
\end{tabular}

7.2 ... multiple analyses of the intervention-outcome relationship?

\begin{tabular}{ll}
\hline 7.3 ... different subgroups? & No \\
\hline 'Risk of bias' judgment & Low \\
\hline
\end{tabular}




\begin{tabular}{|c|c|c|c|c|}
\hline & $\begin{array}{l}\text { Study/bias do- } \\
\text { main }\end{array}$ & Question & Answer & Explanation \\
\hline \multirow[t]{3}{*}{ Gunning 1978} & $\begin{array}{l}\text { Bias due to con- } \\
\text { founding }\end{array}$ & $\begin{array}{l}1.1 \text { Is there potential for confounding of the } \\
\text { effect of intervention in this study? }\end{array}$ & No & $\begin{array}{l}\text { No factors prognos- } \\
\text { tic for the outcome } \\
\text { are known; also, the } \\
\text { study is a cross-over } \\
\text { study and thus the } \\
\text { characteristics of the } \\
\text { intervention group are } \\
\text { identical to those of } \\
\text { the control group }\end{array}$ \\
\hline & & 'Risk of bias' judgment & Low & \\
\hline & $\begin{array}{l}\text { Bias in selection } \\
\text { of participants } \\
\text { into the study }\end{array}$ & $\begin{array}{l}2.1 \text { Was selection of participants into the } \\
\text { study (or into the analysis) based on partici- } \\
\text { pant characteristics observed after the start } \\
\text { of intervention? }\end{array}$ & No & $\begin{array}{l}\text { Seven volunteers were } \\
\text { selected and informed } \\
\text { written consent was } \\
\text { obtained; not clear } \\
\text { if these participants } \\
\text { were selected based } \\
\text { on certain character- } \\
\text { istics. However, be- } \\
\text { cause of the cross- } \\
\text { over design there were } \\
\text { no differences in char- } \\
\text { acteristics between } \\
\text { the intervention and } \\
\text { control group }\end{array}$ \\
\hline
\end{tabular}

\begin{tabular}{|c|c|c|}
\hline & $\begin{array}{l}2.4 \text { Do start of follow-up and start of interven- } \\
\text { tion coincide for most participants? }\end{array}$ & Yes \\
\hline & 'Risk of bias' judgment & Low \\
\hline \multirow{4}{*}{$\begin{array}{l}\text { Bias in classifi- } \\
\text { cation of inter- } \\
\text { ventions }\end{array}$} & 3.1 Were intervention groups clearly defined? & Yes \\
\hline & $\begin{array}{l}3.2 \text { Was the information used to define inter- } \\
\text { vention groups recorded at the start of the in- } \\
\text { tervention? }\end{array}$ & Yes \\
\hline & $\begin{array}{l}3.3 \text { Could classification of intervention status } \\
\text { have been affected by knowledge of the out- } \\
\text { come or risk of the outcome? }\end{array}$ & No \\
\hline & 'Risk of bias' judgment & Low \\
\hline \multirow[t]{2}{*}{$\begin{array}{l}\text { Bias due to de- } \\
\text { viations from } \\
\text { intended inter- } \\
\text { ventions }\end{array}$} & $\begin{array}{l}4.1 \text { Were there deviations from the intended } \\
\text { intervention beyond what would be expected } \\
\text { in usual practice? }\end{array}$ & No \\
\hline & 'Risk of bias' judgment & Low \\
\hline \multirow[t]{2}{*}{$\begin{array}{l}\text { Bias due to } \\
\text { missing data }\end{array}$} & $\begin{array}{l}5.1 \text { Were outcome data available for all, or } \\
\text { nearly all, participants? }\end{array}$ & Yes \\
\hline & $\begin{array}{l}5.2 \text { Were participants excluded due to missing } \\
\text { data on intervention status? }\end{array}$ & No \\
\hline
\end{tabular}


5.3 Were participants excluded due to missing No data on other variables needed for the analysis?

'Risk of bias' judgment

Low

\section{Bias in mea- surement of outcomes}

6.1 Could the outcome measure have been influenced by knowledge of the intervention received?

No

6.2 Were outcome assessors aware of the in- Probably yes
tervention received by study participants?

6.3 Were the methods of outcome assessment Yes comparable across intervention groups?

\begin{tabular}{|c|c|c|}
\hline $\begin{array}{l}6.4 \text { Were any systematic errors in measure- } \\
\text { ment of the outcome related to intervention } \\
\text { received? }\end{array}$ & No & \\
\hline 'Risk of bias' judgment & Low & \\
\hline $\begin{array}{l}\text { Is the reported effect estimate likely to be se- } \\
\text { lected, on the basis of the results, } \\
\text { from... } \\
7.1 \text {... multiple outcome measurements with- } \\
\text { in the outcome domain? }\end{array}$ & Probably no & $\begin{array}{l}\text { The outcome was } \\
\text { measured at different } \\
\text { time points, and out- } \\
\text { comes until } 30 \text { min- } \\
\text { utes following the in- } \\
\text { tervention were mea- } \\
\text { sured; however this is } \\
\text { the time frame where } \\
\text { the effect most likely } \\
\text { is observed }\end{array}$ \\
\hline
\end{tabular}

\begin{tabular}{ll}
\hline $\begin{array}{l}7.2 \text {... multiple analyses of the interven- } \\
\text { tion-outcome relationship? }\end{array}$ & No \\
\hline $7.3 \ldots$ different subgroups? & No \\
\hline 'Risk of bias' judgment & Low \\
\hline
\end{tabular}

\section{Appendix 5. Descriptions of participants}

\begin{tabular}{lll}
\hline Study ID & Criteria & Description \\
\hline Chlup 2009 & Inclusion criteria & Being adult and healthy \\
\cline { 2 - 3 } & Exclusion criteria & - \\
\cline { 2 - 3 } & Diagnostic criteria & - \\
\hline Barennes 2005 & Inclusion criteria & $\begin{array}{l}\text { Children 1-15 years who presented to the Hamdallaye Health Center during } \\
\text { the high malaria transmission period (October to December 2002) }\end{array}$ \\
\hline
\end{tabular}


(Continued)

Exclusion criteria Children with severe clinical symptoms of hypoglycaemia requiring immediate treatment; children who swallowed the sugar within 10 minutes were dropped from the study

Diagnostic criteria Moderate clinical symptoms of acute malaria or moderate respiratory tract infections, and blood glucose concentrations $50 \mathrm{mg} / \mathrm{dL}$ to $80 \mathrm{mg} / \mathrm{dL}$

\begin{tabular}{|c|c|c|}
\hline \multirow[t]{3}{*}{ Slama 1990} & Inclusion criteria & $\begin{array}{l}\text { Participants in general good health, with insulin-dependent diabetes; free } \\
\text { from clinical signs and symptoms of peripheral or autonomic neuropathy }\end{array}$ \\
\hline & Exclusion criteria & Any known coronary heart disease, hypertension or advanced retinopathy \\
\hline & Diagnostic criteria & $\begin{array}{l}\text { Intravenous insulin was given until symptoms of hypoglycaemia occurred or } \\
\text { blood glucose values reached } 2.7 \mathrm{mmol} / \mathrm{L} \text { (or } 49 \mathrm{mg} / \mathrm{dL} \text { ) }\end{array}$ \\
\hline \multirow[t]{3}{*}{ Gunning 1978} & Inclusion criteria & Volunteers with intact oral mucosa \\
\hline & Exclusion criteria & Clinical or chemical evidence of disease or a history of diabetes mellitus \\
\hline & Diagnostic criteria & - \\
\hline \multicolumn{3}{|c|}{-: denotes not reported } \\
\hline
\end{tabular}

\section{Appendix 6. Description of interventions}

\begin{tabular}{|c|c|}
\hline Item & Study ID \\
\hline Study author & Chlup 2009 \\
\hline Brief name & Buccal vs oral administration \\
\hline Recipient & Healthy volunteers \\
\hline Why & $\begin{array}{l}\text { To assess the efficacy of different commercially available glucose products on the evolution of } \\
\text { plasma glucose concentration }\end{array}$ \\
\hline What (materials) & $\begin{array}{l}\text { I: glucose spray, manufacturer not mentioned } \\
\text { C: dextrose tablet }(6 \mathrm{~g})\end{array}$ \\
\hline What (procedures) & $\begin{array}{l}\text { The glucose product (intervention or comparator) was administered after an average fasting } \\
\text { time of } 8 \text { to } 9 \text { hours (range was } 6 \text { to } 13 \text { hours). Plasma glucose concentration was measured, and } \\
\text { the glucose product was administered immediately after the first measurement. Each interven- } \\
\text { tion was administered } 3 \text { times (on separate days, following fasting) }\end{array}$ \\
\hline Who provided & Researcher, no further information available \\
\hline $\begin{array}{l}\text { How (mode of delivery; individual } \\
\text { or group) }\end{array}$ & $\begin{array}{l}\text { I: spray doses applied on the mucosa of the cheek, without swallowing } \\
\text { C: chewing and consumption of the tablet }\end{array}$ \\
\hline Where & Experimental setting \\
\hline When and how much & I: 10 glucose spray doses ( 5 doses per cheek); one single administration \\
\hline
\end{tabular}


(Continued)

C: one dextrose tablet $(6 \mathrm{~g})$; one single administration

\begin{tabular}{|c|c|}
\hline Tailoring & NA \\
\hline $\begin{array}{l}\text { Modification of intervention } \\
\text { throughout the study }\end{array}$ & NA \\
\hline $\begin{array}{l}\text { Strategies to improve or maintain } \\
\text { intervention fidelity }\end{array}$ & NA \\
\hline Extent of intervention fidelity & NA \\
\hline Study author & Barennes 2005 \\
\hline Brief name & Sublingual vs oral administration \\
\hline Recipient & $\begin{array}{l}\text { Children 1-15 years with moderate symptoms of malaria or respiratory tract infections and low } \\
\text { blood glucose concentrations }\end{array}$ \\
\hline Why & To compare different forms of glucose administration to relieve hypoglycaemia \\
\hline What (materials) & $\begin{array}{l}\text { I: wet sugar } \\
\text { C: sugar }\end{array}$ \\
\hline What (procedures) & Glucose was given in the morning, after fasting overnight (starting after dinner) \\
\hline Who provided & Physician \\
\hline $\begin{array}{l}\text { How (mode of delivery; individual } \\
\text { or group) }\end{array}$ & $\begin{array}{l}\text { I: wet sugar was applied under the tongue without swallowing } \\
\text { C: sugar on the tongue, swallowed }\end{array}$ \\
\hline Where & Hamdallaye Health Center \\
\hline When and how much & $\begin{array}{l}2.5 \mathrm{~g} \text { of sugar (intervention or comparator) was administered in intervention and comparator } \\
\text { group }\end{array}$ \\
\hline Tailoring & NA \\
\hline $\begin{array}{l}\text { Modification of intervention } \\
\text { throughout the study }\end{array}$ & NA \\
\hline $\begin{array}{l}\text { Strategies to improve or maintain } \\
\text { intervention fidelity }\end{array}$ & NA \\
\hline Extent of intervention fidelity & NA \\
\hline Study author & Slama 1990 \\
\hline Brief name & Dextrose gel vs oral administration \\
\hline Recipient & Participants with insulin-dependent diabetes \\
\hline Why & $\begin{array}{l}\text { To evaluate the efficacy of different forms of sugar in correcting the hypoglycaemic reactions of } \\
\text { insulin-treated diabetic patients }\end{array}$ \\
\hline What (materials) & $\begin{array}{l}\text { I: } 15 \mathrm{~g} \text { of glucose in the form of } 40 \mathrm{~g} \text { of a } 40 \% \text { dextrose gel (Hypostop, Novo Industries) } \\
\text { C1: glucose tablet ( } 15 \mathrm{~g} \text { ) (Glucose Tablets, Becton Dickinson) } \\
\text { C2: a solution of } 15 \mathrm{~g} \text { of glucose in } 150 \mathrm{~mL} \text { of water }\end{array}$ \\
\hline
\end{tabular}


(Continued)

$\mathrm{C} 1$ and $\mathrm{C} 2$ were combined as one "oral group" in the data analyses

\begin{tabular}{ll}
\hline What (procedures) & See above \\
\hline Who provided & Not reported, but probably a physician (hospital setting) \\
\hline $\begin{array}{ll}\text { How (mode of delivery; individual } \\
\text { or group) }\end{array}$ & $\begin{array}{l}\text { I: not described how the gel was applied, but should be applied to the cheek according to the } \\
\text { manufacturer } \\
\text { C1: swallowed without water } \\
\text { C2: swallowed }\end{array}$ \\
\hline Where & Hospital \\
\hline When and how much & I: $15 \mathrm{~g}$ \\
C1: 1 tablet $(15 \mathrm{~g})$ \\
$\mathrm{C} 2: 15 \mathrm{~g}$ of glucose in $150 \mathrm{~mL}$ water
\end{tabular}

\begin{tabular}{|c|c|}
\hline Tailoring & NA \\
\hline $\begin{array}{l}\text { Modification of intervention } \\
\text { throughout the study }\end{array}$ & NA \\
\hline $\begin{array}{l}\text { Strategies to improve or maintain } \\
\text { intervention fidelity }\end{array}$ & NA \\
\hline Extent of intervention fidelity & NA \\
\hline Study author & Gunning 1978 \\
\hline Brief name & Buccal vs oral administration \\
\hline Recipient & Healthy volunteers \\
\hline Why & $\begin{array}{l}\text { To evaluate the efficacy of instant glucose by studying the absorption of this preparation in nor- } \\
\text { mal volunteers }\end{array}$ \\
\hline
\end{tabular}

What (materials) Instant glucose containing $50 \mu \mathrm{Ci}$ of 2-tritiated glucose

What (procedures) At 8 AM after an overnight fast, an indwelling intravenous cannula was inserted into an antecubital vein. After a 30-minute rest period, two initial blood samples were obtained, following which $15 \mathrm{~g}$ of instant glucose was administered.

Blood samples were analysed for glucose using fluorometric enzymatic techniques

\begin{tabular}{ll}
\hline Who provided & Researcher, no further information available \\
\hline $\begin{array}{l}\text { How (mode of delivery; individual } \\
\text { or group) }\end{array}$ & $\begin{array}{l}\text { I: glucose was placed between the teeth and cheek of each subject. Participants were encour- } \\
\text { aged not to swallow } \\
\text { C: glucose was swallowed }\end{array}$ \\
\hline Where & Experimental setting \\
\hline When and how much & 15 g of labelled instant glucose was administered in intervention and comparator group \\
\hline Tailoring & NA \\
\hline Modification of intervention & NA \\
throughout the study &
\end{tabular}


(Continued)

Strategies to improve or maintain NA intervention fidelity

Extent of intervention fidelity

NA

\section{-: denotes not reported}

C: comparator; g: gram; I: intervention; NA: not applicable; $\boldsymbol{\mu C i}$ : micro Curie; $\mathbf{m L}$ : millilitre 


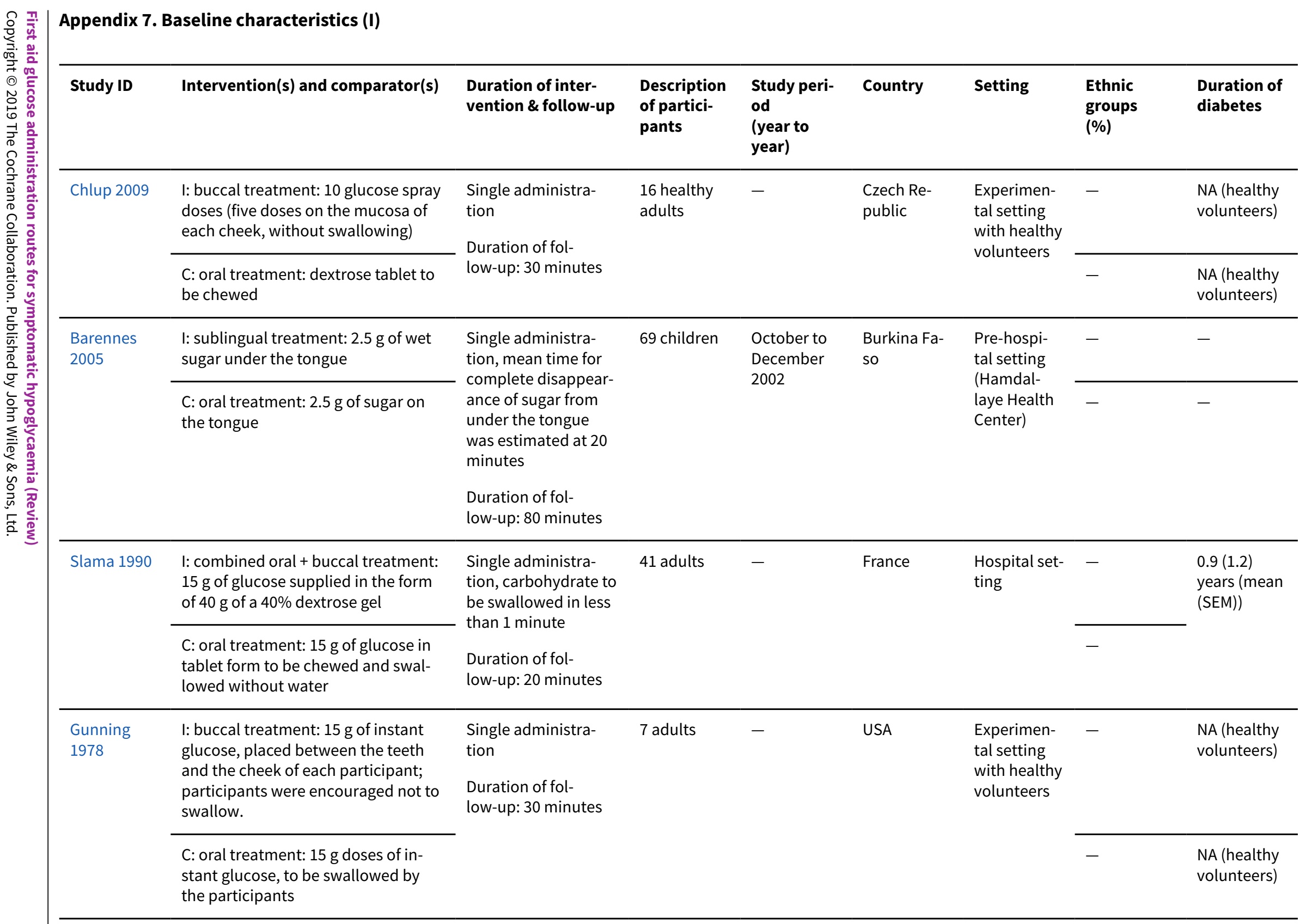

-: denotes not reported 


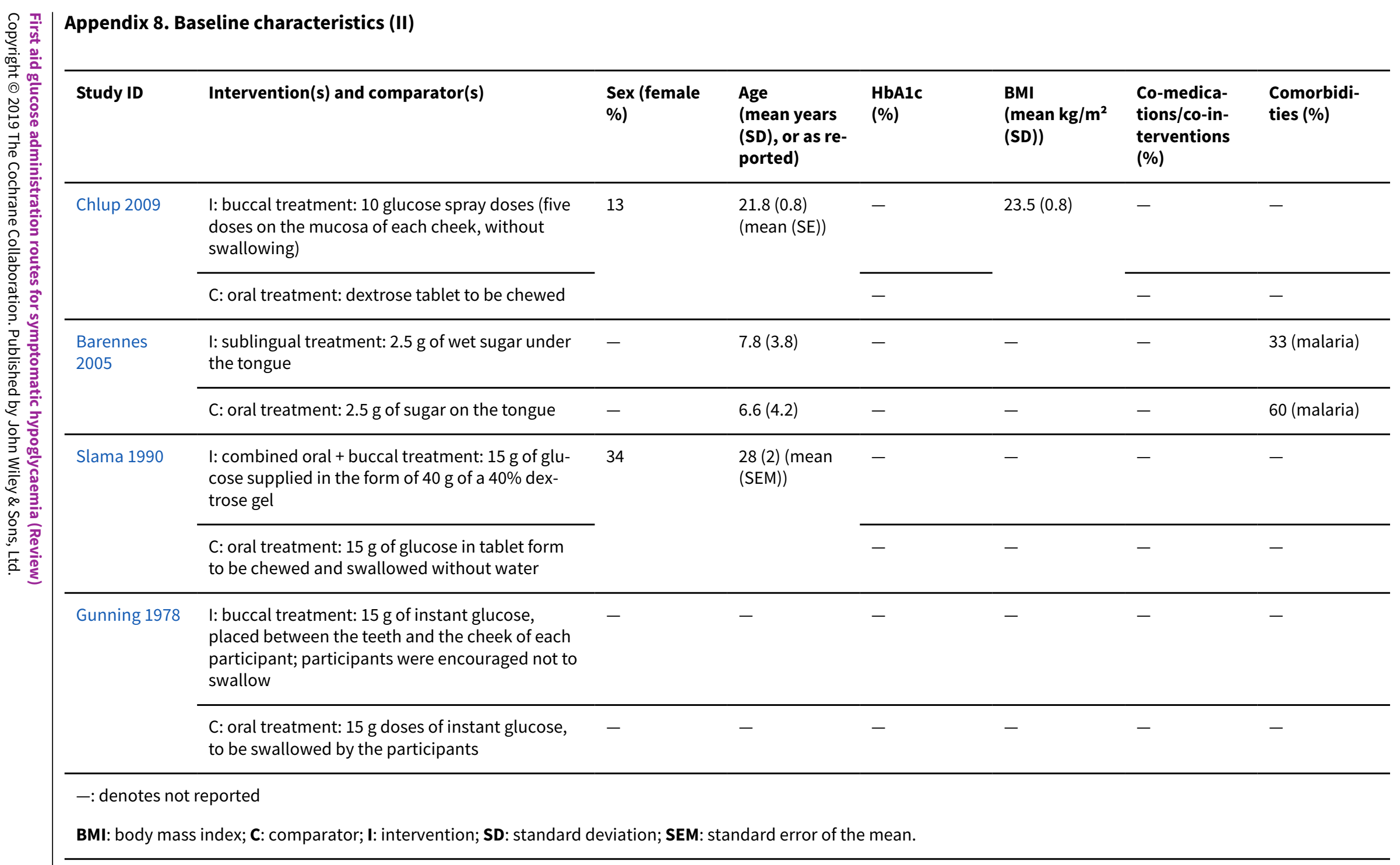




\section{Appendix 9. Study endpoints and timing of outcome measurement}

\begin{tabular}{|c|c|c|}
\hline Study ID & Review's primary and secondary outcomes & $\begin{array}{l}\text { Timing of outcome measure- } \\
\text { ment in study }\end{array}$ \\
\hline \multirow[t]{7}{*}{ Chlup 2009} & Resolution of symptoms & - \\
\hline & Time to resolution of symptoms & - \\
\hline & Blood or plasma glucose concentration at 20 minutes & $\begin{array}{l}\text { Plasma glucose levels measured } \\
\text { at } 0,5,10,15,20 \text { and } 30 \text { minutes }\end{array}$ \\
\hline & Resolution of hypoglycaemia & - \\
\hline & Time to resolution of hypoglycaemia & - \\
\hline & Adverse events & - \\
\hline & Treatment delay & - \\
\hline \multirow[t]{7}{*}{ Barennes 2005} & Resolution of symptoms. & - \\
\hline & Time to resolution of symptoms & - \\
\hline & Blood or plasma glucose concentration at 20 minutes & $\begin{array}{l}\text { Blood glucose levels measured at } \\
0,20,40,60 \text { and } 80 \text { minutes }\end{array}$ \\
\hline & Resolution of hypoglycaemia & At 80 minutes \\
\hline & Time to resolution of hypoglycaemia & At 20 minutes \\
\hline & Adverse events & $\begin{array}{l}\text { At any time during study period } \\
\text { (80 minutes) }\end{array}$ \\
\hline & Treatment delay & - \\
\hline \multirow[t]{7}{*}{ Slama 1990} & Resolution of symptoms & $\leq 10, \leq 15, \leq 20$ or $>20$ minutes \\
\hline & Time to resolution of symptoms & - \\
\hline & Blood or plasma glucose concentration at 20 minutes & $\begin{array}{l}\text { Plasma glucose was measured } \\
\text { every minute for } 10 \text { minutes, and } \\
\text { at } 15 \text { and } 20 \text { minutes }\end{array}$ \\
\hline & Resolution of hypoglycaemia & - \\
\hline & Time to resolution of hypoglycaemia & - \\
\hline & Adverse events & - \\
\hline & Treatment delay & - \\
\hline \multirow[t]{2}{*}{ Gunning 1978} & Resolution of symptoms & - \\
\hline & Time to resolution of symptoms & - \\
\hline
\end{tabular}




\begin{tabular}{lc} 
Blood or plasma glucose concentration at 20 minutes & At 20 minutes \\
\hline Resolution of hypoglycaemia & - \\
\hline Time to resolution of hypoglycaemia & - \\
\hline Adverse events & -
\end{tabular}

- denotes not reported

Appendix 10. High risk of outcome reporting bias according to Outcome Reporting Bias In Trials (ORBIT) classification

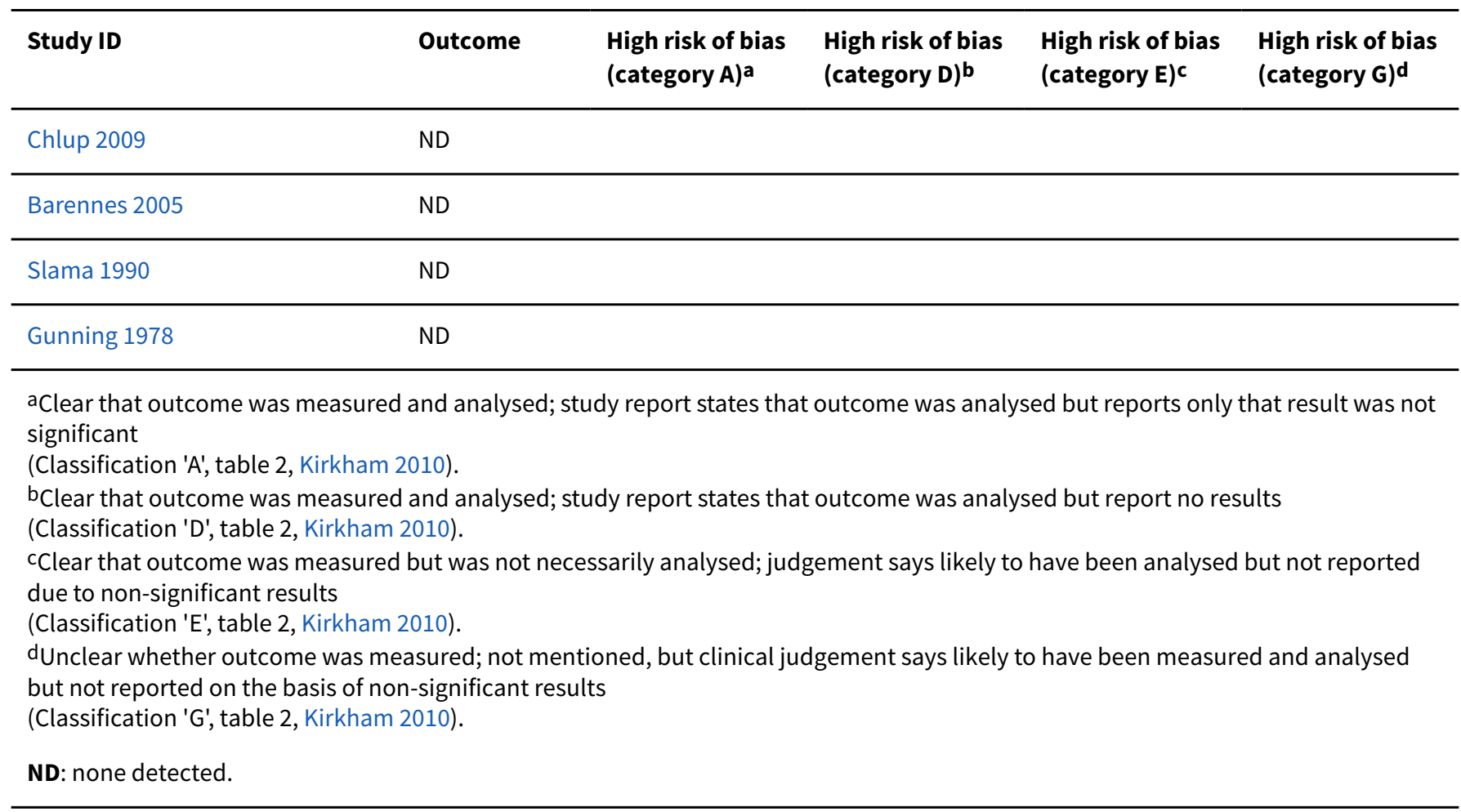




\begin{tabular}{|c|c|c|c|c|c|c|c|c|}
\hline Study ID & $\begin{array}{l}\text { Resolution } \\
\text { of symp- } \\
\text { toms }\end{array}$ & $\begin{array}{l}\text { Time to res- } \\
\text { olution of } \\
\text { symptoms }\end{array}$ & $\begin{array}{l}\text { Blood or plasma glu- } \\
\text { cose concentration at } \\
20 \text { minutes }\end{array}$ & Resolution of hypoglycaemia & $\begin{array}{l}\text { Time to res- } \\
\text { olution of } \\
\text { hypogly- } \\
\text { caemia }\end{array}$ & $\begin{array}{l}\text { Adverse } \\
\text { events }\end{array}$ & $\begin{array}{l}\text { Treatment } \\
\text { delay }\end{array}$ & $\begin{array}{l}\text { Severe/se- } \\
\text { rious } \\
\text { adverse } \\
\text { events } \\
\text { (specify) }\end{array}$ \\
\hline Chlup 2009 & $\mathrm{NI}$ & $\mathrm{NI}$ & $\begin{array}{l}\text { Plasma glucose tested } \\
\text { in finger-prick capillary } \\
\text { blood }\end{array}$ & $\mathrm{NI}$ & $\mathrm{NI}$ & $\mathrm{NI}$ & $\mathrm{NI}$ & $\mathrm{NI}$ \\
\hline $\begin{array}{l}\text { Barennes } \\
2005\end{array}$ & $\mathrm{NI}$ & $\mathrm{NI}$ & $\begin{array}{l}\text { Blood glucose con- } \\
\text { centrations, collected } \\
\text { through finger prick }\end{array}$ & $\begin{array}{l}\text { Treatment failure rate, propor- } \\
\text { tion of children not reaching a } \\
\text { blood glucose concentration of } \\
\geq 90 \mathrm{mg} / \mathrm{dL} \text { during the study pe- } \\
\text { riod. These data were used to de- } \\
\text { termine 'resolution of hypogly- } \\
\text { caemia within } 80 \text { minutes'. } \\
\text { Early treatment failure rate: pro- } \\
\text { portion of children with no blood } \\
\text { glucose gain at } 20 \text { minutes. These } \\
\text { data were used to determine 'res- } \\
\text { olution of hypoglycaemia within } \\
20 \text { minutes' }\end{array}$ & $\begin{array}{l}\text { Time to glu- } \\
\text { cose con- } \\
\text { centration } \\
\text { normalisa- } \\
\text { tion }\end{array}$ & $\begin{array}{l}\text { Any adverse } \\
\text { event }\end{array}$ & $\mathrm{NI}$ & $\mathrm{NI}$ \\
\hline Slama 1990 & $\begin{array}{l}\text { Clinical } \\
\text { recovery } \\
\text { (complete } \\
\text { sympto- } \\
\text { matic relief) }\end{array}$ & $\begin{array}{l}\text { Clinical re- } \\
\text { covery time }\end{array}$ & $\begin{array}{l}\text { Plasma glucose determi- } \\
\text { nation, using a glucose } \\
\text { oxidase method }\end{array}$ & $\mathrm{NI}$ & $\mathrm{NI}$ & $\mathrm{NI}$ & $\mathrm{NI}$ & $\mathrm{NI}$ \\
\hline $\begin{array}{l}\text { Gunning } \\
1978\end{array}$ & $\mathrm{NI}$ & $\mathrm{NI}$ & $\begin{array}{l}\text { Number of participants } \\
\text { with increased blood } \\
\text { glucose at } 20 \text { minutes }\end{array}$ & $\mathrm{NI}$ & $\mathrm{NI}$ & $\mathrm{NI}$ & $\mathrm{NI}$ & $\mathrm{NI}$ \\
\hline
\end{tabular}

aln addition to definition of endpoint measurement, description who measured the outcome (AO: adjudicated outcome measurement; IO: investigator-assessed outcome measurement; SO: self-reported outcome measurement).

ND: not defined; NR: not reported; NI: not investigated. 


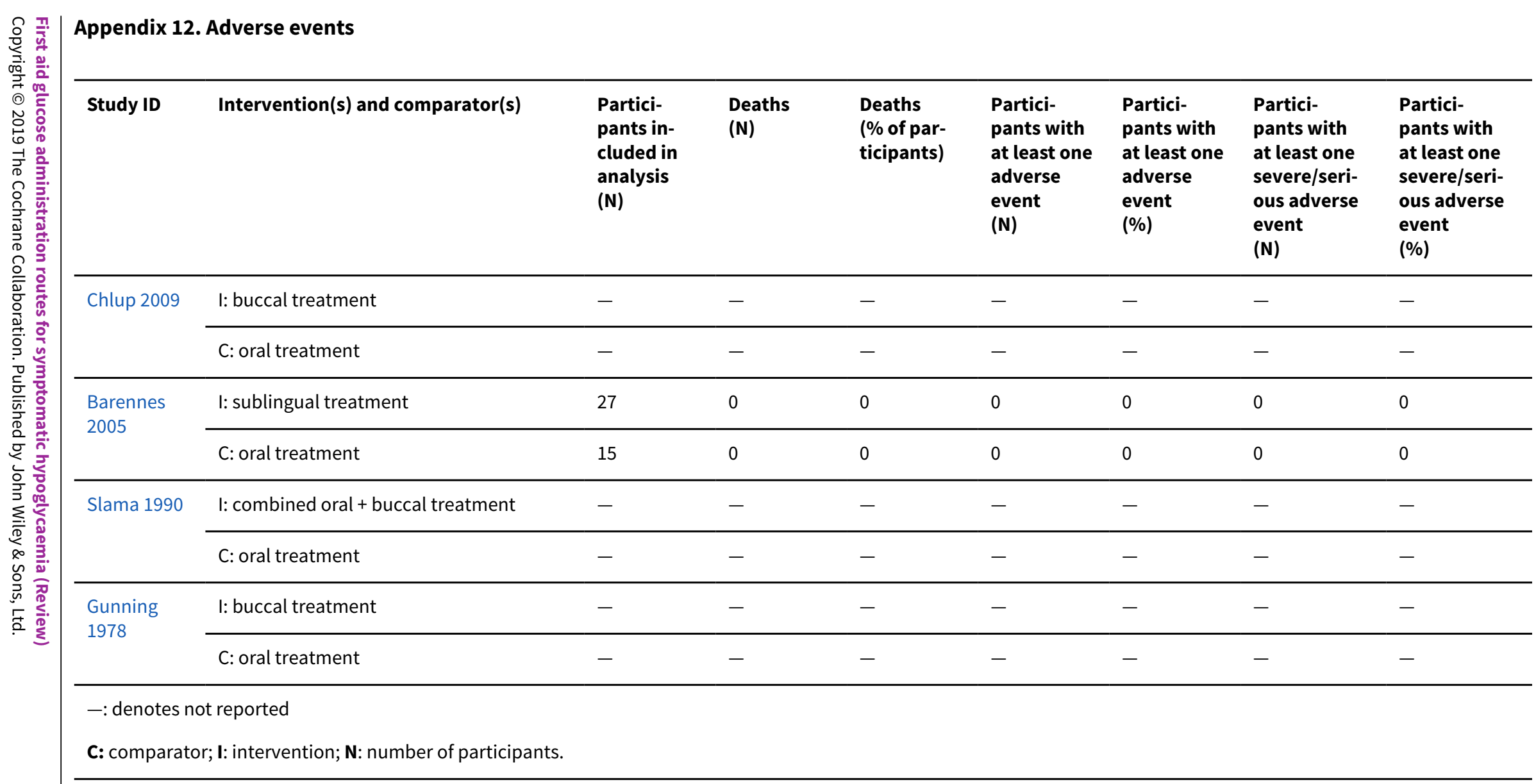


Appendix 13. Survey of study investigators providing information on included studies

\begin{tabular}{|c|c|c|c|c|}
\hline $\begin{array}{l}\text { Included stud- } \\
\text { ies }\end{array}$ & $\begin{array}{l}\text { Date study au- } \\
\text { thor contacted }\end{array}$ & $\begin{array}{l}\text { Date study au- } \\
\text { thor replied }\end{array}$ & $\begin{array}{l}\text { Date study author was asked for addi- } \\
\text { tional information } \\
\text { (short summary) }\end{array}$ & $\begin{array}{l}\text { Date study author pro- } \\
\text { vided data } \\
\text { (short summary) }\end{array}$ \\
\hline Chlup 2009 & - & - & - & - \\
\hline Barennes 2005 & - & - & - & - \\
\hline Slama 1990 & 15 March 2018 & 8 June 2018 & $\begin{array}{l}\text { Since according to the manufacturer, the } \\
\text { dextrose gel can be applied in two ways } \\
\text { (direct ingestion or buccal administration), } \\
\text { and this was not clearly stated in the pa- } \\
\text { per, we contacted the study authors to ask } \\
\text { for clarification }\end{array}$ & $\begin{array}{l}\text { Study authors answered } \\
\text { that the gel was swal- } \\
\text { lowed; therefore we did } \\
\text { not categorise this inter- } \\
\text { vention as buccal admin- } \\
\text { istration }\end{array}$ \\
\hline Gunning 1978 & - & - & - & - \\
\hline
\end{tabular}




\begin{tabular}{|c|c|c|c|c|c|c|c|c|}
\hline Items & & $\begin{array}{l}\text { (1) Reso- } \\
\text { lution of } \\
\text { symptoms }\end{array}$ & $\begin{array}{l}\text { (2) Time to } \\
\text { resolution } \\
\text { of symp- } \\
\text { toms }\end{array}$ & $\begin{array}{l}\text { (3) Blood or } \\
\text { plasma glu- } \\
\text { cose con- } \\
\text { centration } \\
\text { at } 20 \text { min- } \\
\text { utes }\end{array}$ & $\begin{array}{l}\text { (4) Reso- } \\
\text { lution of } \\
\text { hypogly- } \\
\text { caemia }\end{array}$ & $\begin{array}{l}\text { (5) Time to } \\
\text { resolution } \\
\text { of hypogly- } \\
\text { caemia }\end{array}$ & $\begin{array}{l}\text { (6) Adverse } \\
\text { events }\end{array}$ & $\begin{array}{l}\text { (7)Treat- } \\
\text { ment delay }\end{array}$ \\
\hline \multirow{9}{*}{$\begin{array}{l}\text { Trial limita- } \\
\text { tions } \\
\text { (risk of } \\
\text { bias)a }\end{array}$} & $\begin{array}{l}\text { Was random sequence generation used (i.e. } \\
\text { no potential for selection bias)? }\end{array}$ & NA & NA & Unclear & Unclear & Unclear & Unclear & \multirow[t]{10}{*}{ NA } \\
\hline & $\begin{array}{l}\text { Was allocation concealment used (i.e. no po- } \\
\text { tential for selection bias)? }\end{array}$ & & & Unclear & Unclear & Unclear & Unclear & \\
\hline & $\begin{array}{l}\text { Was there blinding of participants and per- } \\
\text { sonnel (i.e. no potential for performance bias) } \\
\text { or outcome not likely to be influenced by lack } \\
\text { of blinding? }\end{array}$ & & & Yes & Yes & Yes & No $(\downarrow)$ & \\
\hline & $\begin{array}{l}\text { Was there blinding of outcome assessment } \\
\text { (i.e. no potential for detection bias) or was } \\
\text { outcome measurement not likely to be influ- } \\
\text { enced by lack of blinding? }\end{array}$ & & & Yes & Yes & Yes & Yes & \\
\hline & Was an objective outcome used? & & & Yes & No $(\downarrow)$ & No $(\downarrow)$ & No $(\downarrow)$ & \\
\hline & $\begin{array}{l}\text { Were more than } 80 \% \text { of participants enrolled } \\
\text { in trials included in the analysis (i.e. no poten- } \\
\text { tial reporting bias)?e }\end{array}$ & & & Yes & Yes & Yes & Yes & \\
\hline & $\begin{array}{l}\text { Were data reported consistently for the out- } \\
\text { come of interest (i.e. no potential selective re- } \\
\text { porting)? }\end{array}$ & & & Yes & Yes & Yes & Yes & \\
\hline & $\begin{array}{l}\text { No other biases reported (i.e. no potential of } \\
\text { other bias)? }\end{array}$ & & & Yes & Yes & Yes & Yes & \\
\hline & $\begin{array}{l}\text { Did the trials end up as scheduled (i.e. not } \\
\text { stopped early)? }\end{array}$ & & & Yes & Yes & Yes & Yes & \\
\hline Indirectness & $\begin{array}{l}\text { Were the populations in included studies ap- } \\
\text { plicable to the decision context? }\end{array}$ & & & $\begin{array}{l}\text { Poorly ap- } \\
\text { plicable }(\downarrow)\end{array}$ & $\begin{array}{l}\text { Poorly ap- } \\
\text { plicable }(\downarrow)\end{array}$ & $\begin{array}{l}\text { Poorly ap- } \\
\text { plicable }(\downarrow)\end{array}$ & $\begin{array}{l}\text { Poorly ap- } \\
\text { plicable }(\downarrow)\end{array}$ & \\
\hline
\end{tabular}


Were the interventions in the included studies applicable to the decision context?

Was the included outcome not a surrogate outcome?

Was the outcome timeframe sufficient?

Were the conclusions based on direct comparisons?

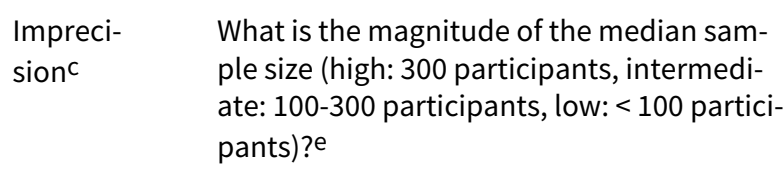

Impreci- What is the magnitude of the median samsionc ple size (high: 300 participants, intermediate: 100-300 participants, low: < 100 participants)?e

What was the magnitude of the number of included studies (large: $>10$ studies, moderate: 5-10 studies, small: $<5$ studies)?e

Was the outcome a common event (e.g. oc curs more than $1 / 100)$ ?

Publication Was a comprehensive search conducted?

biasd

Was grey literature searched?

Were no restrictions applied to study selection on the basis of language?

There was no industry influence on studies included in the review?

There was no discrepancy in findings between published and unpublished trials?

Applicable Applicable Applicable Applicable

\begin{tabular}{llll}
\hline Yes & Yes & Yes & Yes \\
\cline { 1 - 2 } & & & \\
Sufficient & Sufficient & Sufficient & Sufficient
\end{tabular}

Yes

Yes

Yes

Yes

Yes

$\operatorname{Low}(\downarrow)$

$\operatorname{Low}(\downarrow)$

$\operatorname{Low}(\downarrow)$

$\operatorname{Low}(\downarrow)$

Small $(\downarrow) \quad$ Small $(\downarrow) \quad$ Small $(\downarrow) \quad$ Small $(\downarrow)$

\begin{tabular}{llll}
\hline $\begin{array}{l}\text { Not applica- } \\
\text { ble }\end{array}$ & Yes & $\begin{array}{l}\text { Not applica- } \\
\text { ble }\end{array}$ & No $(\downarrow)$ \\
\hline Yes & Yes & Yes & Yes \\
\hline Yes & Yes & Yes & Yes \\
\hline Yes & Yes & Yes & Yes \\
\hline Yes & Yes & Yes & Yes \\
\hline Yes & Yes & Yes & Yes
\end{tabular}

aQuestions on risk of bias are answered in relation to the majority of the aggregated evidence in the meta-analysis rather than to individual trials. bQuestions on inconsistency are primarily based on visual assessment of forest plots and the statistical quantification of heterogeneity based on $I^{2}$.

cWhen judging the width of the confidence interval it is recommended to use a clinical decision threshold to assess whether the imprecision is clinically meaningful. dQuestions address comprehensiveness of the search strategy, industry influence, funnel plot asymmetry and discrepancies between published and unpublished trials. eDepends on the context of the systematic review area. 


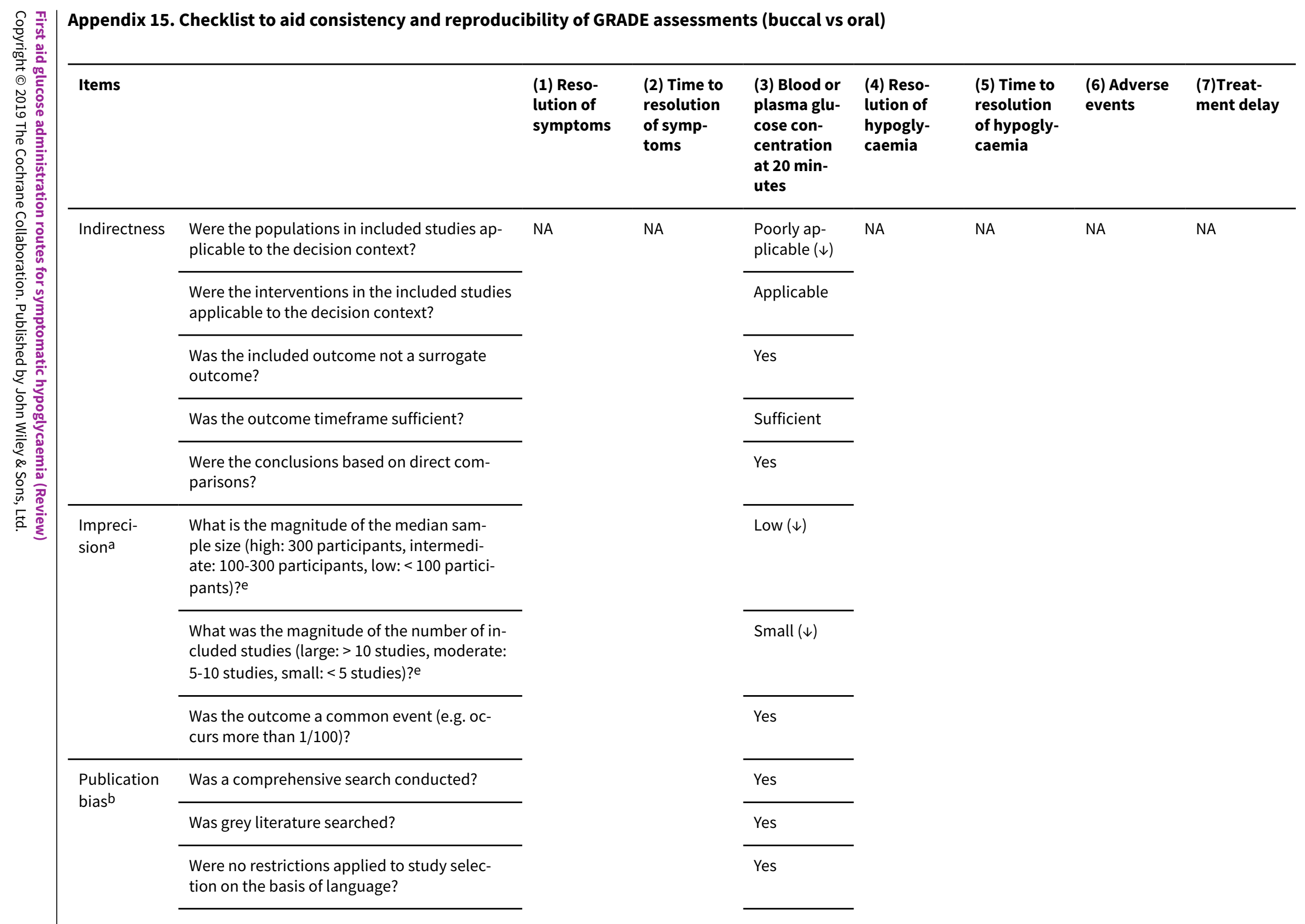


aWhen judging the width of the confidence interval it is recommended to use a clinical decision threshold to assess whether the imprecision is clinically meaningful. bQuestions address comprehensiveness of the search strategy, industry influence, funnel plot asymmetry and discrepancies between published and unpublished trials.

( $\downarrow$ : key item for potential downgrading the certainty of the evidence (GRADE) as shown in the footnotes of the 'Summary of finding' table(s); NA: not applicable 


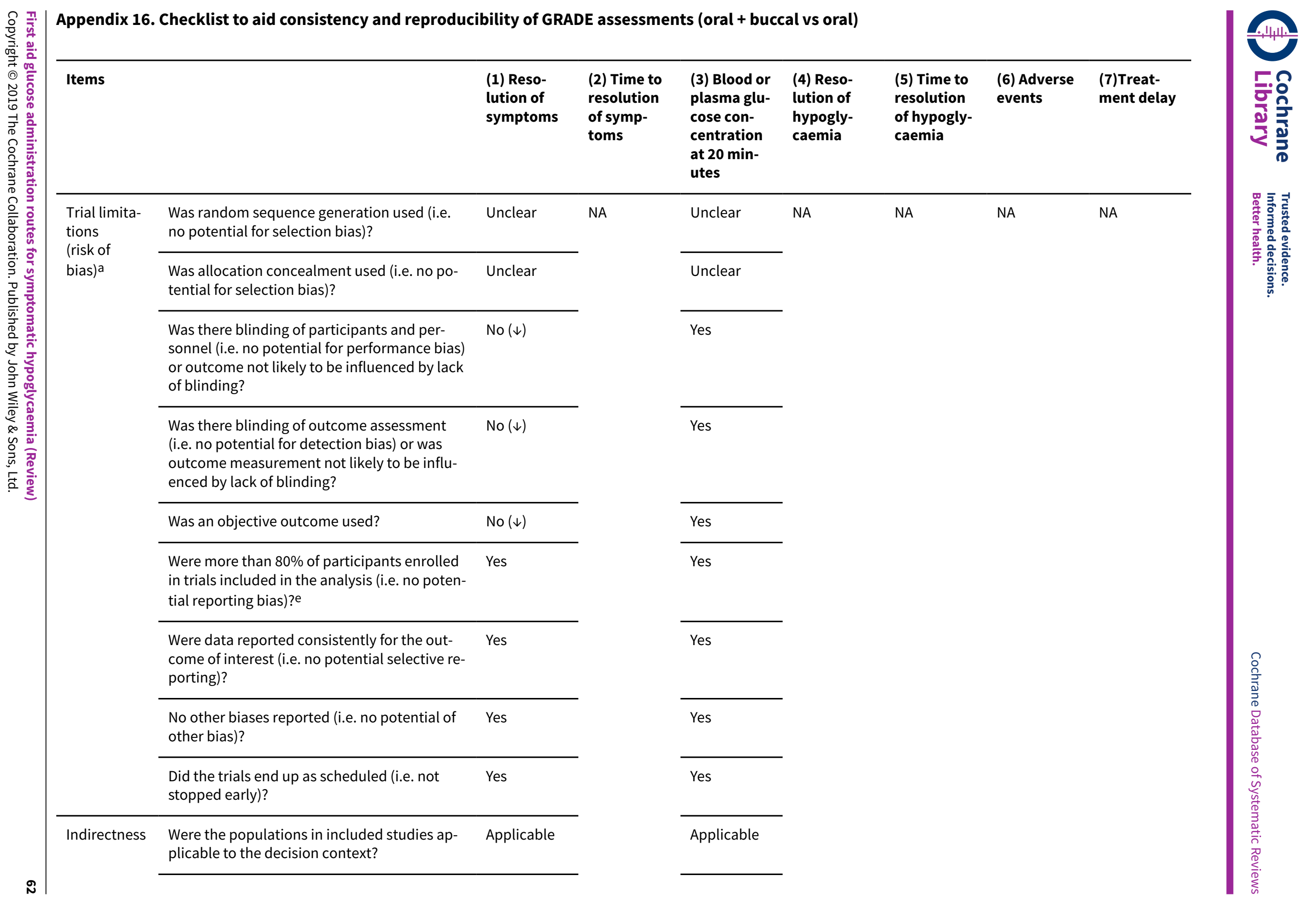


Were the interventions in the included studies applicable to the decision context?

Highly ap plicable

Was the included outcome not a surrogate

Yes

outcome?

\begin{tabular}{ll}
\hline Was the outcome timeframe sufficient? & Sufficient \\
\hline $\begin{array}{l}\text { Were the conclusions based on direct com- } \\
\text { parisons? }\end{array}$ & Yes
\end{tabular}

Impreci- What is the magnitude of the median sam-

sionc ple size (high: 300 participants, intermedi-

ate: 100-300 participants, low: $<100$ partici-

pants)?e

What was the magnitude of the number of in- $\quad$ Small $(\downarrow)$

cluded studies (large: $>10$ studies, moderate:

5-10 studies, small: $<5$ studies)?e

Was the outcome a common event (e.g. oc- Yes curs more than $1 / 100)$ ?

\begin{tabular}{lll}
\hline $\begin{array}{ll}\text { Publication } \\
\text { biasd }\end{array}$ & Was a comprehensive search conducted? & Yes \\
\cline { 2 - 3 } & Was grey literature searched? & Yes \\
\cline { 2 - 3 } & $\begin{array}{l}\text { Were no restrictions applied to study selec- } \\
\text { tion on the basis of language? }\end{array}$ & Yes \\
\hline
\end{tabular}

There was no industry influence on studies in- Yes cluded in the review?
Highly ap-

plicable

Yes

Sufficient

Yes

$\operatorname{Low}(\downarrow)$

Small $(\downarrow)$

Not applica-

ble

\begin{tabular}{l}
\hline Yes \\
\hline Yes \\
\hline
\end{tabular}

Yes

Yes

aQuestions on risk of bias are answered in relation to the majority of the aggregated evidence in the meta-analysis rather than to individual trials.

bQuestions on inconsistency are primarily based on visual assessment of forest plots and the statistical quantification of heterogeneity based on ${ }^{2}$.

cWhen judging the width of the confidence interval it is recommended to use a clinical decision threshold to assess whether the imprecision is clinically meaningful.

dQuestions address comprehensiveness of the search strategy, industry influence, funnel plot asymmetry and discrepancies between published and unpublished trials.

eDepends on the context of the systematic review area.

( $\downarrow)$ : key item for potential downgrading the certainty of the evidence (GRADE) as shown in the footnotes of the 'Summary of finding' table(s); NA: not applicable 


\section{CONTRIBUTIONS OF AUTHORS}

Emmy De Buck (EDB): performed the literature search, data extraction, data interpretation, drafted the manuscript, critically revised and approved the final manuscript

Vere Borra (VB): data extraction, data interpretation, drafted the manuscript, critically revised and approved the final manuscript

Jestin N Carlson (JNC): data interpretation, critically revised and approved the final manuscript

David A Zideman (DAZ): designed the PICOST question for the systematic review, data interpretation, critically revised and approved the final manuscript

Eunice M Singletary (EMS): designed the PICOST question for the systematic review, data interpretation, critically revised and approved the final manuscript

Therese Djärv (TD): performed the literature search, data extraction, data interpretation, drafted the manuscript, critically revised and approved the final manuscript

\section{DECLARATIONS OF INTEREST}

EDB: contracted by the American Heart Association on behalf of ILCOR (International Liason Committee on ResuscitationFirst Aid Task Force) as systematic reviewer to conduct the current systematic review; employee at Belgian Red Cross, providing first aid training to laypeople. None of the declared competing interests did influence any of the steps undertaken for the current systematic review.

VB: employee at Belgian Red Cross, providing first aid training to laypeople. This did not influence any of the steps undertaken for the current systematic review.

JNC: none known.

DAZ: none known.

EMS: volunteer member of the First Aid Task Force for the International Liaison Committee on resuscitation; reimbursed for travel expenses related to reviews performed by this organization.

TD: none known.

\section{SOURCES OF SUPPORT}

\section{Internal sources}

- No sources of support supplied

\section{External sources}

- American Heart Association, USA.

This systematic review received funding from the American Heart Association on behalf of the International Liaison Committee on Resuscitation (ILCOR). The funder was involved in the ILCOR process, but had no role in this systematic review study design, data collection and analysis, or preparation of the manuscript.

\section{DIFFERENCES BETWEEN PROTOCOL AND REVIEW}

\section{Changes from the protocol}

Unit of analysis issues: in the protocol we proposed to use the methods reported by Elbourne and colleagues (Elbourne 2002) to calculate effect measures in case of paired data. We now further specify that this was done for the continuous outcomes. We used the Bonnetprice test and the McNemar test in $\mathrm{R}$ for the dichotomous outcomes.

Dealing with missing data: since one study only reported the standard deviation (SD) for two of the three study arms, we imputed the SD for the third study arm based on these values.

\section{Methods not implemented}

Selection of studies: we did not identify any studies where none of our primary or secondary outcomes was reported in the study, and therefore we did not provide any data of such studies in the 'Characteristics of studies awaiting classification' table. 
Searching other resources: we did not identify any relevant abstracts or conference proceedings, and therefore did not provide any information of such studies in the 'Characteristics of studies awaiting classification' table.

Data extraction and management: we did not identify any ongoing trials, and therefore did not provide any information of such studies in the 'Characteristics of ongoing studies' table.

Dealing with duplicate and companion publications: we did not identify any duplicate or companion publications.

Data from clinical trials registers: we did not identify any data from clinical trials registers.

Assessment of risk of bias in included studies: we did not contact authors to request missing data on 'Risk of bias' items.

Measures of treatment effect: we did not encounter continuous outcomes that measured the same underlying concept (e.g. health-related quality of life) but used different measurement scales, and thus we did not use the standardised mean difference (SMD). We did not encounter time-to-event data, and thus did not use hazard ratios (HR).

Assessment of reporting biases: reporting bias could not be assessed due to the limited number of included studies.

Data synthesis and subgroup analysis: an insufficient number of studies was identified per administration route to enable meta-analysis. Therefore, the methods described in the protocol for assessing heterogeneity, data synthesis and subgroup analysis were not applicable to this systematic review. Instead the effect measures for glucose concentrations (continuous outcome) were presented in a forest plot without pooling. The generic inverse variance method was used, because data were lacking to perform the standard inverse variance method (as stated in the protocol).

Sensitivity analysis: an insufficient number of studies was identified to enable a sensitivity analysis.

\section{N O T E S}

Portions of the background and methods sections, the appendices, additional tables and figures 1 to 3 of this review are based on a standard template established by Cochrane Metabolic and Endocrine Disorders.

\section{INDEX TERMS}

\section{Medical Subject Headings (MeSH)}

Administration, Oral; Diabetes Complications; Diabetes Mellitus [blood]; First Aid; Glucose [*administration \& dosage] [therapeutic use]; Hypoglycemia [ ${ }^{*}$ drug therapy]

\section{MeSH check words}

Adult; Child; Humans 